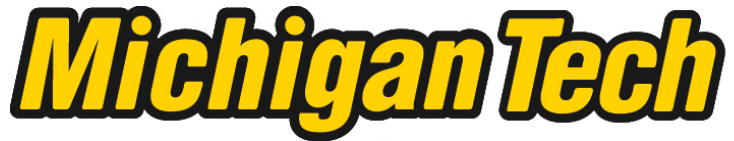 \\ Michigan Technological University Create the Future Digital Commons @ Michigan Tech
}

2012

\section{Governmentality in higher education : a critical analysis of the National Survey of Student Engagement (NSSE)}

Bonnie B. Gorman

Michigan Technological University

Follow this and additional works at: https://digitalcommons.mtu.edu/etds

Part of the Rhetoric and Composition Commons

Copyright 2012 Bonnie B. Gorman

\section{Recommended Citation}

Gorman, Bonnie B., "Governmentality in higher education : a critical analysis of the National Survey of Student Engagement (NSSE)", Dissertation, Michigan Technological University, 2012.

https://doi.org/10.37099/mtu.dc.etds/86

Follow this and additional works at: https://digitalcommons.mtu.edu/etds

Part of the Rhetoric and Composition Commons 
GOVERNMENTALITY IN HIGHER EDUCATION: A CRITICAL ANALYSIS OF THE NATIONAL SURVEY OF STUDENT ENGAGEMENT (NSSE)

By

Bonnie B. Gorman

\begin{abstract}
A DISSERTATION
Submitted in partial fulfillment of the requirements for the degree of DOCTOR OF PHILOSOPHY

(Rhetoric and Technical Communication)
\end{abstract}

MICHIGAN TECHNOLOGICAL UNIVERSITY

2012

(C) 2012 Bonnie B. Gorman 
This dissertation, "Governmentality in Higher Education: A Critical Analysis of the National Survey of Student Engagement (NSSE)," is hereby approved in partial fulfillment of the requirements for the Degree of DOCTOR OF PHILOSOPHY IN RHETORIC AND TECHNICAL COMMUNICATION.

Department of Humanities

Signatures:

Dissertation Advisor

Patricia J. Sotirin

Committee Member

Jennifer D. Slack

Committee Member

Robert R. Johnson

Committee Member

Bradley H. Baltensperger

Department Chair

Ronald L. Strickland

Date 
To Hugh.

Yo te amo con todo mi corazón. 


\section{Table of Contents}

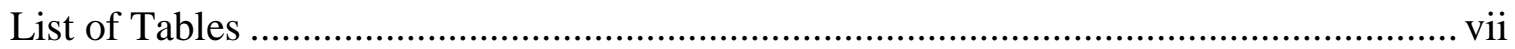

Acknowledgements ........................................................................................ viii

List of Abbreviations ........................................................................................ xi

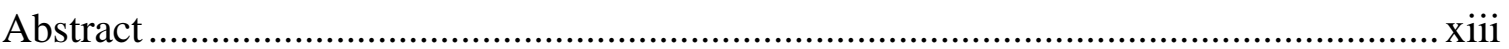

Chapter One - Introduction ............................................................................. 15

The Terrain of Higher Education .................................................................... 18

NSSE: A Tool for Measuring Educational Quality ........................................... 22

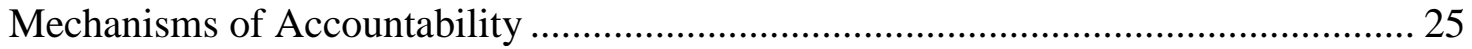

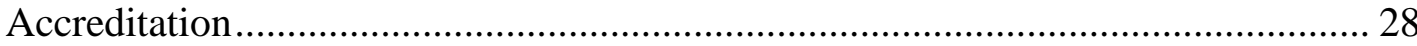

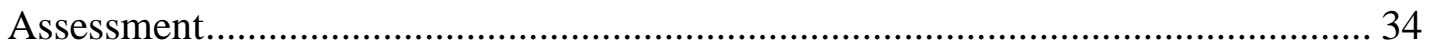

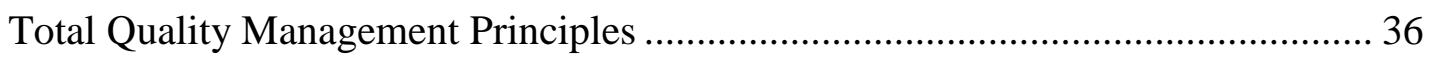

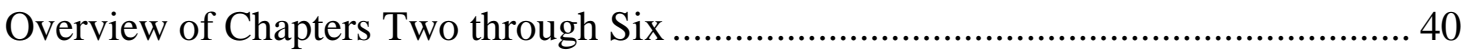

Chapter Two - Why Governmentality: An Approach for Understanding the Relations of Power and the Forces Shaping Practices in Higher Education .................................... 46

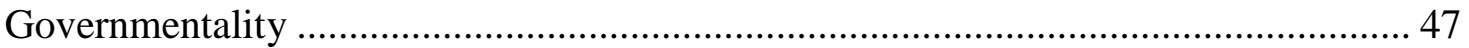

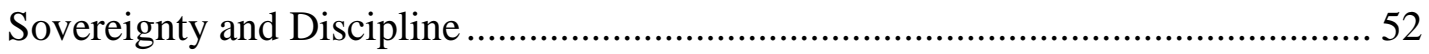

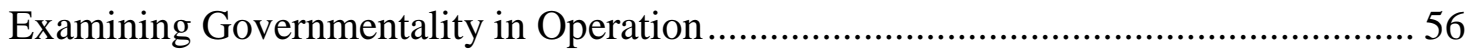

Power, Knowledge, and Subjectivity ............................................................... 56

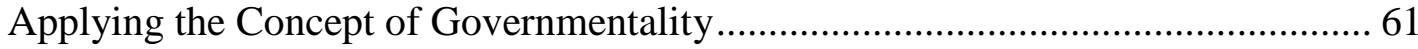

Chapter Three - Power Relations in the Milieu of Accountability ............................... 68

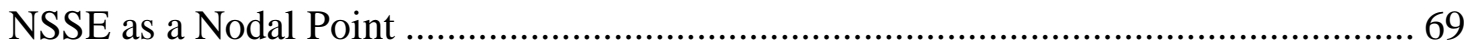

Re-defining Higher Education in Market Terms .................................................. 72 
The Public Good Paradigm.............................................................................. 74

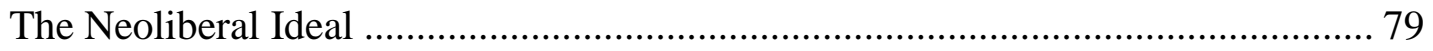

A Point of Struggle: Accountability v. Autonomy …........................................ 83

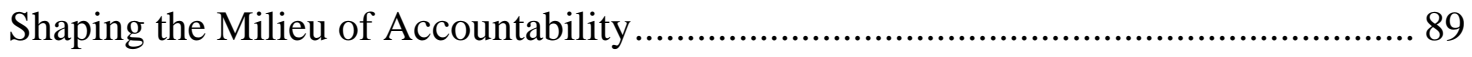

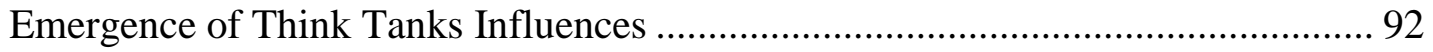

Expanding the Student Engagement Construct.............................................. 103

The Academic Capitalist/Knowledge Regime ................................................. 108

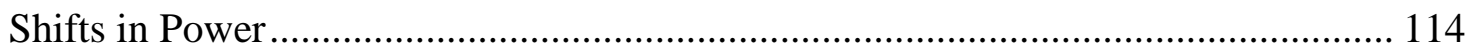

Chapter Four - Sorting Populations: Systems of Normalization in Higher Education .. 119

Establishing Standards and Systems for Sorting Students................................... 121

Four Options for Sorting Students ............................................................... 123

Scholastic Aptitude Test (SAT): A Mechanism to Differentiate and Compare ..... 126

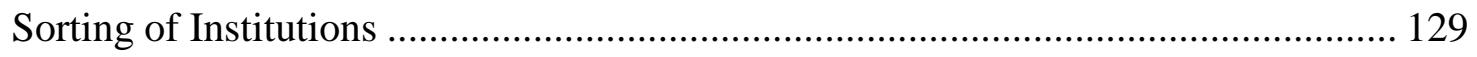

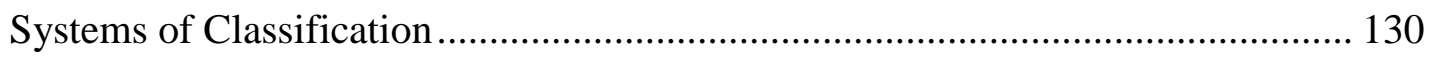

Governing Practices Emerging through Accreditation ..................................... 139

Sorting Faculty and Graduate Programs ........................................................ 142

Mobilizing Ranking Systems within the Academy ......................................... 142

Advancing Students as Consumers .................................................................... 151

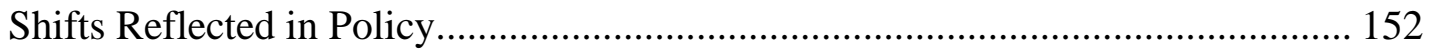

The Sorting of Colleges and Universities for Consumers ................................ 159 
Chapter Five - Governing Assessment .................................................................. 164

Student Engagement as an Object of Knowledge ………........................................ 167

Reform and Expert Knowledge ...................................................................... 169

(Re)constructing Student Engagement .............................................................. 175

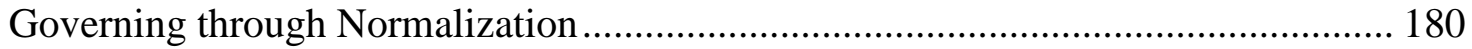

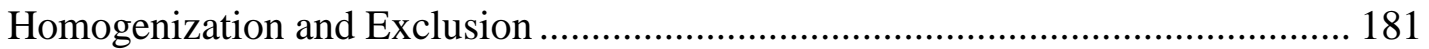

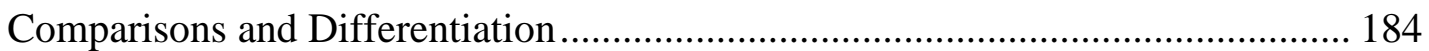

Prescribing the Student Engagement Message ...................................................... 187

Resisting and Normalizing Practice-changing Knowledge ........................................ 192

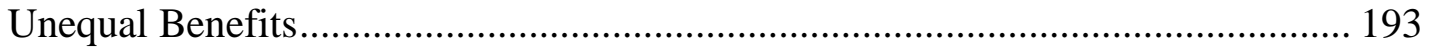

Resisting Normalizing Efforts of Student Engagement........................................... 194

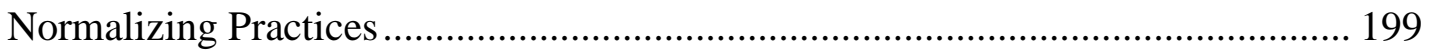

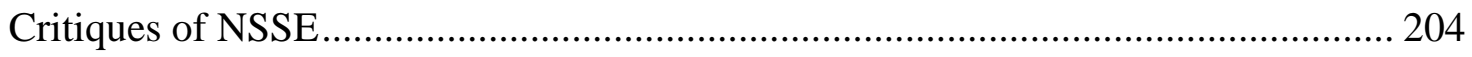

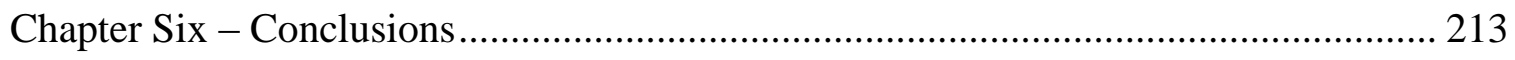

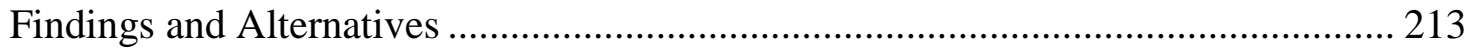

Challenges and Limitations.................................................................................. 221

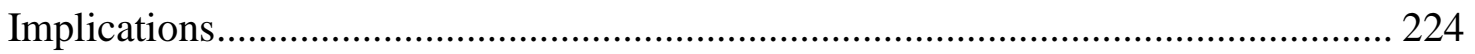

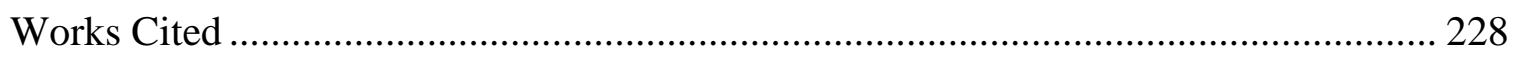




\section{List of Tables}

Table 1.1 NSSE Benchmarks of Effective Educational Practice and Highlights of Questions Asked ................................................................................... 24

Table 2.1 Foucault's Forms of Power, Their Targets, and Methods ............................ 47 


\section{Acknowledgements}

I am indebted to many who provided direction and words of encouragement throughout my pursuit of this degree. There are too many to name individually, but I'm pleased to acknowledge some who made this effort possible.

First and foremost, is my Dissertation Committee. Patty Sotirin, my advisor, told me early on in this process that earning a PhD was a "license to learn." She wasn't kidding as she prodded me to think in different ways and from perspectives outside my comfort zone. I'm most appreciative of her patience throughout this process. In addition, I am grateful to the other members of my committee, Bob Johnson, Jennifer Slack, and Brad Baltensperger for reading and commenting on my work. Any errors, however, are all mine.

There are also people from across campus that deserve my thanks. I call them infrastructure people - these are the folks none of us can't do without; the ones that keep everything running smoothly — always willing to answer a question, or point us in the right direction. The support staff in the department over the years included Marjorie Lindley, Susan Niemi, and Kim Puuri. From the library, I'm especially appreciative of the interlibrary loan staff, Cathy Greer, Stephanie Reed, and Nora Allred. Mary Mongeau and Rhianna Williams were also helpful in times of need. And, of course, the assistance provided by the Graduate School, especially Debra Charlesworth and Nancy ByersSprague, makes this process manageable.

There are many colleagues who have provided continuous encouragement. When I announced I was going down this road in 2005, instead of questioning my judgment, the 
Student Life staff provided encouragement. That staff is now dispersed, but Pete Pelissero, Jenny Greyerbiehl, Jen Van Essen, and Travis Pierce continued to stay in touch, monitor my progress, and offer support. Beth Lunde and John Lehman are two of the best colleagues a person could ask for and I can't thank them enough for that and for being good friends, as well. Suzanne Sanregret is one of the few who asked what my dissertation was really about and whose eyes didn’t glaze over when I told her. Brenda Rudiger offered me numerous tips and strategies to help me stay organized and to writealways, always encouraging me. One day, when I was feeling particularly overwhelmed with all I had to do, Mary Jane Lowney said to me “don't let anyone take away your dreams." What may have been a casual comment on her part saw me through more days than she'll ever know. And, when I was in the middle of this journey, Sue Dilsworth reminded me (more than once) that it would not last forever.

During this time, my career took an unexpected turn and I ended up in working in University Marketing and Communications - the entire staff there saw me through comps - and was incredibly thoughtful and understanding. They also had my back when I changed my work schedule in order to get more writing done. I owe special debt of gratitude to Linda Watson for her unwavering support and gentle encouragement. As well, Gail Sweeting continually assured me that one day I would finish and that the effort would be worth it.

I'm also indebted to Les Cook who prodded and gently pushed me on to this path and then provided his generous and unconditional support throughout the process. As well, Shea McGrew was my boss during most of the time that I've been pursuing this 
degree - he provided encouragement on a weekly basis and never let me take myself too seriously.

My family has also been steadfast in their support. Nobody could ask for a more encouraging set of parents_-Loisanne and Bill Bilka. They understood that there would be fewer visits and fewer spontaneous phone calls so that I could read, study, and write. My mom is a role model for me in most aspects of life, and this journey is no exception, earning her $\mathrm{PhD}$ at a time when few women did. My dad lovingly supported her through the process and I have enjoyed his constant love and support as well. My sister, Betsy Balmer, thought I was nuts from day one, but that hasn't stopped her from encouraging me unceasingly over the years. My good friend, Ellen Boros, must be mentioned too as she has been my friend for more than thirty years and has been a part of everything in my life that has mattered - and this is no exception. She gave me the space I needed to get the work done and I'm grateful that she didn't throw up her hands and give up on our friendship.

Last, but certainly not least, I'm fortunate to be married to an accomplished scholar, Hugh S. Gorman. He has been more than supportive from the beginning, and while cliché, this dissertation could not have been written without him. I've benefited immeasurably from his curious mind, disciplined work ethic, and bad jokes. My gratitude to him is immense. 


\section{List of Abbreviations}

\begin{tabular}{|c|c|}
\hline AAC\&U & Association of American Colleges and Universities \\
\hline AACC & American Association of Community Colleges \\
\hline AAHE & American Association for Higher Education \\
\hline AASCU & Association of State Colleges and Universities \\
\hline AAU & Association of American Universities \\
\hline AAUP & American Association of University Professors \\
\hline $\mathrm{ACE}$ & American Council on Education \\
\hline ACPA & American College Personnel Association \\
\hline AEI & American Enterprise Institute \\
\hline AFT & American Federation of Teachers \\
\hline APLU & Association of Public Land-grant Universities \\
\hline AQIP & Academic Quality Improvement Program \\
\hline BEOG & Basic Educational Opportunity Grant \\
\hline CAAP & Collegiate Assessment of Academic Proficiency \\
\hline CEEB & College Entrance Examination Board \\
\hline CHEA & Council for Higher Education Accreditation \\
\hline CIRP & Cooperative Institutional Research Program \\
\hline CLA & Collegiate Learning Assessment \\
\hline CSEQ & College Student Experiences Questionnaire \\
\hline DEEP & Documenting Effective Educational Practices \\
\hline EOG & Educational Opportunity Grant \\
\hline ETS & Educational Testing Service \\
\hline FRACHE & Federation of Regional Accrediting Commissions \\
\hline FTE & Full Time Equivalent \\
\hline HEA & Higher Education Act \\
\hline HLC & Higher Learning Commission \\
\hline IPEDS & Integrated Postsecondary Education Data System \\
\hline LEAP & Liberal Education and America's Promise \\
\hline MISAA & Middle Income Student Assistance Act \\
\hline NAICU & National Association of Independent Colleges and Universities \\
\hline NASU & National Association of State Universities \\
\hline $\mathrm{NCA}$ & National Commission on Accrediting \\
\hline NDEA & National Defense Education Act \\
\hline NEA & National Education Association \\
\hline NERCHE & New England Resource Center for Higher Education \\
\hline NILOA & National Institute for Learning Outcomes Assessment \\
\hline NIST & National Institute of Standards and Technology \\
\hline
\end{tabular}




$\begin{array}{ll}\text { NSF } & \text { National Science Foundation } \\ \text { NSSE } & \text { National Survey of Student Engagement } \\ \text { SAT } & \text { Scholastic Aptitude Test } \\ \text { SHEEO } & \text { State Higher Education Executive Officers } \\ \text { TQM } & \text { Total Quality Management } \\ \text { U-CAN } & \text { University and College Accountability Network } \\ \text { VSA } & \text { Voluntary System of Accountability }\end{array}$




\section{Abstract}

In this dissertation, the National Survey of Student Engagement (NSSE) serves as a nodal point through which to examine the power relations shaping the direction and practices of higher education in the twenty-first century. Theoretically, my analysis is informed by Foucault's concept of governmentality, briefly defined as a technology of power that influences or shapes behavior from a distance. This form of governance operates through apparatuses of security, which include higher education. Foucault identified three essential characteristics of an apparatus - the market, the milieu, and the processes of normalization - through which administrative mechanisms and practices operate and govern populations. In this project, my primary focus is on the governance of faculty and administrators, as a population, at residential colleges and universities.

I argue that the existing milieu of accountability is one dominated by the neoliberal assumption that all activity —including higher education—works best when governed by market forces alone, reducing higher education to a market-mediated private good. Under these conditions, what many in the academy believe is an essential purpose of higher education - to educate students broadly, to contribute knowledge for the public good, and to serve as society's critic and social conscience (Washburn 227) — is being eroded. Although NSSE emerged as a form of resistance to commercial college rankings, it did not challenge the forces that empowered the rankings in the first place. Indeed, NSSE data are now being used to make institutions even more responsive to market forces. Furthermore, NSSE's use has a normalizing effect that tends to homogenize classroom practices and erode the autonomy of faculty in the educational process. It also 
positions students as part of the system of surveillance. In the end, if aspects of higher education that are essential to maintaining a civil society are left to be defined solely in market terms, the result may be a less vibrant and, ultimately, a less just society. 


\section{Chapter One - Introduction}

Higher education in the twenty-first century is contested terrain. Recent books such as University Inc.: The Corporate Corruption of Higher Education (Washburn), DIY U: Edupunks, Edupreneurs and the Coming Transformation of Higher Education (Kementz), and Wannabe U: Inside the Corporate University (Tuchman) depict a system of higher education that is in crisis. Continual increases in tuition are viewed as unsustainable and market forces along with greater demands for accountability are seen as having overtaken other priorities. Colleges and universities are being pushed to quantify countless aspects of routine practices and implement strategies directly from the corporate playbook, including brand marketing and quality improvement procedures. In the process, faculty and administrators find themselves wrestling with the conflicting expectations of various stakeholder groups, including government policymakers, prospective students, and potential employers, often resisting the changes in daily practices that these expectations imply. Yet in an effort to compete, many colleges and universities have had little choice but to adopt a more corporate model, one that emphasizes efficiency and views students as consumers and, once they've earned degrees, as "products."

Reputational ranking systems such as "America's Best Colleges" produced by U.S. News and World Report, which facilitate comparisons and pit schools against each other, have further exacerbated the situation. While the creators of these ranking systems position them as representative of institutional quality, the metrics underlying these systems are generally not useful for assessing and improving educational practices. For 
example, increasing the percentage of alumni who donate, which is one of the metrics, does little to improve the educational environment. Still, numerous university leaders, seeking to move up in the rankings, devote resources to improving their performance on these metrics (Hazelkorn). At the same time, U.S. News periodically changes its method for determining a university's rank, frustrating universities that are trying to improve their position (Morse and Flanigan, How We Calculate the Rankings). U.S. News justifies altering its methodology with claims of helping "our readers compare schools as they're making decisions about where to apply and enroll," reinforcing the role of the rankings as a tool for consumers (Morse, Birth of College Rankings).

In general, as colleges and universities attempt to respond to insatiable demands for evidence of institutional quality—not only by attempts to move up in the rankings, but also in association with numerous other accountability mechanisms-many scholars argue that the data being generated fail to measure what would seem to matter most: student learning. In 1998, in an effort to address this concern, a group of leading higher education experts developed the National Survey of Student Engagement (NSSE) ${ }^{1}$, an instrument frequently described as a proxy for measuring student learning. The survey assesses how well colleges and universities make use of effective educational practices by querying students about their experiences. Over the last ten years, the survey has grown in use from the 75 pilot schools that administered the survey in 1999 to over 1,300 schools that use it today. The data generated by this survey are now being used in numerous ways, ranging from institutional assessment and accreditation efforts to general

\footnotetext{
${ }^{1}$ I use the acronym NSSE to refer to the survey instrument, its creators, and administrators. In context, it will be obvious to what/which group I am referring.
} 
education reform and faculty development (National Survey of Student Engagement, Using NSSE Data). In addition, the aggregated data offer a broad portrait of the practices of colleges and universities and allow one to track patterns of students' experiences. Today, NSSE is ever-present in the national conversation about educational quality. For example, the survey received full-page coverage in USA TODAY on November 9, 2009 in an article titled "A Laboratory of Learning Helps Students Thrive: Student Engagement Survey Changes How Colleges Judge Success, Identify Weaknesses" (Marklein). It has also been endorsed by the Commission on the Future of Higher Education (commonly referred to as the Spellings Commission) as well as multiple higher education associations such as the Association of Public and Land-grant Universities (APLU), and the American Association of State Colleges and Universities (AASCU).

What does the increasing use of NSSE by colleges and universities reveal about the forces shaping the direction and practices of higher education early in the twenty-first century? And, in turn, how do these forces influence the practices of faculty and administrators as a population? In this project, I use NSSE as a way to gain insight into the contingent relations of power at work in higher education, how the organizational practices of colleges and universities are shaped in the process, and what vision of higher education is privileged as a result.

Theoretically, my approach is informed by the concept of governmentality. This term, originally conceived by Michel Foucault, refers to a technology of power that operates not from a hierarchical position of authority, but by regulating or controlling behavior from a distance. Translated from French as the "conduct of conduct," 
governmentality is understood as "a form of activity aiming to shape, guide or affect the conduct of some person or persons" (Gordon 2). More specifically, governmentality describes the complex form of power exercised through an ensemble of institutions, procedures, strategies, and tactics, allowing the conduct of a population to be controlled without force (Foucault, “Governmentality” 102). In effect, people behave, regulate, or change their behavior in response to distant and unseen influences eventually becoming — in the absence of resistance — self-governing participants in that system of regulation.

In this chapter, I briefly examine the terrain of higher education relevant to a study of governing influences. I then offer a description of NSSE in order to position it in the larger context. I continue with a discussion of three key mechanisms of accountability in which NSSE is enmeshed and point to the larger structures of power that shaped its creation and contributed to its rapid dissemination. In the end, I argue that assessment tools such as NSSE, which shape the daily practices of faculty and administrators, are being co-opted by market forces that frame higher education as a private good.

\section{The Terrain of Higher Education}

Conceptions of the purpose of higher education have always been contested and are continually being re-constructed by different stakeholders with varying agendas. In the process, assorted priorities are placed on a range of endeavors, including research and scholarly activities, educating students to participate as responsible (and governable) citizens, and developing the workplace skills of future employees. In addition, the landscape of higher education is also being significantly impacted by economic 
conditions - increasing costs and declining state funding — that are amplifying tensions among various constituencies. State officials are arguing that institutions should be graduating more students with less financial support; deans are justifying the increasing use of adjunct faculty on the need to do more with less; and, students are questioning whether college is worth it (Immerwahr, Johnson, and Gasbarra 6). In parallel, market pressures and demands for transparency and accountability are ever increasing.

Today, many scholars argue that the private aspects of higher education are being favored over those that serve the public good. Robert Zemsky et al. argue that higher education has in fact gone private: private from the standpoint of being a personal investment and gain; private from the point of view of serving those who can pay; and, private from the position of state and federal officials who continue to reduce funding and reinforce the notion that higher education is a consumer good (5-7). Similarly, in the fifth edition of Uses of the University, Clark Kerr points out that students are making curricular choices based primarily on their employment potential and less on an interest in education for the sake of learning (214). To some extent, institutional priorities are being redefined to reflect the value that students place on vocational goals. In addition, there is pressure to meet the expectations of corporations who provide support to universities with the hope of influencing curricular decisions and reaping the benefits of their investment by hiring their graduates. The existence of for-profit universities, many with increasing enrollment, is also a reflection of the growing trend to see higher education as a private good. 
In contrast, for those who maintain that higher education also has a public component, one that cannot be determined by market forces alone, the tendency to see education as a private good is perceived as a threat to the future of liberal education and higher education's contributions to society as a whole - that is, the public good. Sandy Baum and Michael McPherson explain in an article entitled "Is Education a Public Good or a Private Good?" that the public good means that "there are positive externalities—not all the benefits accrue to students." A specific example of how society benefits from higher education's contributions is offered by sociologist Martin Trow: there is "evidence that higher education increases the tolerance of citizens for unpopular political views, and decreases racial prejudice and bigotry that have been such powerful forces for ill in American political and social life" (118). Trow goes on to argue and provide evidence that "higher education has been systematically undermining the foundations of racial prejudice and misinformation" (118). Although markets can certainly result in valuable contributions to the public good, there is no guarantee that they will. In addition, if accountability mechanisms are constructed primarily in market terms, then important aspects of a liberal education may be lost.

Many scholars explicitly frame higher education's purpose in terms of its contributions to the public good. For example, scholars such as Stanley Fish identify creating new knowledge and scholarly pursuits as higher education's main objective, while Derek Bok sees college's purpose as something broader, which is to foster an understanding of how to live in a global world. He suggests that there should be a "carefully circumscribed effort to foster generally accepted values and behaviors, such as 
honesty and racial tolerance" (Our Underachieving Colleges 66). Henry Giroux’s vision for higher education is to integrate a pedagogical philosophy that "reclaims the links between education and democracy, knowledge and public service, and learning and democratic social change" ("Higher Education Under Siege” 63). Similarly, Ernest Boyer claims the aim of undergraduate education "is not only to prepare the young for productive careers, but also to enable them to live lives of dignity and purpose; not only to generate new knowledge, but to channel that knowledge to humane ends; not merely to study government, but to help shape a citizenry that can promote the public good" (297). These views are comparable to what is deemed essential by the Association of American Colleges and Universities (AAC\&U), an organization that strongly supports campus efforts to include an intellectually engaging liberal education as a part of their curriculums.

Still, as market influences permeate higher education, institutions have been forced to react to economic pressures and adjust their priorities accordingly, adopting corporate practices such as branding and implementing accountability systems to measure quality. Furthermore, those who hold a neo-liberal approach to political economy not only embrace this infiltration of the market into areas that were previously governed by other factors but advocate it (Washburn xviii). From their perspective, the only policy choices regarding the future of higher education that are needed are ones that make colleges and universities more responsive to market demands. For those who see everything in society as a private good, there is no need for reaching consensus on communal issues that impact the larger society. NSSE's success has been, in part, due its 
compatibility with a range of priorities and perspectives, including both the neo-liberal view that markets alone should determine the future of higher education and the view that higher education has a public component that should be buffered from markets.

\section{NSSE: A Tool for Measuring Educational Quality}

NSSE was conceived in 1998 when the Pew Charitable Trusts assembled a group of leaders in higher education research to discuss the need for a way to measure academic quality beyond popular reputational ranking systems. It was believed that if such an instrument could be developed, it would provide valuable information to college and universities as well as to their respective stakeholders. The expressed goals for the survey included a way to help institutions improve undergraduate education and, at the same time "advance the national conversation about college quality to a new level" (Edgerton and Ewell). Given that the survey is intended to assess the quality of the educational experience on individual campuses, it clearly has the potential to guide the choices and decisions that faculty and administrators make as they attempt to improve that experience. In addition, these same data are packaged in a way that is convenient to use, if made public, for comparing institutions.

The administration of The College Student Report, which is the actual name of the survey, is coordinated by the NSSE Institute housed at Indiana University Center for Postsecondary Research. Schools that decide to participate in the survey select either the paper or web version of the instrument. They then work with the Institute to create materials inviting students to take the survey. Schools also provide a data file of email addresses so that students can be reminded to complete the survey. The NSSE Institute is 
responsible for both printing and sending the invitations and for sending email reminders. The Institute also coordinates the data collection and prepares individual institutional reports. The cost, affordable for most institutions, is based on undergraduate enrollment and, today, includes a $\$ 300.00$ registration fee and an administrative fee ranging from $\$ 3,375$ for a school of less than 4,000 to $\$ 7,500$ for more than 12,000 . (National Survey of Student Engagement, Cost of Survey Participation).

The survey instrument includes twenty-eight multi-part questions and offers schools or a consortium of schools with particular interests, the opportunity to add their own questions. The survey asks questions about students' activities both in and out of class as well as about "the quality of [their] relationships with faculty, administrators, and other students" (National Survey of Student Engagement, Converting Data into Action). In addition, several questions explicitly ask students to evaluate their educational experience. To illustrate, question thirteen asks "How would you evaluate your entire educational experience at this institution?" Students must select a response from “excellent, good, fair, or poor." Question fourteen poses "If you could start over again, would you go to the same institution you are now attending?" The responses include “definitely yes, probably yes, probably no, and definitely no" (National Survey of Student Engagement, The College Student Report).

The results from the survey are organized into five benchmarks of effective educational practice: level of academic challenge, active and collaborative learning, student-faculty interaction, enriching educational experiences, and supportive campus environment. Table 1.1 shows the type of questions on the survey that are associated with 
Table 1.1

NSSE Benchmarks of Effective Educational Practice and Highlights of Questions Asked

\begin{tabular}{|c|c|}
\hline Benchmark & Examples of Types of Questions Asked \\
\hline $\begin{array}{l}\text { Level of Academic } \\
\text { Challenge }\end{array}$ & $\begin{array}{l}\text { - About how many hours do you spend in a typical 7-day week } \\
\text { preparing for class (studying, reading, writing, rehearsing, and other } \\
\text { activities related to your academic program)? } \\
\text { - In your experience at your institution during the current school year, } \\
\text { about how often have you worked harder than you thought you could } \\
\text { to meet an instructor's standards or expectations? }\end{array}$ \\
\hline $\begin{array}{l}\text { Active and } \\
\text { Collaborative } \\
\text { Learning }\end{array}$ & $\begin{array}{l}\text { - In your experience at your institution during the current school year, } \\
\text { about how often have you done each of the following? } \\
\text {--Asked questions in class or contributed to class discussions } \\
\text {--Made a class presentation } \\
\text {--Worked with classmates outside of class to prepare class assignments } \\
\text {--Participated in a community-based project as part of a regular course }\end{array}$ \\
\hline $\begin{array}{l}\text { Student-Faculty } \\
\text { Interaction }\end{array}$ & $\begin{array}{l}\text { - In your experience at your institution during the current school year, } \\
\text { about how often have you done each of the following? } \\
\text {--Discussed grades or assignments with an instructor } \\
\text {--Talked about career plans with a faculty member or advisor } \\
\text {--Discussed ideas from your readings or classes with faculty members } \\
\text { outside of class } \\
\text {--Worked with faculty members on activities other than coursework } \\
\text { (committees, orientation, student-life activities, etc.) } \\
\text {--Received prompt written or oral feedback from faculty on your } \\
\text { academic performance }\end{array}$ \\
\hline $\begin{array}{l}\text { Enriching } \\
\text { Educational } \\
\text { Experiences }\end{array}$ & $\begin{array}{l}\text { - In your experience at your institution during the current school year, } \\
\text { about how often have you done each of the following? } \\
\text {--Had serious conversations with students who are very different from } \\
\text { you in terms of religious beliefs, political opinions, or values } \\
\text {--Had serious conversations with students talking with students of a } \\
\text { different race or ethnicity than your own } \\
\text { - To what extent does your institution encourage contact among students } \\
\text { from different economic, social, and racial or ethnic backgrounds? } \\
\text { - Which of the following have you done or do you plan to do before you } \\
\text { graduate from your institution? } \\
\text {--Practicum, internships, field experience, co-op experience, or clinical } \\
\text { assignment } \\
\text {--Community service or volunteer work } \\
\text {--Foreign language coursework } \\
\text {--Culminating senior experience (capstone course, senior project or } \\
\text { thesis, comprehensive exam, etc.) }\end{array}$ \\
\hline $\begin{array}{l}\text { Supportive Campus } \\
\text { Environment }\end{array}$ & $\begin{array}{l}\text { - To what extent does your institution emphasize each of the following? } \\
\text {--Providing the support you need to help you succeed academically } \\
\text {--Helping you cope with your non-academic responsibilities (work, } \\
\text { family, etc.) } \\
\text {--Providing the support you need to thrive socially }\end{array}$ \\
\hline
\end{tabular}

Source: National Survey of Student Engagement, Benchmarks of Effective Educational Practice, Indiana University Center for Postsecondary Research, [2000], Print. 
each benchmark. Colleges and universities are provided with their individual survey results in two reports: the Frequency Distribution Report and the Benchmark Comparisons Report. Both include data that allow for institutional comparisons against peer institutions.

Embedded in the questions that appear on NSSE, as in any assessment instrument used in higher education, are certain assumptions about the goals of higher education that reflect the influences of particular political, social and economic forces. NSSE, however, is an instrument that is more fluid than most, with the result being that it can be used in a variety of ways and for various purposes. Indeed, this fluidity is partly the result of the NSSE design team being mindful of the needs of multiple audiences and, attuned to the larger forces at work in higher education. As a result, this fluidity allows it to conform to whatever social and political forces are governing its use and that, I contend, explains much of its success.

\section{Mechanisms of Accountability}

NSSE is part of an extensive system of accountability at work in higher education that includes three overarching and highly intertwined mechanisms: accreditation, assessment of student learning, and total quality management. Each mechanism involves the creation of metrics and standards and all, to a greater or lesser extent, involve complex relations of power operating on multiple levels both within and outside the academy. It is primarily (though not totally) through these metrics, standards, and mechanisms of accountability that distant forces shape the daily practice of faculty and administrators. 
The importance of standards is further amplified when they are used for comparing institutions that are competing for a scarce set of resources. When data are used for comparison purposes, especially in a highly competitive market, any nuance associated with interpreting the data disappears. If, for example, a university with a low graduation rate discovers that the low rate is due to its serving a large population of students under prepared for college, administrators may attempt to find more resources for remedial programs. However, if the same data are used for consumer comparisons or simply as a metric in the competition for resources, the university — in an effort to improve its performance on that metric — might abandon any commitment to this underserved population and adopt short-term strategies that can improve its graduation rate in a way that is less resource intensive. For example, they could shift to serving students who are better prepared or simply lower their standards for graduation. Either way, it is difficult to associate either of these options with improvements in educational practice.

Increasingly, though, institutions are being called upon to be more transparent and to develop standardized measures of institutional performance for the purpose of market comparisons. For many, including many government officials, this accountability to the market is more important than accountability to other governing institutions, including accrediting agencies which may hold universities to standards that students and others might not see as important, such as serving underprepared students. The accountability issues are clearly multi-faceted, and, as Gary Rhoades, former general secretary of the American Association of University Professors (AAUP) points out, "It's not a question of 
whether [colleges and faculty should be held accountable], but how, and by whom. It's about who's developing the measures, and what behaviors do they encourage?" (Lederman, "Defining Accountability").

In response to potential pressures that undermine aspects of higher education not valued by the market, several large and influential organizations in higher education have issued policy statements and action plans to assure that learning outcomes are set by institutions and not by external agencies. For example, AAC\&U and the Council for Higher Education Accreditation (CHEA) together issued New Leadership for Student Learning and Accountability: A Statement of Principles, Commitments to Action, a policy publication that outlines a statement of principles emphasizing the importance of a liberal education and an action plan built on the notion that "a college degree should ensure that graduates are well prepared to contribute to society as knowledgeable, engaged, and active citizens" (1). Their plan is a delicate dance of acknowledging standardized measures (like NSSE, but the plan doesn't identify any specific instruments by name) while at the same time arguing in support of the idea that educational goals and assessments must be rooted in a curriculum designed by faculty (5). At the same time, a cornerstone of this document emphasizes transparency and communicating evidence of student learning to the public in a coherent, easily accessible, and consistent way.

Overall, there are nine different national accountability initiatives underway with sponsors from various higher education organizations such as the Higher Learning Commission (HLC) and the National Institute for Learning Outcomes Assessment (NILOA). The American Council on Education's (ACE) Center for Policy Analysis has 
created an online resource to follow these projects, which range from strengthening accreditation processes and validating assessment approaches to documenting improved student learning and defining what students should know and be able to demonstrate upon graduation.

Each of these programs reflects a particular perspective about the direction and purpose of higher education. At first glance, this begs the question: the purpose according to whom? However a more significant question should be asked: what are the forces shaping these directions, purposes, and practices and how are they shaping higher education? Addressing this question in a way that reveals the power relations operating in higher education is the goal of this project. Here, I briefly examine accreditation, assessment, and total quality management principles along with NSSE's link to each mechanism for the purpose of establishing NSSE as a useful nodal point situated at the intersection of many current debates.

\section{$\underline{\text { Accreditation }}$}

For more than 100 years, colleges and universities have provided evidence of their quality through the system of accreditation. This credentialing procedure, designed to demonstrate a minimum threshold of quality for institutions, represents "a seal of approval that shows an academic program, school, college or university meets quality standards established by professional peers" (Greenberg, "What Administrators Should Know About Accreditation”). Accrediting organizations are private, self-governing, and non-profit and each accrediting agency has its own standards and criteria for institutional evaluations. Accreditation then does not have the same meaning nationally, across 
institutions. There are approximately eighty recognized accrediting organizations serving different kinds of institutions:

Regional accreditors. Accredit public and private, mainly nonprofit and degree- granting, two- and four-year institutions.

National faith-related accreditors. Accredit religiously affiliated and doctrinally based institutions, mainly nonprofit and degree-granting.

National career-related accreditors. Accrediting mainly for-profit, career-based, single-purpose institutions both degree and non-degree.

Programmatic accreditors. Accredit specific programs, professions, and freestanding schools e.g. law, medicine, engineering, and health professions (Eaton, An Overview of

\section{U.S. Accreditation 2)}

Advocates for this system of accountability argue that it derives its legitimacy from being governed by those who best understand the goals and values of higher education: those within the academy. The accreditation process typically includes peer and on-site reviews that are completed by a team of volunteer faculty and administrators from other institutions. In addition, these accrediting bodies are granted recognition by the U. S. Department of Education and, more specifically, by the National Advisory 
Committee on Institutional Quality and Integrity. ${ }^{2}$ Most of these groups are also recognized by CHEA which serves as an advocate and an organizing body for accreditors. CHEA requires "accreditors to advance academic quality, demonstrate accountability, encourage purpose of change and needed improvements, employ appropriate and fair procedures in decision-making, continually reassess accreditation practice, and sustained fiscal stability" (Eaton, An Overview of US Accreditation 6). To affiliate with either an accrediting agency and/or CHEA, institutions pay an annual membership fee in addition to fees and expenses associated with the accreditation process which usually occurs on a ten-year cycle. According to their web site, the 2011-2012 institutional dues for the Higher Learning Commission of the North Central Association include base dues of $\$ 2,500+\$ 0.50$ per full time equivalent (FTE) student $+(\$ 75 \mathrm{x}$ the number of campus sites $)$ for the total due.

The agenda of market accountability has placed the accreditation system under significant scrutiny with some questioning the potential conflicts of interest when institutions pay the accrediting agency for their evaluation (Neal 14). For example, the Spellings Commission recommended that the accreditation process be changed to better serve consumers. The Commission proposed that the Secretary of Education establish a National Working Group, including broad participation by key accreditation stakeholders, to develop a blueprint for transforming accreditation. The blueprint would address four overarching goals: strengthen public-private governance (by opening the accreditation process to non-academic stakeholders), “develop a national accreditation framework, set expectations and build capacity for learning, and promote greater

\footnotetext{
${ }^{2}$ See http://www.ed.gov/about/bdscomm/list/naciqi.html for an explanation of the Committee's mission.
} 
transparency" (Schray 1). Although there has been a change of administration since this proposal was released, the goal of reforming accreditation to address issues of accountability is also on the agenda of the Obama administration. According to Judith Eaton, president of CHEA, by May 2009, there were "twenty-nine new federal rules for higher education - all of which focused on accreditation (Eaton, "Accreditation and the Federal Future of Higher Education”).

The importance of the federal government's recognition of the accrediting agencies lies in the accreditation process being the "gatekeeper for the federal student loan program" (Neal 6). Accreditation is required not only for students to receive financial aid, but also for courses to be accepted for transfer, tuition reimbursement by employers, and professional licensure. Further, philanthropic organizations frequently look for proof of accreditation when making funding decisions (Eaton, An Overview of US Accreditation 2). As a result, the federal government's certification of accrediting organizations is imbued with significant authority in higher education.

Concerned that increased federal involvement might become too prescriptive, academic organizations continue to see ways to buffer the independence of universities and the accreditation process in general. One alternative laid out in early 2009 by Robert C. Dickeson, president emeritus of the University of Northern Colorado, at CHEA's annual meeting, suggested that CHEA seek a Congressional charter to strengthen the system. As reported in Inside Higher Ed, Dickeson argued that government involvement would demand more reporting and regulations, when what is required is a system "that balances institutional interests with public interests." He continued, "such a balance can 
best be obtained by strengthening the accreditation recognition system, preserving the values that matter, and doing so through a thoughtful but aggressive initiative that charters independent accreditation coordination as a national value (Lederman, "Whither Accreditation?"). A Congressional charter offers government recognition, but no supervision of the organizations it charters - a strategy that could preserve the autonomy associated with the accrediting process. This idea met with both intrigue and skepticism, with Michael B. Goldstein, a higher education lawyer, describing a "Congressional charter as a double-edged sword, [since] one thing we've all learned...is the capacity of Congress to end up doing and saying things that none of us intended to have it do" (Lederman, "More Meaningful Accreditation”).

Responding to the same concerns as Dickeson, Eaton laid out a new vision of accreditation which she believed would continue to give institutions and faculty key decision-making authority. According to Dr. Eaton, "Accreditation 2.0" as she is calling it, will likely be characterized by six elements: "community-driven, shared general education outcomes, common practices to address transparency, robust peer review, enhanced efficiency of quality improvement efforts, diversification of the ownership of accreditation, and alternative financing models for accreditation" (Eaton, "Accreditation $2.0 ")$.

At a practical level, several regional accrediting agencies have responded to demands for more rigor and transparency by restructuring their processes to separate compliance from improvement efforts. For example, the Higher Learning Commission of the North Central Association of Colleges and Schools has separated evidence of 
compliance from institutional improvement initiatives. The compliance data would be made available to the public while institutions could specify self-improvement projects and their accreditation would be based on how well they executed their plan (Lederman, “More Meaningful Accreditation”).

NSSE administrators explicitly support accreditation efforts, by making the data generated by the survey valuable to colleges and universities. Working with the six regional accrediting bodies, NSSE created a "toolkit" to map NSSE questions to accreditation criteria in an effort to help institutions with the accreditation process. To illustrate, one of the criterion that schools accredited by the Higher Learning Commission of the North Central Association of Schools and Colleges accrediting agency need to provide is evidence that "internal and external constituencies value the service the organization provides" (Higher Learning Commission, Criteria for Accreditation). The NSSE questions mapped to this criterion are all related to the students' evaluation of support services and satisfaction with their overall educational experience such as: "provide the support to help you succeed academically, provide support you need to thrive socially, and how would you evaluate your entire educational experience at this institution," to name a few (National Survey of Student Engagement, Accreditation Toolkit). Using NSSE results in the accreditation process, reflects NSSE's desire to support the academy while at the same time is pliable enough to respond to the pressures on the system of accreditation to become more transparent. 


\section{$\underline{\text { Assessment }}$}

Mired in the accreditation debate is the role of assessment on individual campuses. At one level, assessment can be seen as an evaluation of what takes place in the classroom when faculty determine what students have learned and assign grades. Accrediting agencies are interested in that type of assessment, but relying on grades alone as evidence of student learning is problematic if the goal is to determine whether programs are meeting broader agreed upon standards. Most accrediting agencies require institutions to have assessment plans. What is being evaluated though is not only student learning but also whether universities are employing effective educational practices. Examples of different assessment tools and approaches include evaluating portfolios of student work, comparing student responses on national and local surveys, and requiring capstone projects as well as administering standardized knowledge tests.

Assessment practices, in addition to generating data to determine if certain standards are being met, can also be used to guide institutional improvements based on goals they've set. When used for compliance alone, though, assessment practices are perceived to be oversimplified and nothing more than a bureaucratic exercise, producing little evidence student learning is taking place. It's no surprise that in a recent report titled More Than You Think, Less Than We Need: Learning Outcomes Assessment in American Higher Education, the NILOA is trying to promote better use of assessment tools and increase faculty participation. Garnering support for assessment activities is identified as a "major challenge" (Kuh and Ikenberry 9). 
In some cases, the data generated by assessment efforts are being used not only to meet accrediting demands, but also to compare the performance of universities. Data from standardized tests, for example, could potentially be used in such comparisons. AAC\&U's policy is in opposition to using standardized tests, making the point that "assessing what students have learned in colleges and universities requires a sophisticated understanding both of context and of how knowledge and skills are to be used" (Association of American Colleges and Universities 2). Scholar Trudy W. Banta makes a similar point in an article titled "Reliving the History of Large-Scale Assessment in Higher Education" citing researcher James Pelligrino who asserted that "assessment that is external to an on-going process of learning and teaching... will not produce the desired outcomes by itself...assessment must become an essential part of the design and enactment of contemporary learning environments" (3). Banta added that "any valid measure of student achievement must do a reasonable job of testing what faculty in a given context are trying to teach" (3). Her point that assessment should be sensitive to what faculty are trying to teach also raised the issue of standardized tests putting pressure on faculty to teach to the test, which makes the test rather than the faculty the subject expert or authority. In the end, if assessment practices generate data that external constituencies can use to compare institutions, it is unlikely that the results will be sensitive enough to the learning environment to guide improvements in the classroom (Wehlburg 5).

The data generated by NSSE can be used internally by faculty and administrators and to facilitate comparisons. NSSE administrators, however, have avoided the debates 
about how the data are used. They hold the position that they will not publicize the results of any individual schools - leaving that decision to each institution. At the same time, they encourage the "public disclosure of student engagement results in ways that serve to increase understanding of collegiate quality and that support institutional improvement efforts" (National Survey of Student Engagement, NSSE's Position Statement). Here again, NSSE seems to be attempting to support the efforts of colleges and universities to use the data for internal purposes while leaving the door open for use of the data by external constituencies to make comparisons in a competitive market.

\section{Total Quality Management Principles}

In addition to assessment practices developed to demonstrate compliance with accreditation criteria, many schools have also adopted and/or integrated total quality management (TQM) principles to define, monitor, and measure progress toward institutional goals. TQM, originally developed in a manufacturing setting, emphasizes meeting the needs of customers, continuous improvement, and process management. For example, in 1999, the Higher Learning Commission of the North Central Association began offering an alternative approach to the self-study and peer review procedure and endorsed the Academic Quality Improvement Program (AQIP), a continuous improvement process. AQIP identifies nine categories in which institutions must set goals and that "together describe the interrelationships among systems essential to any effective college or university, using quality to refer to the never-ending improvement of systems and processes in support of mission" (Academic Quality Improvement Program: Higher Learning Commission 6). The nine categories include: 
1. Helping students learn.

2. Accomplishing other distinctive objectives.

3. Understanding students' and other stakeholders' needs.

4. Valuing people.

5. Leading and communicating.

6. Supporting institutional operations.

7. Measuring effectiveness.

8. Planning continuous improvement.

9. Building collaborative relationships (6).

Schools that choose the continuous improvement option must first set goals specific for their institution. The accrediting agency, after approving those goals, assesses the institution on how well it implements the process and makes progress toward those goals. Another quality improvement program that includes a customer focus that some institutions of higher education work toward is the Malcolm Baldrige National Quality Award. It also has industrial roots and is managed by the U.S. Department of Commerce and is awarded by the President of the United States. Comparable to AQIP, although not an accreditation program, the Baldrige criterion for education examines practices based on seven broad categories. These include leadership, strategic planning, customer focus, measurement, analysis and knowledge management, workforce focus, process management, and results (National Institute of Standards and Technology). The Spellings Commission held up these criteria as a "starting point" to define excellence and pursue continuous improvement for higher education (Schray 3). 
Continuous improvement processes can also reach more directly into the classroom. For example, the academic audit, launched in Great Britain in the 1990s and now gaining interest in the U.S., is such a process. It concentrates on establishing learning goals and evaluates the curriculum and teaching methods specifically in light of those goals. According to William F. Massy, author of "Auditing Higher Education to Improve Quality," this comprehensive and rigorous exercise is intended to foster academic improvements in a flexible and inexpensive way.

Generally, as TQM and other corporate practices have been adopted by higher education, concerns have been raised about the effects of using these strategies, especially those that reach into the classroom. Frank Edler and others (Hoecht, Aronowitz, Readings) specifically contend that TQM practices interfere with teachingand-learning, which Edler views as inseparable. Continuous improvement in the classroom, they suggest, implies standardized instruction, fails to account for student involvement in the learning process, and restricts faculty autonomy and creativity. As well, teaching is reduced to a "means of production" and becomes one function among many within the institution. In addition, Andreas Hoecht, who writes about quality assurance in UK higher education, argues that the audit format provides "rituals of verification and may well be detrimental to innovative teaching and learning" (541). Lousie Morley, author of Quality and Power in Higher Education, asserts that "quality 
audits are essentially relationships of power between observers and observed" (vii). She goes on:

an important part of the power relations is the way in which norms are created and maintained. Norms can constitute an invisible web of power because the norms become internalized and more difficult to recognize and contest. The psychic operation of the norm can offer a more insidious route for regulatory power than explicit coercion (vii).

If introducing TQM principles into the university — and assessing the university in terms of their ability to define and meet internally established measures - is controversial, a closely related corporate practice, "branding," has generated even more concern. In short, branding has become the process of marketing and selling an experience, not a product. Naomi Klein offers Nike as example, explaining that Nike's mission statement is not about selling shoes, "but to enhance people's lives through sports and fitness and to keep the magic of sports alive" (23). When translated into the university context, branding involves defining a market-driven, experienced-based mission and shaping university practices to support that mission across the institution.

The data generated by NSSE are useful to any institution seeking to characterize the experiences of its students as a population for the purpose of making decisions about how to improve practices. Administrators responsible for assessment initiatives might want to know how many ten-page papers the average student at their institution is writing 
or how frequently they work in groups. However, some of these data are especially useful to institutions that desire to gauge whether their branding efforts are successful and how to tweak their brand to be more attractive. After all, NSSE is, in many ways, akin to an end-of-the-term student evaluation of the entire university or college, not just a particular course, with questions about their satisfaction with various aspects of the university being particularly revealing metrics. In his book Management Fads in Higher Education: Where They Come From, What They Do, Why They Fail, Robert Birnbaum argues that "institutions of higher education cannot satisfactorily demonstrate their technical success by measuring their outputs; they do so by incorporating rational elements, such as innovative management techniques, into their structures and processes" (154). NSSE, however, provides a mechanism for measuring output, albeit more as a measure of satisfaction not necessarily as a measure of learning.

\section{Overview of Chapters Two through Six}

In the following chapters I make the case that while the creators of NSSE hoped to change the conversation about collegiate quality, simply introducing a new tool into an environment driven by a wide range of social, political, and economic forces was not enough. Unless there can be explicit dialogue that addresses how to define and buffer aspects of higher education that serve the public good from market forces, no instrument or assessment tool can have a significant impact especially on based on a concept as fluid as engagement. As long as higher education is framed as being governed by competitive markets, all assessment tools eventually end up serving those market values, with the data being used by external constituencies to compare institutions and by colleges and 
universities to make themselves more competitive. Even assessment mechanisms traditionally used for holding schools accountable for providing a liberal education are now being reconfigured in market terms, further strengthening the market's ability to govern college and university practices. In this milieu, aspects of higher education that ultimately benefit the larger public but provide no direct benefit to market constituencies are likely to be weakened.

In Chapter Two, "Why Governmentality: An Approach for Understanding the Relations of Power and the Forces Shaping Practices in Higher Education," I describe the approach that framed the way I examine higher education using NSSE as a nodal point. This method involves using the concept of governmentality and its focus on how populations are governed at a distance to examine the power relations at work in higher education. In this project, residential colleges and universities - and, more specifically faculty and administrators that make up these institutions - are the focal populations that I view as being governed from a distance. This chapter examines how governmentality as a technology of power is suited for an investigation into higher education as, in Foucault's terms, an apparatus of security because of the complexities of the social forces in operation.

Chapter Three, "Power Relations in the Milieu of Accountability," explores what NSSE's rapid rise reveals about power relations at work in higher education. More specifically, I examine the growing influence of neoliberalism on forces governing colleges and universities and the erosion of the public good paradigm. Here it is made evident that the neoliberal assumptions deeply embedded in the structures and practices 
governing colleges and universities have overtaken the notion that higher education has a public good component. As a result, data being generated by tools such as NSSE are being used by institutions to guide their internal improvement processes on metrics valued by external constituencies. In the long term, as schools compete to engage students, market values — which tend to be more career-centered and less focused on educating students to be independent thinkers and thoughtful citizens - are shaping the practices of institutions and their members.

Next, in Chapter Four, "Sorting Populations: Systems of Normalization in Higher Education," I examine the systems for sorting populations - students, faculty, and institutions - that emerged before NSSE, investigating how knowledge generated through sorting and normalizing these populations has long been used and co-opted for different purposes. Furthermore, I show how more recent changes in demographics, competition for resources, technology, and policies have given rise to an expanding perception of students as consumers with purchasing power who should demand evidence of institutional quality. Ultimately, these shifting relations led to commercial entities such as U.S. News and World Report becoming arbitrators of collegiate quality, and state policies pressuring higher education to be more responsive to students as consumers. NSSE emerged with the goal of providing more meaningful measures of effective educational practice but, in a milieu of accountability dominated by market competition, has become another instrument governed by larger forces and power relations.

Chapter Five, “Governing Assessment," investigates how NSSE's creators challenged the commercial rankings in an effort to change the conversation about 
collegiate quality. Rooted in the scholarship of higher education research, they drew from a body of literature focusing on what constitutes effective educational practices and the importance of student involvement both in and outside the classroom. In the end, they framed student engagement as a proxy for learning and designed a tool to measure the extent to which students experience an engaging education. This approach had significant appeal within the academy as an improvement over using the metrics associated with college rankings. At the same time, I argue that little change occurred in the conditions that gave rise to college rankings in the first place. Furthermore, the knowledge NSSE produces can be (and is) used for competitive comparisons and, in some ways, has resulted in colleges and universities being even more responsive to external constituencies. In the process, internal constituencies, such as student affairs professionals, are the beneficiaries of additional resources as universities seek to improve their performance on aspects of student engagement that support the brand. Still, changes in the classroom are being made through processes of normalization, resulting in the adoption of teaching practices held up by NSSE as the norm. I argue, however, that these changes are eroding faculty autonomy in the educational process. A growing number of scholars have begun to critique NSSE, but those who have made such critiques have focused on its deficits as an assessment tool and not on its position in a larger milieu of accountability. Such efforts fail to recognize the neoliberal forces influencing policy decisions that privilege consumers and position higher education as a private good. In Chapter Six, "Conclusions," I summarize the findings of this work and look at the overall implications of this effort. I emphasize that the myriad political, social, and 
economic forces influencing the population of colleges and universities and their members are rooted in neoliberal assumptions. As a result, the notion that higher education has a public component which cannot be determined by the interplay of producers and consumers is often lost. I argue that, in the long term, as schools compete to engage students, market values will continue to shape the practices of institutions and their members, with NSSE being just one of many mechanisms facilitating this process. The ultimate question then is one offered by David L. Kirp in Shakespeare, Einstein, and the Bottom Line: The Marketing of Higher Education:

Can the public be persuaded that universities represent something as ineffable as the common good-more specifically that higher education contributes to the development of knowledgeable and responsible citizens, encourages social cohesion, promotes and spreads knowledge, increases social mobility, and stimulates the economy? Can the argument be convincingly made that the university offers something of such great value that it is worth subsidizing, even in the teeth of bottom-line pressures - that, as NYU's John Sexton says, in certain spheres "money is not the coin of the realm" (263)?

I close by suggesting several alternatives to the current course and identify three conversations going on in higher education today that this project can inform. In the end, using NSSE as a nodal point to examine the patterns associated with the forces shaping 
higher education allows one to identify critical practices that have been adopted almost without question and are essential to re-examine. 


\section{Chapter Two - Why Governmentality: An Approach for Understanding the Relations of Power and the Forces Shaping Practices in Higher Education}

How can one make the forces and relations shaping the direction of higher education visible? In this project, I take an approach that is informed by Foucault's concept of governmentality, which encourages the examination of how power in different groups, organizations, and institutions operates subtly, and on multiple levels, to influence the behavior of a population (Miller and Rose 27). Foucault was less interested in the terminal forms of power such as state sovereignty and laws and more interested in how power functions as a web of strategies and practices that not only influences behavior but also elicits struggle, confrontation, and resistance (Foucault, History of Sexuality 92-93). Andrew Gray and Stephen Harrison have described governmentality as being about "achieving 'action at a distance' so that actors come to perceive problems in similar ways and accept responsibility to seek ways of transforming their position themselves" (18). Woven into the self-governing or identity-shaping aspect of this theory is the production of knowledge and the exercise of power through "systems of technique and instrumentality; of notation, evaluation, monitoring and calculation" that "render society governable" (18). My purpose in this project is to examine the emergence of such systems in the institution of higher education and specifically identify the way in which the heterogeneous and complex forces govern faculty and administrators as a population. In this chapter, I begin with a discussion of governmentality as a technology of power. After reviewing how Foucault suggests applying the notion of governmentality, I continue by examining how two scholars have used the concept. I close by summarizing 
my approach for this project by outlining how the National Survey of Student Engagement (NSSE) as a nodal point can be analyzed using the concepts of governmentality in order to reveal patterns of power, knowledge production, and subjectivity operating in higher education.

\section{Governmentality}

A functional study of power relations might begin by examining formal channels of power defined by position or delegated authority - taking a top down view. Foucault encouraged a more complex analysis that considers the practices of governance based on their methods and objects of control. Table 2.1 summarizes four forms of power identified by Foucault and specifies the object being governed and how each form of power was exercised. Such a table, of course, fails to capture the messiness and interconnected nature of each. In practice, sovereignty, discipline, and governmentality are entangled and interrelated, working through apparatuses of security with the population as their ultimate target (Foucault, "Governmentality" 102). Davi Johnson,

Table 2.1

Foucault's Forms of Power, Their Targets, and Methods

\begin{tabular}{|c|c|l|}
\hline Form of Power & \multicolumn{1}{|c|}{ Object } & \multicolumn{1}{c|}{ Mechanism } \\
\hline Pastoral power & Flock & Willing obedience \\
\hline Sovereignty & Individuals of a state & $\begin{array}{l}\text { Legislative and judicial } \\
\text { action }\end{array}$ \\
\hline Discipline & Individuals & $\begin{array}{l}\text { Behavior is controlled } \\
\text { through observation, } \\
\text { normalization and } \\
\text { examination }\end{array}$ \\
\hline Governmentality & Population & $\begin{array}{l}\text { Apparatuses of security } \\
\text { characterized by spaces, } \\
\text { the aleatory, and } \\
\text { normalization }\end{array}$ \\
\hline
\end{tabular}


for example, describes the shift from a disciplinary society to one governed by apparatuses of security "not as a rupture" but as "an extension and mutation" (347).

According to Foucault, over time, sovereignty and discipline melded into more complex modes of governing as complex political and economic conditions emerged and gave rise to conditions requiring the governing large populations rather than individuals and families. As a part of this shift, the population came to be understood in terms of statistics such as birth and death rates, levels of employment, and other factors of interest to a state. This form of governance is exercised through both large-scale efforts and daily practices that people are frequently unaware of to ensure the welfare of a productive population (Foucault, "Governmentality” 100).

The mechanisms of governmentality, that is the way the population is managed or conducted, operate through apparatuses of security. These apparatuses of security include not only protective services like police forces but also, and perhaps most relevant to this work, systems like healthcare and education. Each includes the institutional and administrative mechanisms and practices "that secure the economic, demographic and social processes" that exist within that population (Dean 20). In Security, Territory, and Population, Foucault suggests three characteristics to consider when examining how apparatuses of security are layered over and integrated with forms of sovereignty and discipline to govern populations: spaces of security, the aleatory (the market), and normalization (11).

In considering spaces of security, Foucault first notes that discipline is carried out on individuals in a space associated with hierarchy and function-a hospital, a prison, a 
school, etc. (Foucault, Security, Territory, and Population 20). However, governmentality operates on populations, not individuals, and hence in "spaces" that are far more complex, in a "milieu" that operates as a part of a series of events or elements regulated at various levels within a pliable framework (20). According to Foucault, the milieu "is what is needed to account for action at a distance of one body on another. It is therefore the medium of an action and the element in which it circulates" (20-21). This milieu also can be understood as the circuitry through which social, political, technological, and commercial networks operate. In the case of higher education, well defined spaces such as classrooms, labs, and offices still exist of course, but what happens in those spaces and the ways in which practices are assessed and changed cannot be understood without examining this circuitry and its influences.

The second feature of apparatuses of security is what Foucault calls "the treatment of the uncertain, the aleatory," in which he focuses on the operation of markets. (Security, Territory, and Population 11). What he describes is a laissez-faire system that, unlike discipline, allows "things to take their course," operating on entire populations by creating and managing scarcity. Ultimately, he urges "a political-economic analysis that integrates the moment of production, the world market, and finally the economic behavior of the population of producers and consumers" (41). Further, it is a system that is ever expanding and integrating additional elements and, "therefore involves organizing, or anyway allowing the development of ever-wider circuits" (45). In the case of higher education, the role of the market in shaping and governing daily practices through mechanisms of accountability is a central issue. 
Third, and essential for understanding the apparatuses of security that operate in a landscape of governmentality, is Foucault's notion of normalization. He explicitly differentiates the way in which normalization operates in a disciplinary regime from the way in which it operates through apparatuses of security. Simply put, discipline classifies and separates individuals with the goal of modifying their behavior and moving them closer to the norm (Security, Territory, and Population 57). In apparatuses of security, however, normalization is based not on the behavior of individuals but on population statistics and the management of the norm. Techniques of security operate to reduce what Foucault labels as the "most unfavorable, deviant normalities" (62) or, shifting cases that appear in the tail(s) of a normal distribution curve more to the middle. As Foucault explains:

So we have here something that starts from the normal and makes use of certain distributions considered to be, if you like, more normal that the others or at any rate more favorable than the others. These distributions will serve as the norm. The norm is an interplay of differential normalities. The normal comes first and the norm is deduced from it, or the norm is fixed and plays its operational role on the basis of this study of normalities (63).

In the case of colleges and universities, powerful tools of assessment position population statistics as the critical measure for admissions policies, faculty evaluations, and overall 
institutional performance, with a variety of important correlations and political assumptions buried deep within those measures.

Finally, there is the question of the population on which apparatuses of security operate (Security, Territory, and Population 65). Foucault argues that "those whom one governs are people, individuals, or groups," and not states or political structures (Security, Territory, and Population 122). In this case then, the primary groups I focus on are various administrators and faculties who are members of colleges and universities that comprise the system of higher education in the United States. While students are a part of the network of forces, I do not specifically include them. It is the routine behaviors administrators and faculties that are the ultimate object of control in the apparatus of security (Markula 54). As a form of shorthand here, I refer to colleges and universities as the groups being governed at a distance.

Governing populations means acquiring the various resources and implementing actions or strategies based on calculations and knowledge. Foucault uses the metaphor of governing a ship to illustrate the complexities of the process.

What does it mean to govern a ship? It means to clearly to take charge of the sailors, but also the boat and its cargo; to take care of a ship means also to reckon with winds, rocks, and storms; and it consists in that activity of establishing a relation between the sailors who are to be taken care of and the ship which is to be taken care of and the cargo which is to be brought safely to port, and on all those eventualities 
like wind, rocks, storms and so on; this is what characterizes governing a ship (“Governmentality” 93-94).

The application of this metaphor to colleges and universities implies the need for financial resources as well as strategies to operate the institution-to maintain facilities, recruit students, compensate faculty and staff, lobby legislators, educate students and much more. At the same time, there are multiple layers of interests, practices, and beliefs, which both disrupt and support these activities (Dean 11). In addition to such a political dimension, Mitchell Dean points out that there is a moral or ethical aspect to governing. As he explains, moral actions are linked to both the governing agency as well as to the subjects being governed. The way individuals or groups respond to a governing action is a self-regulating choice resulting both in how they allow themselves to be governed and how they "govern themselves" (12). When people resist being governed Foucault describes their behavior as "counter conduct" in an effort to reflect "the sense of struggle against procedures implemented for conducting others" (Security, Territory, and Population xxii). This counter behavior can then change or destabilize the relations of power and open up new possibilities for conducting others (xxii).

\section{$\underline{\text { Sovereignty and Discipline }}$}

Although governmentality integrates the notions of sovereignty and discipline, it is helpful to examine these concepts independently in order to understand how they operate as elements of governmentality. Sovereignty, for example, is most commonly understood as the ultimate authority over subjects within a territory and exercised through formal channels of authority and legal mechanisms such as constitutions and laws. 
According to Majia Nadesan, in Governmentality, Biopower, and Everyday Life, the sovereign/state complex secularized the concept of pastoral power to stabilize everyday life (8). Foucault discussed pastoral power in length in Security, Territory, and Population. Here, he explained that in this religious form of power, God is understood as the pastor, or the shepherd and the people are his flock, being led willingly like sheep (125). Accordingly, characteristics defining the power of the shepherd include the notion that it is the shepherd who goes ahead of the sheep, showing them the way to salvationwhat path to take, and where to eat and rest. This guidance is provided through kindness and care, preventing the sheep from wandering or suffering.

Foucault asserts that sovereignty is typically exercised by a means of deduction, a mechanism that takes away wealth, services, labor, and, at times, life itself. If the life of the sovereign was in question or the defense of the territory was required, decisions about life and death could be exercised. Foucault points out that the sovereign exercised his right of life only by exercising his right to kill, or by refraining from killing; he evidenced his power over life only through the death he was capable of requiring. The right which was formulated as the "power of life and death" was in reality the right to take life or let live (History of Sexuality 35).

Emerging in contrast to deduction is the art of governing that is productiveincreasing wealth and happiness, multiplying life, and strengthening the prominence of the state. Foucault distinguishes between sovereignty and the art of governing. To 
illustrate this distinction, he uses Machiavelli's The Prince to show that the sovereign is external and transcendent from his principality. The goal for the prince is to exercise power in a way that allows for an assessment of danger to the principality and, "to develop the art of manipulating relations of force that will allow the prince to ensure the protection of his principality, understood as the link that binds him to his territory and his subjects" (“Governmentality" 90). This shift to productive governing does not eliminate sovereignty; instead, this mechanism of power is tied to politics and the formal apparatus of the state. This in turn, facilitates a degree of self-governing or governing from a distance. To illustrate, any piece of legislation that directly affects people's practicessuch as a law that requires colleges who receive financial aid to be accredited - is an expression of sovereignty.

Disciplinary power is like sovereignty in that it also operates on individuals but it is a more subtle form of control. In Discipline and Punish: The Birth of the Prison, Foucault identified three techniques of disciplinary control as they apply to individuals: observation, normalization, and examination (170). Jeremy Bentham's design for the panopticon prison is the well-known example Foucault uses to demonstrate the power of observation. The plan allowed for constant observation and operates even when no guard is present. "The inmate cannot see whether or not the guardian is in the tower, so must behave as if surveillance were perpetual and total. If the prisoner is never sure when he his being observed, he becomes his own guardian" (Rabinow 19). Expanding this notion, Michael Sauder and Wendy Espeland point out that this spatial surveillance can be replaced by "conceptual arrangements such as statistical or actuarial surveillance" (69). 
The concept of normalization, the second mechanism of disciplinary control emphasized by Foucault, works on the basis that there is a standard set of behavioral expectations that people are to follow. He described the discipline for the failure to meet these standards as a kind of "micro-penalty" too trivial to be a law, but now exercised as power with the goal to reform, to normalize (Discipline and Punish 178). Hubert Dreyfus and Paul Rabinow in Michel Foucault: Beyond Structuralism and Hermeneutics describe the end result of normalization as systems for separating and ranking individuals:

It proceeds from an initial premise of formal equality among individuals. This leads to an initial homogeneity from which the norm of conformity is drawn. But once the apparatus is put in motion, there is a finer and finer differentiation and individuation, which objectively separates and ranks individuals (158).

The resulting classification system then serves a dual function which is to reward or punish those it classifies (Sauder and Espeland 72).

Finally, examination is the method of disciplinary control that combines observation with normalization. "It is a normalizing gaze, a surveillance that makes it possible to qualify, to classify, and to punish" (Foucault, Discipline and Punish 184). The examination makes the individual the target of disciplinary power. Further, the results of an exam provide documentation that makes the individual a describable object and constitutes a system of comparisons that can calculate differences between people. 
In this project, I use the concept of governmentality in order to understand what the increasing use of the NSSE by colleges and universities reveals about the relations of power shaping the direction and practices of higher education. This lens frames higher education as an apparatus of security operating in what I describe as a "milieu of accountability," with market decisions playing a significant role in the overall processes of both normalizing and shaping behavior. More specifically, governmentality provides a way to make visible the heterogeneous forces and knowledge practices that are subtly shaping conduct — action at a distance — and affecting the beliefs, choices, and actions, both resistive and compliant, of faculty and administrators working in higher education.

\section{Examining Governmentality in Operation}

Foucault himself saw the concept of governmentality as not fully developed and open to exploration, but believed that it could be fruitfully used in revealing the power relations at work in an apparatus of security (Security, Territory, and Population116). Here, I briefly examine the assemblage of power, knowledge, and subjectivity that Foucault described as being inherent to relations of power. I then discuss his strategy for applying the concept of governmentality and examine at how two scholars have drawn on the term. I close the chapter with the approach I use for this project.

\section{Power, Knowledge, and Subjectivity}

From Foucault's perspective, power, knowledge, and subjectivity - the assemblage at the heart of any power relations - cannot be separated from one another. They function in a reciprocal manner and cannot "be explained in terms of the other, nor reduced to the other" (Dreyfus and Rabinow 114). Simola, Heikkinen, and Silvonen 
explain that while power, knowledge, and subjectivity can understood as one totality, in examining how each element functions or contributes to that totality, additional layers of the assemblage are revealed. In their view, Foucault's assemblage of power, knowledge, and subjectivity "resembles an onion revealing layer after layer when peeled" (69).

Whether power is exerted over individuals or over populations through layers of accountability demands and market decisions, Foucault explains that it is necessary to examine power relations and not simply the capacity of power. Relations of power are "a way in which some act on others" (Power 340). They focus on the connections among actors and the methods or strategies by which one shapes the behavior of the other.

Power though is not a one-way association, operating top down from one set of actors on to others. In a power relation, each can act on the other. Power circulates in the various networks through knowledge created and/or revealed. Foucault argues that "power is employed and exercised through a net-like organization" (Power/Knowledge 98). As well, layered in these relations of power are goals, motivations, and intentions. These elements take different forms, result from various conditions, and occur in different places, and thereby meld together in response to a specific circumstance (Foucault, Power 338).

This depiction of power relations - as "a way in which some act on others" suggests a battle of control, but Foucault points out that even in the midst of struggle, power can be productive, that "it induces pleasure, forms knowledge, produces discourse. It needs to be considered as a productive network which runs through the whole social body, much more than as a negative instance whose function is repression" 
(Power/Knowledge 119). By referring to power as something that runs through the "whole social body," Foucault moves away from the larger structures power, like the state, and directs the attention to everyday activities that have a regulating effect. He calls this "capillary" power and describes it as "the point where power reaches into the very grain of individuals, touches their bodies, and inserts itself into their actions, attitudes, their discourses, learning processes and everyday lives" (Power/Knowledge 39). Ultimately, then, "the exercise of power is a 'conduct of conducts' and a management of possibilities," a form of governing "more or less considered and calculated...destined to act upon the possibilities of action of other people" (Foucault, Power 341).

Foucault suggests examining "forms of resistance against different forms of power" as a useful strategy of analysis (Power 329). In general, he is anxious to expose the power relations, to understand their location, and to determine where and how they are being applied—in short, to recognize their real effects (Power/Knowledge 97). Stuart Hall explains that we are all "caught up in its circulation-oppressors and oppressed" (Hall 50). As a result, there are numerous ways actors can respond or resist, and then again, be acted upon. This freedom affords an array of possibilities allowing for different responses and results (Foucault, Power 340).

It is a set of actions on possible actions; it incites, it induces, it seduces, it make easier or more difficult; it releases or contrives, makes more probable or less; in the extreme, it constrains or forbids absolutely, but it is always a way of acting upon one or more acting subjects by virtue 
of their acting or being capable of action. A set of actions upon other actions (Power 341).

Of course when a vast network of actors is involved more points of resistance can emerge as the relationships become more complex.

Integral to any power relation is knowledge that mediates it. In Discipline and Punish, Foucault explains "that there is no power relation without the correlative constitution of a field of knowledge, nor any knowledge that does not presuppose and constitute as the same time power relations" (27). In this view, Foucault is interested in the connection between power and knowledge. Different methods or strategies of power produce different kinds of knowledge which in turn influences how people act (O'Farrell 101). In addition, Foucault argued that scientific knowledge tends to be privileged because it is seen as objective and producing truth. However, he was less concerned about 'truth' and more interested in understanding the use of knowledge in the exercise of power for regulating behavior. Indeed, Foucault challenged the privileged position of scientific knowledge and called for a closer examination of the effects of the power/knowledge relationship. To Hall, knowledge, power, and truth are intimately entwined:

Knowledge linked to power, not only assumes the authority of 'truth' but has the power to make itself true. All knowledge once applied in the real world has real effects, and in that sense at least "becomes true." Knowledge, once 
used to regulate the conduct of others, entails constraint, regulation and the disciplining of practices (49).

For Foucault, the knowledge aspect of a power relation is manifested through discourse (History of Sexuality 100). Discourse then has a governing function. Defining how to talk and think about a topic simultaneously limits other ways of understanding it. Individuals therefore, conduct themselves based on the knowledge disclosed through the discourse (Hall 44).

Finally, the third component of a power relation, subjectivity, can be viewed as the effects of power/knowledge on the object of power. Thus, the power/knowledge that is working in everyday life turns individuals into subjects. Foucault explained that "there are two meanings of the word "subject:" subject to someone else by control and dependence and tied to his own identity by a conscience or self-knowledge" (Power 331). In other words, 'subject' carries the dual meaning of an object being acted upon (a product of discourse) and an active knowing subject. According to James D. Marshall, who wrote about Foucault in the context of educational research, "in terms of discourse we can say that the subject both speaks and is spoken of; in epistemological terms we can say that man appears in his ambiguous position as an object of knowledge and as a subject that knows" (14). The subject is not locked into being determined solely by its history and experience rather it can be dissolved and reestablished in conjunction with the production of new knowledge and practices (O'Farrell 113). Nadesan explains that "this stance implies that governmentality holds that there is no subjectivity outside the social; government is not seen as an external force acting upon otherwise free agents. Rather 
individuals are constituted as such within and by social relations" (10). The relationship between power, knowledge and subjectivity can be seen in Foucault's discussion in

\section{Discipline and Punish:}

These power/knowledge relations are to be analyzed therefore, not on the basis of a subject of knowledge who is free in relation to the power system, but on the contrary, the subject who knows, the objects to be known and the modalities of knowledge must be regarded as so many effects of these fundamental implications of power/knowledge and their historical transformations (28).

This assemblage operates in all arrangements of power: sovereignty, discipline and governmentality. Understanding power relations in any form and all levels therefore requires one to examine this assemblage in context.

\section{Applying the Concept of Governmentality}

With the power, knowledge and subjectivity assemblage in mind, Foucault discusses ways for examining governmentality in operation in Security, Territory, and Population. First, governmentality requires the analyst to "move outside the institution and replace it with the overall point of view of the technology of power" (117). This method necessitates going beyond organizational operations to develop an understanding of how a particular institution is positioned in the context of larger society and reconstructing "a whole network of alliances, communications, and points of support" (117). In studying prisons, for example, Foucault did not assume that prisons existed in 
isolation; instead they are a product of numerous social forces at work. Second, he encourages the investigator to look beyond an evaluation of the functions we expect from an institution and, instead, "to substitute the external point of view of strategies and tactics" as a way to acquire knowledge (Security, Territory, and Population 118). To illustrate, Foucault explained that in studying prisons, he "noticed the real history of the prison is undoubtedly not governed by the successes and failures of its functionality, but is in fact inserted within strategies and tactics that find support even in these functional defects themselves" (Security, Territory, and Population 117-118). Here, Foucault is interested in micro-practices used in the prison like isolation and the length of an individual's sentence relative to their reform (Deflem). Third and finally, Foucault addresses the object; governmentality refuses to acknowledge concepts such as delinquency, sexuality, or mental illness as objectively defined (Security, Territory, and Population 118). Mental illness, for example, cannot be measured as a pre-existing object, or as only one thing. Instead, the conception is constituted through a broader understanding from various domains of knowledge. Foucault summarizes the method in this way:

In short, the point of view adopted... involved the attempt to free relations of power from the institution, in order an analyze them from the point of view of technologies; to distinguish them also from function, so as to take them up within a strategic analysis; and to detach them from the privilege of the object, so as to resituate them within the 
perspective of the constitution of fields, domains, and objects of knowledge (Security, Territory, and Population 118).

Applying the notion of governmentality — like any critical analysis — encourages an examination that challenges or "destabilizes" organizational practices which are taken for granted. "Such destabilization is to introduce a certain kind of awkwardness in the very fabric of our experience, by making our narrative of such experiences 'stutter"” (Rose, Powers of Freedom 20). Dean, in Governmentality: Power and Rule in Modern Society explains that an analytics of government calls us to examine our "taken-for-granted ways of doing things" because they are not necessarily self-evident (21). Going further he explains:

An analytics of a particular regime of practices, at a minimum, seeks to identify the emergence of that regime, examine the multiple sources of the elements that constitute it, and follow the diverse processes and relations by which these elements are assembled into relatively stable forms of organization and institutional practice (21).

More specifically, Rose explains that governmentality studies "try to diagnose an array of lines of thought, of will, of invention of programmes and failures, of acts and counter-acts" (Powers of Freedom 21). The objective is "to draw attention to the heterogeneity of authorities that have sought to govern conduct, the heterogeneity of 
strategies, devices, ends sought, the conflicts between them, and the ways in which our present has been shaped by such conflicts" (Rose, Powers of Freedom 21).

Several scholars (Dean, Miller and Rose, Bratich, Packer, and McCarthy) propose using Foucault's notion of "problematization" to identify those points where tensions arise as a result of current practices. This method of inquiry requires identifying circumstances where the activity or situation of governing becomes a problem, "calling into question some aspect of the "conduct of conduct"" (Dean 27). In higher education, for example, disagreements over how to demonstrate the quality of colleges and universities can be viewed as such a circumstance.

An analysis informed by governmentality, then, unfolds on several dimensions. The problem under investigation needs to be understood in the context of the present, examining the interconnected assemblage of power, knowledge, and subjectivity in operation. It also includes an interpretive element that offers an alternative perspective to current conditions. Together these dimensions mirror the way Dreyfus and Rabinow describe Foucault's work, that of "interpretive analytics."

First, the interpreter must take up a pragmatic stance on the basis of some socially shared sense of how things are going. ... Second, the investigator must produce a disciplined diagnosis of what has gone on and is going on in the social body to account for the shared sense of distress or well being....Finally, the investigator owes the reader an account of why the practices he describes should produce 
the shared malaise or contentment which gave rise to the investigation" (200).

Ultimately an analysis of governmentality entails an interpretation of the forces and relations that are uncovered along with suggested alternatives. According to Rose, O’Malley, and Valverde “one seeks to identify different styles of thought, their conditions of formation, the principles and knowledges that they borrow from and generate, the practices that they consist of, how they are carried out, their contestations and alliances with other arts of governing" (84). Bratich, Packer, and McCarthy suggest using questions as a heuristic device in order to facilitate the interpretation and make a case for what might be done differently: "how did that particular form of conduct come under scrutiny?; what forms of knowledge were created for, directed at, and affected by this conduct?...and what conduct is made intelligible for reflection and guidance?" (11).

Two examples of scholars that have used governmentality to analyze networks of power, the production of knowledge, and the shaping of the subject to reveal practices of governing from a distance include Nikolas Rose's Governing the Soul: The Shaping of the Private Self, and Davi Johnson's article "Psychiatric Power: The Post-Museum as a Site of Rhetorical Alignment." Although they both focus on an analysis of governmentality that links a complex network of forces with self-regulating behavior, the scope of their work is different.

Rose, in his project, explores the self in four contexts: war, work, family, and personal care, looking at how conditions and relations have changed over time and identifying practices that have resulted in shaping individuals in ways that allow them to 
be governable and self-governing. He included several categories of material in his investigation: explanations, technologies, authorities, subjectivities and strategies (xi). He points out that these categories do not amount to a methodology and are not appropriate for every problem, yet "they sensitize us to the kinds of connections and relations amongst diverse elements that have brought our contemporary ways of thinking, judging, and acting into being" (xii). To illustrate the use of these various elements, in the chapter titled "The Contented Worker," Rose begins by explaining employment in terms of a contractual relationship between labor and management. Yet over the course of the twentieth century, he argues that work became socialized and situated "within a wider network of relations between the worker, the employer, and the state" (61). The chapter continues with an examination of the subjectivity of the worker in conjunction with "economic policy, the search for social integration, the management of industrial harmony, and the quest for business efficiency" (62). Overall, Rose considers this multipart work a "contribution to the genealogy of subjectivity" as well as a "contribution to the history of psychology" (vii, and ix).

The scope of Davi Johnson's work is somewhat narrower than Rose's effort. Johnson, in her study of how psychiatric languages shapes peoples' attitudes and behaviors about mental health, uses what she calls a "nodal point" to investigate the complex network of corporations, government agencies, and social institutions relative to individual participation in pharmaceutical consumption. In one study, she examined a single museum exhibit, "Brain: The World Inside Your Head," to explore the forces and relations that ultimately aligned corporate and individual interests and functioned "as a 
mechanism of governmentality" (359). In this research, Johnson situates the exhibit, funded by Pfizer (one of the world's largest pharmaceutical companies) and the National Institutes of Health (the federal medical research agency), within a "society of control" and examines its rhetorical elements "to show how the dispersal of biological vocabularies constructs individuals as active consumers empowered and obligated to maintain and manage their health" (346).

In this project, I followed Johnson's lead in using a "nodal point" as a focusing device. Here, NSSE serves as the nodal point through which I examine higher education as an apparatus of security. The main goal is to understand what the increasing use of NSSE - a tool that purports to measure the degree to which colleges and universities are delivering a quality education capable of engaging students — reveals about the relations of power shaping the direction and practices of higher education. Using governmentality as my lens, I identify the larger forces in operation. 


\section{Chapter Three - Power Relations in the Milieu of Accountability}

For most of the twentieth century, it was generally assumed that colleges and universities existed for the purpose of creating new knowledge and educating students to use that knowledge for their benefit and the benefit of the public good. It was also generally assumed that institutional priorities were defined by tenured faculty along disciplinary lines (Riesman 3). However, over the course of a long century, from roughly 1870 to 1980 , an important shift occurred in the forces governing higher education. Among other things, a dramatic expansion in the scale and scope of higher education, changing demographics and expectations, greater federal and state oversight, escalating costs, and increased competition have resulted in national demands for accountability operating through a complex network of institutions and practices.

Today, the complex milieu of accountability that governs higher education in the United States shapes the practices of administrators and faculty in myriad ways. The sovereign power of governments and the disciplinary power of institutions are now entangled and embedded in a larger system of control in which market forces and systems of accountability are salient features. As would be expected from Foucault's conception of governmentality, the power relations operating in this milieu — and the different philosophies, goals, and agendas of those seeking to influence the direction in which higher education is moving - are embedded in the daily practices that are shaping the course of higher education.

In this chapter, after examining the National Survey of Student Engagement's (NSSE) position in the middle of several on-going debates, I make the case that the 
existing milieu of accountability frames higher education as a market-mediated private good with universities competing for students and resources and where market demands for evidence of educational quality dominate. I argue that the neoliberal ideal - that is the notion that all decisions should be made through interplay of producers and consumersis shaping the practices of higher education and that this ideal has secured a significant foothold in systems of accountability. There appears to be little room for debate about whether the contributions of higher education that are difficult to measure and tend not to be vocational should be buffered from market forces. Increasingly, institutions are reduced to a statistical profile that facilitates market comparisons and compete to improve their performance on those metrics as they deliver the services that students desire.

This emphasis on education as a private good reinforces the views of those who frame the notion of "engagement" in terms of the experiences that students as consumers value. The idea of engagement as intellectually curious students wrestling with the challenges that faculty put before them, becomes less central. In the process, as universities compete to attract students who tend to have goals that are more vocational, the public good component of education and the autonomous role of faculty is also being eroded. Proponents who emphasize higher education's role in fostering open inquiry and educating students as citizens point to significant challenges in sustaining this role in the face of market forces that appear blind to these values (London 14).

\section{NSSE as a Nodal Point}

NSSE has objectified the notion of student engagement. By designing and widely promoting an instrument that positions student engagement as a proxy for learning, it 
suggests that "engagement" is something that can be measured in concrete terms-a notion that has wide appeal to numerous constituencies. The rhetoric of student engagement has the characteristics of unassailable virtue. At the same time, its meaning is fluid and ambiguous. To some, it is associated with active participation in the classroom; to others, it is framed it in terms of being involved in the entire college experience. Those who see higher education as having a public component are more likely to associate engagement with civic participation, while those who view education as a market-mediated private good are more likely to see engagement as a measure of product quality. The ambiguity of the term allows groups with different visions of higher education to embrace the concept - and NSSE — for different reasons. Using NSSE as a nodal point, therefore, proves to be a fruitful way to examine the power relations operating in higher education.

Indeed, NSSE is embraced by constituencies with a variety of goals: by those who see value in using it as an assessment instrument for the purpose of internal institutional self-improvement and by those who see it as a tool for accountability and a way to measure institutional quality. For example, NSSE has direct appeal for college and universities seeking to maintain their autonomy because individual schools are not required to make their results public, seemingly providing relief from the constant pressure of competitive comparisons and rankings. Groups outside the academy, though, seek to use the results as a mechanism for greater accountability (Kelly and Aldeman 6). To illustrate, under the Bush administration, the Spellings Commission embraced NSSE in its report "A Test of Leadership: Charting the Future of US Higher Education" as an 
exemplary assessment tool to address accountability concerns. At the same time, higher education associations that resisted many of the recommendations in this report have endorsed NSSE as a tool that encourages high impact educational practices. This mutual endorsement of NSSE by constituencies that have conflicting priorities has contributed to its rapid dissemination.

Another aspect of NSSE that makes its use valuable as a nodal point is that it positions engagement as a proxy for learning. Since learning is a fundamental goal of the academy, a tool to measure learning — especially in the milieu of accountability—is of significant interest. However, as a proxy for learning, NSSE avoids the need for potentially contentious debates over the specific content of what to assess. The same assessment instrument can be used at institutions with significantly different educational missions and goals. Schools that have a conservative-leaning mission, such as Grove City College and Liberty University, as well as schools that embrace a more progressive mission than most, such as Evergreen State College or Oberlin College, can use the results of NSSE to assess the institution's practices. For example, NSSE asks students to identify the quality of their relationships with other students, faculty members, and administrative personnel, which is a question that is relevant to all institutions (National Survey of Student Engagement, College Student Portrait). In practice, NSSE attempts to assess the degree to which students are engaged in the educational process and the degree to which universities are employing practices that facilitate their engagement.

Finally, NSSE shifts the power relations between students, administrators, and faculty. Although NSSE is presented as a measure of student engagement, it does not 
involve faculty assessing students but students assessing faculty and administrators. Whether NSSE is used as an assessment tool for institutional internal self-improvement or used to generate data for the purpose of accountability - that is, for external audiences to compare institutions - this practice can be viewed as empowering students to shape the behavior of faculty and staff.

As a nodal point then, NSSE can be used to examine several of the larger struggles going on in the academy. More specifically, I argue that neoliberal assumptions about the primacy and power of the market in defining educational quality have come to be assumed. In such a milieu, data generated by NSSE are privileged if they help universities be more responsive to market demands or allow external constituencies to compare the performance of universities. Over the long term, as colleges and universities compete to attract students, the values of those who frame higher education solely as a private good will end up with increasing power to shape the practices of faculty and administrators.

\section{Re-defining Higher Education in Market Terms}

Debates over the future of higher education, including those involving the role of instruments to assess learning such as NSSE, cannot be understood unless placed in the context of a larger debate, one that contrasts higher education as being autonomous - as being self-governed and committed to preparing students as responsible citizens through open inquiry — with the neoliberal ideal that all institutions, public and private, should be governed by market forces. Other ideological positions are, of course, also represented in this debate, which plays out not only in philosophical terms, but in direct effects to 
reshape the networks in which power relations are constituted. Thus, while actors push, pull, and position in myriad ways to advance various agendas and different priorities, they also aim to embed processes and practices to reflect their position.

Complicating matters is the involvement of a new set of actors in efforts to shape the direction of higher education in the United States. In particular, advocacy think tanks have emerged as influential actors in the networks operating in higher education. To illustrate, the American Enterprise Institute, a conservative think tank, held a forum in fall 2009 on the theme of "Increasing Accountability in American Higher Education." Presenters addressed a range of topics they saw as part of the accountability conversation including making more rankings information available so that additional comparisons are available to consumers and policy makers, improving student outcomes, rewarding institutions financially based on enrollment at the end of a term instead of at the beginning, reining in tenure, and shifting ultimate accreditation responsibility to the federal government rather than non-profit professional organizations (Lederman, “Defining Accountability”).

Today, as the network of conservative think tanks expands, neoliberal ideals are having an increasing influence on policymakers and the daily decisions of administrators and faculty, significantly challenging the core features of what can be described as the public good paradigm of higher education (Harland 513). Neoliberal ideals position higher education as a private consumer good that should be shaped solely by the consumers of the good themselves (Zemsky, Wegner and Massy 5-7). According to Henry Giroux, this ideology is diminishing the university's place as a public sphere 
where ideas can be critically debated. He sees the university operating now in ways that are "more instrumental, commercial, and practical" than ever before ("Academic Unfreedom in America” 46).

In the next section, I explore further the values associated with both the public good paradigm and the neoliberal ideal, recognizing that they are neither mutually incompatible nor the only views of higher education possible. Their differences, however, serve as a point where resistance to the reforms currently underway is most visible. In particular, I examine the ways in which the uses of NSSE - for assessment in service of institutional goals or market choices - reflect the larger tensions between the public good paradigm and the neoliberal ideal. I first examine each position in more detail and then illustrate how they are reflected in important debates involving assessment strategies in higher education.

\section{$\underline{\text { The Public Good Paradigm }}$}

Historically, higher education has included a public component rooted in the notion that society benefits from the contributions of colleges and universities. The National Forum on Higher Education for the Public Good resists defining this component to precisely, recognizing that such an effort "will always involve contested ideas about vision, values and relationships" (London 10). Nonetheless, they promote educational efforts that "share a commitment to civic and social responsibility, to serving and protecting the common welfare" (London 19). According to those who hold this perspective, foundational values that support this view like equality, justice, service,

academic freedom, and autonomy (Kezar, "Creating a Metamovement" 23) enable higher 
education "to fulfill its role in educating students for the demands of leadership, social citizenship, and democratic public life" (Giroux, "Neoliberalism, Corporate Culture, and the Promise of Higher Education" 433). In addition, this position champions independent inquiry and, as Giroux explains, views the university as a "site of critical learning" not as a place where education is equated to job training (433). Jennifer Washburn author of University Inc.: The Corporate Corruption of Higher Education argues for the critical role of the university in "preserving humankind's greatest intellectual and cultural achievements, to provide expert advice and public service, to protect the public domain of knowledge, and to serve as critic and conscience of society" (227). I refer to these ideas as the "public good paradigm." It is important to note that while this paradigm may have greater appeal to those committed to the goal of a broadly educated society, embedded in it are heterogeneous forces and practices that are also shaping conduct.

Deeply rooted in this paradigm are the values of academic freedom and autonomy which early on, were seen as essential in order for the marketplace of ideas to flourish (Zumeta 5). Academic freedom, defined by the AAUP, is "the freedom to conduct research, teach, speak, and publish, subject to the norms and standards of scholarly inquiry, without interference or penalty, wherever the search for truth and understanding may lead" (R. W. Bowen). Embedded in this definition is the notion that autonomy is crucial to the production of highly original knowledge and in making public knowledge that might be threatening to people in positions of power. It is this independence that allows for debate and a robust exchange of ideas. Further, the historical protection of academic freedom encourages faculty to execute their responsibilities by providing 
students with the most current information in their disciplines and challenging them to think in ways that will develop their roles as productive citizens. In fact, Glenny and Dalglish point out that in the middle of the nineteenth century, the universities of California and Michigan were provided with autonomy as a part of their respective state constitutions (23-25). For most of the twentieth century it was this recognition of the importance of autonomy in the academy that guided policy efforts to improve the quality of higher education in the United States.

The American Association of Colleges and Universities (AAC\&U), a professional higher education organization of more than 1,200 member institutions, explicitly supports the public good paradigm and the importance of an undergraduate liberal education. They advocate four essential learning outcomes for students facing today's societal challenges:

1.) knowledge of human cultures and the physical and natural world,

2.) intellectual and practical skills, including inquiry and analysis, critical and creative thinking, written and oral communication, quantitative literacy, information literacy, and teamwork and problem solving

3.) personal and social responsibility, including civic knowledge and engagement-local and global, ethical reasoning and action, foundations and skills for lifelong learning 
4.) integrative and applied learning, including synthesis and advanced accomplishment across general and specialized studies (Kuh, High-Impact Educational Practices 4$)^{3}$.

NSSE is strongly aligned with AAC\&U, sharing their goal of improving undergraduate education in all these areas. Many of the questions that appear on NSSE directly address these learning outcomes. For example, questions relative to issues of diversity and participation in community service as well as assessing the quantity of reading and writing and the importance of synthesizing material can be seen to support liberal education and the public good model. In addition, AAC\&U recently launched a ten-year initiative — Liberal Education and America's Promise (LEAP) — using data collected from NSSE to identify high-impact educational practices for those who have been historically underserved. AAC\&U is challenging the educational community to use this information broadly and to provide these kinds of experiences for all students.

In terms of improving educational practices the public good model certainly encourages internal self-evaluation through assessment. Proponents of this model, however, consider the public dissemination of this information as detrimental in that once this information is used for external purposes, it discourages future efforts to gather the data. Still, they recognize the need to demonstrate higher education's contributions to society and argue that it is possible to define measures of accountability in terms of educational outcomes that reflect a commitment to the public good (London 52). Indeed,

\footnotetext{
${ }^{3}$ According to a note in this text, this list was developed over the course of several years in conversation with the colleges and universities; an analysis of needs from the business community, and a review of accreditation standards for engineering, business, nursing, and teacher education (4).
} 
NSSE includes some such measures on its survey. For example, question eleven attempts to assess the impact of a liberal education:

To what extent has your experience at this institution contributed to your knowledge, skills, and personal development in the following areas?

a. Acquiring a broad general education

b. Acquiring job or work-related knowledge and skills

c. Writing clearly and effectively

d. Speaking clearly and effectively

e. Thinking critically and analytically

f. Analyzing quantitative problems

g. Using computing and information technology

h. Working effectively with others

i. Voting in local, state, or national elections

j. Learning effectively on your own

k. Understanding yourself

1. Understanding people of other racial and ethnic backgrounds

m. Solving complex real-world problems

n. Developing a personal code of values and ethics

o. Contributing to the welfare of your community

p. Developing a deepened sense of spirituality 
(National Survey of Student Engagement, College

Student Report)

The public good paradigm, then, is rooted in the idea that there is a public component to higher education, one that cannot be defined by market forces alone and depends on the autonomy and academic freedom of institutions and faculty to preserve. If universities were held accountable for this aspect of the educational process, then the increasing accountability of institutions to markets would be less troublesome. However, in a milieu of accountability dominated by neoliberal ideals, these principles are being subtly challenged.

\section{The Neoliberal Ideal}

The neoliberal ideal is not a concept specific to higher education. Rather, it is an approach to political economy and the socio-cultural domain that contends that the interplay of producers and consumers and the expressions of individual values through market decisions is a self-regulating form of governance (Nadesan 45). No public policies are needed other than those that strengthen the power of markets. David Harvey in A Brief History of Neoliberalism explains that the neoliberal state embraces "strong individual private property rights, the rule of law, and the institutions of freely functioning markets and free trade. These are the institutional arrangements considered essential to guarantee individual freedoms" (64).

Neoliberalism is a permutation of laissez-faire capitalism, which emerged in the late nineteenth century when large corporations began to resist government regulations that established labor policies and eliminated the use of monopolistic practices. Laissez- 
faire capitalism, in turn, was an extension of the eighteenth century liberal economic principles advocated by Adam Smith, who argued in favor of free trade and against tariffs, positioning the invisible hand of the market as capable of coordinating production more efficiently than the mercantilist policies. The notion of a self-regulating market generally held sway in guiding U.S. policy until the collapse of the economy in the 1930s, which suggested that the market may not be self-regulating. It was at that time that Keynesian economics explicitly challenged the notion of a self-regulating market, arguing that the government had a role to play in managing the economy to protect the public good (Martinez and Garcia).

In the last twenty-five years, there has been a gradual revival of laissez-faire economic principles, based on the idea that markets are self-governing and rooted in the claim that the policies hearken back to the economic liberalism of Adam Smith. Thus the label "neo" (new) or advanced liberalism. Those who embrace neoliberal values not only reject the legitimacy of regulations and policies established for the public good through the political process, they actively support government efforts to make social institutions more accountable to the market (Martinez and Garcia). Where successful, the result is to eliminate the need for any debate over what constitutes the public good, redefining it in market terms. In addition, it suggests that public resources should not be used to support social institutions that have been buffered from market forces in the past; in this ideal most (if not all) organizations would be privatized. Furthermore, according to scholar Stanley Fish in an article about neoliberalism and higher education, "values like morality, 
justice, fairness, empathy, nobility and love are either abandoned or redefined in market terms."

Foucault explicitly interprets the neo-liberal agenda as an effort to treat the social as part of the economic domain. In "The Birth of Bio-Politics - Michel Foucault's Lecture at the Collège de France on Neo-Liberal Governmentality," Thomas Lemke explains Foucault's view that neoliberals

transpose economic analytical schemata and criteria for economic decision-making onto spheres which are not, or certainly not exclusively, economic areas or indeed stand out for differing from any economic rationality. ...US neoliberals attempt to re-define the social sphere as a form of the economic domain. The model of rational-economic action serves as a principle for justifying and limiting government action, in which context government itself becomes sort of an enterprise whose task it is to universalize competition and invent market-shaped systems of action for individuals, groups, and institutions (196).

Those who champion the neoliberal ideal are working through various organizations such as think tanks, government commissions, and the popular media to push an explicit agenda of market accountability. Their goal is to reform systems of accountability in higher education through the creation of standardized processes and 
procedures that allow one to compare performances of universities, thus fueling competition.

Where the public good paradigm positions NSSE as an assessment tool for internal improvement, the neoliberal model frames it as a tool for generating data that hold an institution accountable to external constituencies. It is in this context that the instrument has been endorsed by influential third-party think tanks that produce recommendations for reforming education policy and private funding agencies that provide financial support for initiating these reforms. Further, NSSE's promotion by USA Today and the use of NSSE's aggregated data as a source of information about the college experience by other media outlets such as the Washington Post and US News and World Report demonstrates its use for market purposes.

Part of NSSE's appeal as an accountability tool is due in large part to the layered system of quantitative comparisons generated annually, creating subtle competition among institution types. For example, the overall NSSE results are organized by Carnegie Classification groups and include percentile distributions for each item on the survey's five "Benchmarks of Effective Educational Practice." NSSE also subtly encourages competition by publishing the aggregated results for schools in the top ten percent of all the U.S. schools surveyed. NSSE's 2010 annual report, Major Differences: Examining Student Engagement by Field of Study, for example, notes that these "institutions set a high bar for schools aspiring to be among the top performers on a particular benchmark" (31). 
Indeed, some states have incorporated NSSE into their systems of accountability. For example, Kentucky produces a report that compares their four-year public institutions with each other and with national averages on each of the benchmarks (Kentucky Council on Postsecondary Education). Some individual institutions are also choosing to publish their results - usually on their institution's website - to highlight their strengths for prospective students. Today, the most accessible use of NSSE results is the USA Today website (USA Today). For colleges and universities who have agreed to have their benchmark scores published, students can simple click by school name, region, or institution type and the benchmark scores are provided and compared with the average scores of other institutions of the same type.

Within the neoliberal framework, then, NSSE can be seen as an accountability tool that generates volumes of data about students' experiences and their evaluations of institutional practices. All of this information can be used to satisfy market demands from various constituencies for evidence of institutional quality. Although the data generated about individual schools are not publicly accessible unless those schools agree to release it, those who fail to do so are increasingly suspect. Once data are created, it is difficult to keep private, especially if these data are seen to be a measure of quality.

\section{A Point of Struggle: Accountability v. Autonomy}

The conflict between the values and priorities underlying the public good paradigm and those underlying the neoliberal ideal provides a framework for analyzing power relations playing out in the higher education. Policymakers responding to a public that sees a college degree as more essential to success than ever before but less and less 
affordable as tuition costs continue to climb, have found the neoliberal ideal attractive. To illustrate, the State Higher Education Executive Officers (SHEEO) issued a report in 2005, titled Accountability for Better Results: A National Imperative for Higher Education, which acknowledged the decentralized system of higher education in the United States and offered strategies for key constituencies — state and federal government, institutional trustees, accrediting associations, faculty and students - to assist in building a better accountability system (State Higher Education Executive Officers). In addition, according to a report from Public Agenda and The National Center for Public Policy and Higher Education entitled Squeeze Play 2009: The Public's View on College Costs Today, "significant numbers of Americans have questions about whether these cost increases are justified and whether colleges are operating in the most cost effective manner" (Immerwahr and Johnson 4). Such queries, along with recent evidence that the U.S. system of higher education had fallen behind other countries, resulted in the Bush administration convening the Spellings Commission in 2006.

The Spellings Commission catapulted the conversation about accountability to center stage with the release of their final report titled A Test of Leadership: Charting the Future of US Higher Education, commonly known as the Spellings Report. It called for reform in six overarching areas: access, learning, cost and affordability, financial aid, transparency and accountability, and innovation. Neoliberal values are evident through the report's focus on comparative value, increased competition, and the privileged role of the consumer. For example, the report called upon higher education to make "all postsecondary learning measures, e.g., test scores, certification and licensure attainment, 
time to degree, graduation rates, and other relevant measures, publicly available in a consumer-friendly form as a condition of accreditation" (Spellings 23). Ultimately, the report included recommendations that emphasized the importance of developing workplace skills for a globally competitive economy and the need for efficiency in the delivery of education in order to reduce costs.

The composition of the group that produced this report reflects the influential forces operating in higher education's networks. It included nineteen high-profile people, with the majority being university presidents, past presidents, or chief executives of higher education institutions/systems focused more on the business of the Universityleveraging resources, fundraising, building relationships with academic, business, and political constituencies - than on classroom learning and assessment activities. In addition, four people represented large, international corporations, three were from public policy think tanks, and two were from foundations. David Ward, the President of the American Council on Education (ACE), the largest and most powerful lobbying organization representing professional organizations in higher education, was also a part of the group. Only one participant was a faculty member who appeared to have no administrative responsibilities. The Commission's Chairman was Charles Miller, the architect of "No Child Left Behind."

Tension between demands for market-based accountability on standard measures and the desire to preserve individual institutional autonomy was reflected in David Ward's refusal to sign the report — an action fully supported by ACE's board and the 
other Big Six ${ }^{4}$ higher education professional associations in the United States. In a press release, Ward stated that "the recommendations as a whole also fail to recognize the diversity of missions within higher education and the need to be cautious about policies and standards based on a one-size fits all approach" (Goral). Other professional organizations also weighed in with critiques of their own. For example, AAC\&U "expressed regret that the Report 'focused almost exclusively on workforce preparation, narrowly defined"' (Ruben, Lewis and Sandmeyer 61). The American Association of University Professors (AAUP) responded to what they saw as "attacks on faculty and their work," pointing out that the faculty appeared only once in the entire report (Ruben, Lewis and Sandmeyer 61). Finally, several others including the American Association of Community Colleges (AACC), the National Education Association (NEA), and the American Federation of Teachers (AFT), all expressed dissatisfaction that the report did not address the decline in state funding (Ruben, Lewis and Sandmeyer 61). Despite these objections, it was clear that if higher education failed to develop strategies for becoming more transparent to consumers and providing evidence of educational quality, the government would begin to legislate practices (Lederman, "More Meaningful Accreditation").

One response to this escalating demand for accountability by both the Department of Education and several higher education associations that are part of the Big Six has been the creation of various databases of information about colleges and universities,

\footnotetext{
${ }^{4}$ The Big Six are powerful lobbying organizations that represent the different types of colleges and universities. They include the American Council of Education (ACE), Association of Public and Landgrant Universities (APLU), American Association of State Colleges and Universities (AASCU), Association of American Universities (AAU), National Association of Independent Colleges and Universities (NAICU), and American Association of Community Colleges (AACC).
} 
framing institutions as a statistically defined population that can be governed through performance based on the metrics in the database. Although these databases include much of the same statistical information, they present the data in a way that that reflects different priorities. For example, the National Center for Education Statistics (a branch of the Department of Education) established the College Navigator, which enables students to conduct customizable web searches that enable side-by-side comparisons of up to four institutions at a time, allowing them to examine data about tuition, admissions standards, and college completion rates. This structure characterizes schools strictly in numeric and comparative terms and is seen as efficient and convenient for external constituencies. The two initiatives promoted by several professional organizations provide similar statistical information as the College Navigator, but they also offer more in-depth information and give institutions a greater role in shaping the information that appears. Initially, neither of these websites enables side-by-side school comparisons, reflecting a rejection of the notion that choosing a college should be based only on quantifiable metrics. To illustrate, the National Association of Independent Colleges and Universities (NAICU) has developed the University and College Accountability Network (U-CAN), a database of private institution profiles which is searchable by institution name, state, and affiliation/mission. It also highlights statistical information that colleges and universities already track, such as enrollment, graduation rates, tuition costs, percent of students receiving financial aid, and links to various college or university pages for more information about campus life, career services, and the like. 
The Voluntary System of Accountability (VSA) developed by the Association of Public Land-Grant Universities (APLU) and the American Association of State Colleges and Universities (AASCU) also reflects resistance to competitive comparisons. ${ }^{5}$ These organizations provide what they believe are richer data about institutions so that prospective students and their parents can make informed decisions about college selection through a common web reporting template, The College Portrait. The data are organized into three categories: consumer information, student experiences and perceptions, and student learning outcomes. The consumer information is routine, similar to what is provided on the U-CAN site. However, in order for institutions to provide information for the sections on student experiences and perceptions, and student learning outcomes, they must choose to administer one of several different standardized surveysof which NSSE is the most popular choice - and standardized knowledge tests such as the Collegiate Assessment of Academic Proficiency (CAAP).

There is a controversy within several higher education networks over the wisdom of embedding standardized instruments into the VSA (Lederman, "Assessing the Assessments"). The concern is that as schools are pressured to participate in the VSA, the information they have gathered for internal assessment purposes_-like NSSE and CAAP results - will become public and used as measures for accountability. Joan Hawthorne, in an article titled “Accountability and Comparability: What's Wrong with the VSA Approach?," argues that using standardized tests for the purposes of comparability undermines truly effective assessment efforts and instead "focuses national attention on

\footnotetext{
${ }^{5}$ However, the newest revision (2012) of the VSA includes a comparison feature.
} 
assessment as a measure of institutional value rather than as to tool for improvement" (29).

The collection of data that allow for the monitoring of colleges and universities by external constituencies also forces institutions to alter their practices simply to conform to the multifaceted demands for accountability. In addition, the data are presented as being objective and technically neutral, focusing on market-defined measures of quality and efficiency, but the overall drive for efficiency and accountability is, in fact, tied to particular interests. Furthermore, there are intangible costs associated with replacing the messy but valuable debates about goals and pedagogy with a set of data without any internal discussions. Indeed, the data have a regulating effect that reduces faculty involvement in decision-making results in a loss of autonomy and an alienation of faculty (Ball 154).

\section{Shaping the Milieu of Accountability}

The debate over whether the data generated by assessment tools such as NSSE for the purpose of improving an institution's educational practices should also be made available to external constituencies seeking to compare institutions is one reflection of the larger effort to make colleges and universities more responsive to market forces and less autonomous in their ability to define what is meant by a quality education. The influences shaping the milieu of accountability are subtle, but the network in operation has the power to (re)shape both administrative and academic spaces. In the process, aspects of higher education that might not be valued by the market or by those who frame higher 
education as a private good are, in the long term, threatened. In this section, I examine three occurrences that illustrate this erosion and reveal the larger forces at work.

First, it is important to note the role of advocacy think tanks, a group of organizations that have become decidedly influential in the networks operating in higher education. In a typology of think tanks offered by Eric Haas, advocacy-based think tanks are those that seek to influence policymaking in ways consistent with their objectives. One area where they have exerted significant influence is over issues of quality in higher education. Their reports and policy briefs have recommended a variety of new measures that ultimately bypass the role of accreditation, which is the traditional mechanism for holding institutions of higher education accountable. In the current milieu, accreditation — a system built on the premise of peer review, academic freedom, and institutional autonomy - is under assault for failing to provide rigorous public evidence of an institution's quality. While there is no doubt that the accreditation process has problems, these reports suggest a lack of trust in the academy's ability to evaluate and judge its peers and a desire to empower the market for the purpose of governing accreditation purpose (Trow 114). Think tanks are advocating for accountability standards — including the use of NSSE — that would replace the existing system of accreditation. Their recommendations and reports have had a significant influence on policy makers seeking a simple fix to complex problems.

Second, I consider the expanding construct of student engagement. In the language of NSSE, student engagement refers not only to the academic involvement of students but also includes the ways in which institutions support and serve students, 
providing them with a more engaging educational experience. Although NSSE positions its survey as helping colleges and universities evaluate whether student learning is occurring, in practice, the survey is used as a measure of how well a university is engaging students academically and otherwise. In a milieu of accountability focused on students as consumers, the notion of engagement becomes another metric of accountability. As a result, student engagement becomes a consumer value capable of, over time, shaping the practices of administrators and faculty by subtly pressuring them to deliver more engaging student experiences.

Third, and finally, I discuss the concept of the academic capitalist/knowledge regime, which scholars Shelia Slaughter and Gary Rhoades describe as replacing the public good paradigm. According to Slaughter and Rhoades, neoliberal ideals are permeating the entire academy and are not limited to the debates about assessment and accountability. With reduced funding and higher costs, as well as increased competition for students, colleges and universities have been forced to look for other revenue sources, which has resulted in an expansion of their commercial practices. In Universities in the Marketplace: The Commercialization of Higher Education, Derek Bok claims that part of the explanation for these practices includes "the growing influence of the market throughout society. Commercialization has plainly taken root, not only in higher education, but also in many areas of American life and culture: health care, museums, public schools, even religion" (5). Today, one of the practices that these social institutions engage in is branding, which is an effort to distinguish themselves from others competing for the same resources. Although colleges and universities have always 
marketed themselves, branding is a strategy that developed as a corporate practice and, in adopting branding, schools are adopting other corporate values as well. As a result, as Stanley Fish explains, even though institutions like colleges, universities, and professional associations in higher education don't consider themselves neoliberal they "will nevertheless engage in practices that mime and extend neoliberal principles." Indeed, NSSE facilitates this for colleges and universities by providing data that can be used to inform and shape the brand, reinforcing the overall student experience.

Evident in these forces - think tanks, the expanding construct of student engagement, and the academic capitalist/knowledge regime - is the pressure to make college and universities more responsive to markets. What is made visible here is the way in which these forces circulate and shape the milieu of accountability that governs higher education.

\section{Emergence of Think Tanks Influences}

As the academy wrestles with issues of accountability and transparency, advocacy think tanks have stepped into the fray and have begun to prescribe new measuring practices for demonstrating institutional quality that bypasses the traditional accreditation process. According to Eric Haas, author of "False Equivalency: Think Tank References on Education in the News Media," in the last half of the twentieth century the number of think tanks has exploded and now, "at the beginning of the $21^{\text {st }}$ century, openly political conservative think tanks dominate. They greatly outnumber and outspend both liberal advocacy-focused think tanks and nonpartisan research-focused think tanks" (69). Furthermore, under the Bush administration, their involvement was encouraged by the 
Department of Education (Spellings 27). This is consistent with the Nikolas Rose's description of the neoliberal agenda in operation as he explains in an article titled "Government, Authority and Expertise in Advanced Liberalism." According to Rose, this agenda is "to detach the substantive authority of expertise from the apparatuses of political rule, relocating experts within a market governed by the rationalities of competition, accountability, and consumer demand" (285).

Many advocacy think tanks present themselves as scholarly organizations, yet the research they conduct is not subject to peer review. In addition, although they are referred to as "think tanks," implying something equating to an academic research unit, some employ only a few or no PhDs who are trained to do complex research, including three of the more familiar neo-liberal, conservative advocacy groups: the Heritage Foundation, Cato Institute, and Family Research Council (Haas 69). Haas documents that on their education staff the Heritage Foundation employs 2 of 7 with PhDs, Cato Institute employs 2 of 8 with PhDs, and Family Research Council has no PhDs on their staff (72). While many of these groups represent themselves as research organizations, they are more focused on creating well-produced publications that are ideologically driven and support a particular partisan view. Kevin Welnar and Alex Molar describe it this way in a commentary written for Education Week in 2007:

Most think tank publications are not original research. A large number are what might best be called "policy briefs." Quality policy briefs, however, generally include a comprehensive consideration of previously published 
research and synthesize what is known in order to draw out policy implications. Accordingly, the usefulness of such briefs to guide sound policy is strongly related to the adequacy of their reviews of literature. Sadly, the influential think tank reports we've been reading rarely provide either a comprehensive review of the literature or a defensible interpretation of the findings of whatever scant research is cited. They tend to opt instead for highly selective reviews of the literature and a necessarily skewed reading of the insights offered by that research.

An obvious goal of these organizations is to disseminate their information in an effort to inform and influence policymakers as well as the general public. According to James G. McGann, director of the Think Tanks and Civil Societies Program at the Foreign Policy Research Institute, think tanks have expanded their marketing efforts in the last twenty years and often employ public relations professionals to disseminate their work. McGann offers the example of the Heritage Foundation whose mission is " to formulate and promote conservative public policies based on the principles of free enterprise, limited government, individual freedom, traditional American values, and a strong national defense" (Heritage Foundation). He notes that the President, Ed Feulner, has an MBA in marketing and that the former director of research was a journalist. A wide range of strategies is used for distributing information from conducting seminars 
and producing publications to courting the media and nurturing governmental relations (16).

Such rigorous PR efforts are bound to yield results, especially in today's 24/7 news cycle. In her investigation of who is producing educational research mentioned in the media, Holly Yettick found that in Education Week, the New York Times, and the Washington Post "any given advocacy-oriented think tank study had a substantially higher probability of being mentioned than any given academic study." In addition, think tank analysts are often presented as expert commentators on television news such as PBS and CNN as well as other news channels (McGann 17). Given that the media present these analysts as authorities, it is no surprise that these results are often accepted at face value and influence educational policy, despite the research rigor of the information being propagated.

Focused on issues of market accountability and demands for greater transparency in higher education, two think tanks - the Education Sector, described by Yettick as a "neoliberal organization," and the conservative American Enterprise Institute (AEI)— teamed up and issued a report titled False Fronts? Behind Higher Education's Voluntary Accountability Systems that was highly critical of U-CAN and VSA. The authors of the report, Andrew P. Kelly and Chad Aldeman, describe these systems as lacking transparency and any easy way to make comparisons:

For these efforts and others like them to improve consumer choice and exert meaningful pressure on schools to improve, they need to be more complete, comparison- 
friendly, and designed to highlight institutional differences. If existing flaws are not resolved, the nation runs the risk of ending up in the worst of all worlds: the appearance of higher education accountability without the reality. As such, policymakers and consumers should not be persuaded that the systems satisfy the need for increasing transparency and accountability in higher education until their flaws are addressed (2).

In addition, since NSSE is embedded in VSA as a tool to reveal information about students' experiences, the report criticizes the way in which VSA presents NSSE results. For example, the VSA report only includes the data summarizing responses from seniors and does not include freshman results. The critics argue that this presentation represents a selection bias, as seniors, since they are still enrolled, are likely to be most engaged (6). In the end, the report argues that "for parents hoping to use VSA's student engagement scores for comparing schools, only a small subset of measures provides informative signals about quality and performance" (9). This critique calls for increasing measures of comparison, and pushes policymakers to move in the direction of applying neoliberal ideals and incorporating them into daily practices without any recognition that the interpretation of such numbers might require additional context.

AEI has more resources than most academics to actively disseminate their work. To illustrate, they pushed the "False Fronts?" report to policy makers and the media and listed it on the AEI website as "Papers and Studies in Congress." And, based on this 
report, U.S. News and World Report posted an online article titled "Higher Education Falls Short in Efforts to Become More Accountable," reiterating the flaws of U-CAN and VSA identified in the report (Morse). Since the document advocates providing consumers with the information they need to make an informed decision, the U.S. News posting used the report to reinforce the value of their comparative rankings project and to promote their online tool that enables school comparisons on a variety of indicators. The point, of course, is that AEI is influencing both policy makers and the public (through the media) by promoting market values. The goal is to increase public pressure and to advocate for legislation that supports market activity.

Think tanks, not all necessarily neo-liberal, are also pushing states to adopt their version of accountability by conducting an evaluation of state efforts. For example, biennially since 2000, the National Center for Public Policy and Higher Education think tank has issued Measuring Up: the National Report Card on Higher Education. The report, funded by the Lumina Foundation for Education and the Bill and Melinda Gates Foundation, evaluates, grades, and compares the performance of all fifty states on six criteria: preparation for college, participation, affordability, completion, benefits, and learning (4). Interestingly, for the last criterion, learning, all fifty states received an "incomplete" because no uniform benchmarks to compare performance are available. The report hints that NSSE may be able to fill this gap, but more pointedly focuses on the importance of assessing the "educational capital" of the population across states (23). Still, in the "Forward" of the 2008 report, James B. Hunt Jr., Chairman of the organization's Board of Directors and a member of the Spellings Commission, explains 
the rationale for this evaluation: "The purpose of providing grades, comparisons, and indicators is to encourage each state to measure its own higher education outcomes against the best performance nationally and internationally" (4). Further, while he acknowledges the distinctive qualities of each state, he believes that all states can benefit from the report by monitoring their performance against each other and evaluating changes over time (4).

This report has been influential, as it was specifically mentioned in the Spellings Report as an example of the kind of data that should be published in partnership with the Department of Education (21). In this case, the National Center for Public Policy and Higher Education has defined educational standards of quality for states based on a simple, reductive grading scale, failing to capture the nuances, challenges, and policy goals of each state and eliminating the opportunity for discussion about what measures should be used to assess a quality education. The notion that all states should have identical policy goals with regard to higher education and hence can be compared using the same metrics, without qualification, is inherent in the approach. This effort also reflects the process of normalization at work in governance. Over time, as states use this, or similar criteria, to evaluate their colleges and universities, institutions will devote resources to improving their performance on these metrics. Such actions forgo any consideration of a school's unique mission or purpose.

In fact, in 2008, the think tank Education Sector issued a report titled Ready to Assemble: A Model State Higher Education Accountability System, also funded by the Lumina Foundation for Education, that examines what accountability measures states 
have in place to evaluate their colleges and universities. The authors, Kevin Carey and Chad Aldeman, argue that it is the responsibility of the states to hold colleges and universities accountable because "states have most of the money and most of the power - about three-quarters of all undergraduates are educated at public two-and fouryear institutions" (1). As a result, they attempted to answer two questions for every state, Puerto Rico, and the District of Columbia: "1) What kinds of information does the state gather about its colleges and students? 2) How does the state use the information it gathers to make colleges and students more successful?" (1). Their investigation revealed that approaches to address accountability vary from performance funding and assessing levels of student learning to collecting data about graduation rates and employment results. They found that NSSE is the most prominently used instrument for assessing institutional practices and cited different ways that institutions are using their results, from reporting on each question to reporting only on the five benchmarks.

In the end, they include NSSE as part of their recommendations for a model state accountability system. $^{6}$

States should incorporate surveys such as the National Survey of Student Engagement (NSSE) and the Community College Survey of Student Engagement

(CCSSE) into all state accountability systems. These surveys are now widely used and accepted and are not costly. NSSE recently completed its 10th year, and

\footnotetext{
${ }^{6}$ This endorsement of NSSE was issued before the comments made in the False Fronts report mentioned previously.
} 
hundreds of colleges and universities are voluntarily reporting their results on their Web sites, as well as to newly established national accountability Web sites, and to USA Today (28; emphasis theirs).

In the report, Carey and Aldeman argue that in order to make all the data states collect meaningful, including NSSE results, it should be injected into three processes that already involve institutional decision-makers-governance and strategic planning, funding, and transparency and markets (21). This recommendation serves as the cornerstone for their model accountability system, which they believe could benefit all states and at the same time "provide strong, constructive incentives for institutional improvement" (27).

Ultimately, the Education Sector-based on this report and others-promotes a model system that ties funding to performance in eight areas: student outcomes, institutional practices, economic development, overall quality of information, state and system-wide information, governance and strategic planning, funding, and transparency and markets. In 2009, they issued another related report, Ready to Assemble: Grading State Higher Education Accountability Systems, that outlines a process for grading states on their accountability efforts based on these eight areas (Aldeman and Carey). These efforts and recommendations by the Education Sector are playing to the sovereignty of the states. The expectation, of course, is that colleges and universities that receive state funding will provide this kind of information to the states. The effort and resources 
required to gather these data at this level normalizes and shapes institutional practices based these measures.

Today, the notion that institutions should be held accountable to markets by generating data that allow for competitive comparisons are often taken for granted. One might expect that more liberal think tanks would approach issues of accountability from a slightly different perspective, perhaps strengthening traditional accreditation mechanisms or for protecting aspects of higher education not valued by markets. However, the Center for American Progress, described as "progressive" in the report Think Tanks and Policy Advice in the US, by James McGann, is also positioning students as consumers and defining accountability in neoliberal terms. In November 2009, the center issued a paper titled Putting the Customer First in College and called for the creation of an Office of Consumer Protection in Higher Education. It proposed that the new office should:

--Produce a College Customer Bill of Rights that enforces truth in advertising regarding: academic quality, student services and support and flexibility and convenience. --Ensure that mandated federal data gathering, assembly, analysis and presentation are conducted in ways that empowers students with usable customer information. --Be an ombudsman for students with state officials and regional accrediting agencies to integrate and publish "truth-in-education" customer data and direct student 
customers to the appropriate officials when they have grievances with their education provider (Soares 2).

In a recent article in the Chronicle of Higher Education titled "Under Obama, Accreditors Are Still in the Hot Seat," author Eric Kelderman points out while some expected the Department of Education under the Obama administration to back off from efforts to measure quality in higher education for the purpose of making comparisons, this has not been the case. Instead, accreditation as a system of quality control is facing increasing scrutiny. Some of the issues stem from flagrant misrepresentations by forprofit colleges and the fact that high-risk students are being given federal loans they are unable to re-pay. The traditional accreditation process, which has come to be linked to eligibility for federal dollars, is framed as the problem, further muddying the conversation about assessing educational quality (Kelderman). Many in higher education are now worried that calls for changes in accreditation will result in accreditors serving in a role "more akin to consumer protection" (Kelderman). Kelderman quotes Judy Eaton, president of the Council for Higher Education Accreditation (CHEA):

Over the past several years, accrediting organizations responded to the growing call accountability and transparency from the public and lawmakers. The groups have worked better to identify and judge student achievement and share more information about what they do and how well the institutions are performing. 
Clearly, these pressures have put those who advocate for the public good paradigm on the defensive. Several of the influential higher education associations have issued policy statements and action plans to emphasize that learning outcomes should be set by the academy and not by external constituencies. These groups are influenced by market pressures, which is evident in their acknowledgement of the need for transparency and for communicating evidence of student learning to the public in an easily accessible way_-both of which re-frame quality in terms of consumer expectations.

In summary, through a range of activities think tanks have had an impact at various levels from the federal government and higher education associations to states and colleges and universities. Their accountability efforts bypass the academy and have a governing influence that is structured to normalized institutional practices in an effort that supports market activities. This increased sensitivity to consumer demands is certainly one effect that neoliberal think tanks are hoping for.

\section{Expanding the Student Engagement Construct}

In making the claim that engagement is a proxy for learning, NSSE not only satisfied the demand for an instrument that could provide quantitative evidence of institutional quality, but it also tapped into the ambiguity of engagement and its position an unassailable virtue. However, in the existing milieu of accountability the expanding definition of engagement privileges what students as consumers value, which for many means the broader college experience. As a result, aspects of engagement attractive to those who embrace the public good paradigm — engagement in the critical analysis of 
problems and issues that prepares one to participate as a responsible citizen - are being subtly replaced.

The questions on NSSE reference many aspects of the broader college experience that has come to be a "de facto operational definition of student engagement" (S. Bowen 4). The survey does ask about academic rigor and classroom experience, but it also includes multiple questions about activities involving leadership opportunities, co-op placements, and study abroad programs as well as questions about the institution's ability to offer both social and academic support. From NSSE's perspective, the questions that go beyond classroom practices represent an inquiry into overall effective educational practices that contribute to student engagement.

The original thinking by NSSE creators was to rank institutions based on their levels of engagement, make the results public, and ultimately feed the market with what they saw as more credible criteria than current ranking systems. However, NSSE administrators backed off from ranking and publishing results when institutions balked at the proposition of the data being made public. It was clear that institutions would be reluctant to participate if the data generated by NSSE were used to facilitate competitive comparisons. Given that NSSE needed to have broad participation if the survey was to become self-sustaining, it adjusted its plan to accommodate this concern: only aggregated data would be made public unless an institution chose to release its data. In 2004, to further appeal to universities, NSSE produced accreditation toolkits that matched specific questions on NSSE to accreditation criteria (National Survey of Student Engagement, Tenth Anniversary Report). This move increased NSSE's appeal more than expected. 
Because NSSE was now seen as an instrument that provided evidence for the accreditation process and institutional improvement efforts, more colleges and universities subscribed.

From the beginning, NSSE administrators actively promoted the instrument to influential actors to secure their endorsement. The more influential the endorsement, the more support the instrument received. According to Alexander W. Astin, founding director of the Higher Education Research Institute at UCLA, NSSE administrators appealed directly to college and university presidents and used the influential names of their funding sources-Pew Charitable Trusts and the Carnegie Foundation for the Advancement of Teaching - to promote this project. In addition, Astin points out that the launch and expansion of NSSE coincided with the assessment and accountability movements, suggesting that NSSE benefited from these larger conversations (Astin email correspondence).

NSSE's creators also benefited from the fluid notion of engagement. For example, in 2006 the influential Carnegie Foundation for the Advancement of Teaching announced an elective classification system for colleges and universities based on their commitment to community engagement. For their purposes, engagement is defined as "the collaboration between institutions of higher education and their larger communities (local, regional/state, national, global) for the mutually beneficial exchange of knowledge and resources in a context of partnership and reciprocity" (Driscoll 39). In some sense, this project represents an effort to recognize institutions that actively demonstrate their commitment to a public component of higher education that may not be valued in the 
market. Over 300 schools have been recognized through this classification process, which does not rank schools but rather classifies them into three categories: curricular engagement, outreach and partnerships, or both of these categories. According to Amy Driscoll, a consulting scholar with the Carnegie Foundation and with the New England Resource Center for Higher Education (NERCHE), many of these schools use NSSE in order to develop an "understanding [of] student engagement in learning through community engagement" (Carnegie Foundation for the Advancement of Teaching). The emergence of the link between NSSE and this system of classification allows NSSE to benefit from the prestige associated with the overall Carnegie Classification System.

More broadly, the notion of student engagement has become so popular that some schools are re-structuring their organizations around the concept, focusing on ways to provide students not only with meaningful academic opportunities, but with an overall satisfying college experience. In 2009, Robert Morris University hired a Dean of Engaged Learning to administer the Student Engagement Transcript——a program that tracks and certifies student participation in faculty-sponsored extracurricular and cocurricular activities" (Lee). In "Making Student Engagement Official," the Inside Higher $E d$ article that announced this new position, NSSE Survey director Alexander McCormick commented that he had not heard of a position being dedicated specifically to engagement before, but was somewhat cautious:

"On the plus side, we're seeing student engagement be formally recognized and legitimated, incorporated into institutional structures like this," McCormick said. "But the 
potential downside is that the concept itself maybe gets

diluted as you have a lot of different institutions developing

their own local definition of what it means." For instance, some might define "engagement" in terms of academics, while others might define it in terms of non-classroomrelated activities (Lee).

More recently, Old Dominion University established a Division of Student Engagement and Enrollment Services with the goal of "establishing a new model for student success and student learning" (Old Dominion University). The departments in this division include enrollment, student life, student advising, and personal support services, which again reflect more concern for the student's overall college experience than specifically for classroom engagement and civic participation.

New tools are also emerging to assist colleges and universities to facilitate engagement by keeping students connected online through social media. Inigral, Inc. is in the business of marketing a Facebook application called Schools App to schools to help them manage what they call the "lifecycle engagement platform," in an effort to keep students connected from the time they are prospective students through becoming alumni and donors. This project has received funding from the Bill and Melinda Gates Foundation because of its goal to increase student retention. As Michael Stanton, cofounder and chief executive of Inigral, explains, attrition is "largely the result of [students] not feeling “engaged." Schools App is meant to help keep students enrolled by 
creating "student interconnectedness" from the very beginning of the experience with an institution" (Calderón).

In short, the structures and practices of higher education are changing in ways that reflect the expanding construct of student engagement. However, these changes are occurring in a milieu of accountability that is increasingly positioning higher education as an institution to be governed by market forces. Because student engagement is being framed as both a proxy for learning and as something that can be measured, it opens the door to measures of engagement being used for competitive comparisons by external constituencies. In addition, as colleges and universities compete to attract student by improving their performance on these measures, there is pressure to emphasize the broader aspects of engagement. With NSSE, the ultimate arbiters of the overall student experience are not educators, but the students who complete NSSE. To the extent that universities act on these evaluations to receive better results in the future, students are shaping the daily practices of faculty and administrators from a distance.

\section{The Academic Capitalist/Knowledge Regime}

The concept of academic capitalism introduced by Slaughter and Rhoades in Academic Capitalism and the New Economy: Markets, State, and Higher Education emphasizes the increasing role of markets as a governing force in numerous aspects of higher education. They claim that an academic capitalist/knowledge regime has emerged that treats both knowledge and education as a private good with commercial potential. Further, they argue the new economy and accompanying neoliberal reforms are changing 
the priorities of higher education and expanding the complexities of the systems and networks in operation.

The theory of academic capitalism is focused on networks — new circuits of knowledge, interstitial organizational emergence, networks that intermediate between public and private sector, extended managerial capacity — that link institutions as well as faculty, administrators, academic professionals, and students to the new economy. New investment, marketing and consumption behaviors on the part of members of the university community also link them to the new economy. Together these mechanisms and behaviors constitute an academic capitalist knowledge/learning regime (15).

Much of their work is dedicated to identifying the complex networks involved in commodifying research and new knowledge through copyrights and patents, fostering entrepreneurial activities that reward both the individual faculty member and the institution (5), reflecting the move to privatize knowledge creation.

The commercialization Slaughter and Rhoades identify can be seen in the marketing of NSSE. The pattern in the past would have been for the organization sponsoring the survey simply to send a letter of invitation to campuses that might be interested in participating. Instead, NSSE aggressively marketed the survey in much the same way as a product might be marketed by a business. Alexander Astin points out that 
with their generous startup funding from Pew they have obviously had the resources to develop an extensive marketing campaign, to hire a large staff, and to support extensive staff travel to professional meetings to publicize their work. From the beginning they were also very smart to market their products directly to college presidents, using the names of the Pew Trust and the Carnegie Foundation to help give them credibility (Astin email correspondence).

In addition, as interest in the concept of student engagement has spread and taken different forms, NSSE has developed surveys for additional markets, such as surveys for measuring the engagement of high school students, beginning college students, community college students, law school students, and faculty, among others. While NSSE is part of a non-profit organization, strategies used in marketing its products resemble those of a commercial enterprise.

Another manifestation of the market's larger governing influence is in the practice of branding. Slaughter and Rhoades see branding initiatives by colleges and universities as occurring at multiple levels. At one level, colleges and universities seek to sell products that bear the university's logo. This effort has students (and others) paying the institution for the dissemination of the schools visual identity as they use these various products. On another level, Slaughter and Rhoades argue that institutions are advertising 
education to prospective students who are trying to evaluate where to go to school "as a service and a lifestyle" (2).

Colleges and universities compete vigorously to market their institutions to high-ability students able to assume high debt loads. Student consumers choose (frequently private) colleges and universities that they calculate are likely to bring a return on educational investment.... Once students have enrolled, their status shifts from consumers to captive markets, and colleges and universities offer them goods bearing the institutions' trademarked symbols, images, and names at university profit centers such as unions and malls (2).

Similarly, in a recent article in The Chronicle of Higher Education, Thomas Benton makes the claim that "increasingly, students are buying an 'experience' instead of earning an education, and, in the competition to attract customers, that's what colleges are selling." NSSE also meshes well with efforts of universities to brand themselves. It does so by not only providing feedback from consumers - that is, the students - but also by legitimizing the branding of the overall student experience.

According to STAMATS, a marketing and communication firm specializing in assisting college and universities with their marketing messages, "a brand is a trustmark, a warranty, a promise" (Sevier). Naomi Klein, author of No Logo, describes brands as having migrated from selling a product to selling a message or an experience (24). 
Similarly, in Brands: Meaning and Value in Media Culture, Adam Arvidsson explains that

contemporary brand management presupposes that the value of brands does not primarily derive from the qualities of the products that wear their mark. It is something else. The brand resides at the 'social' and even the 'spiritual' level; it embraces the whole relationship between a product and its consumer. Building a brand empire is 'about staking out emotional turf in our consciousness.' 'A product is no more than an artifact around which customers have experiences — brands are the total sum of those experiences;' the key to its value resides in the 'emotional links' that it can create with its audience (81-82).

More specifically, Wally Olins explains that a brand does three things. First, it requires a company that is marketing a product that is almost indistinguishable from others to find ways to differentiate itself. Second, brands offer consistency and reassurance. Third, and perhaps most important, brands foster empathy and help the consumer to define who they are. According to Olins, brands that succeed in touching an emotional nerve linked to identity "inspire loyalty beyond reason" (63).

For colleges and universities, branding often means creating messaging that reflects the unique attributes of the college experience and highlights them more than the pursuit of knowledge. A brand can feature specific programs, services, or co-curricular 
activities and present them as being core to the university's identity. In addition, many schools have rich and lasting traditions and rituals that can be presented as a representation of the brand, conveying to students that they will be a part of this legacy if they choose to attend this institution. The real challenge for schools is to depict themselves and their brand in ways such that prospective students can visualize themselves as thriving at the institution - thus, making an emotional connection linked to a student's identity.

Another important role of the brand is its function in coordinating decisionmaking and communication across an institution. In colleges and universities, the brand helps convey to staff and faculty what the institution is trying to accomplish (Molotch 209). According to Stephen King, once the brand is decided, employees (in this case administrators and faculty) are expected to be "brand builders" and change their practices in order to deliver on the brand's promise (267). Theoretically, if an institution is able to build organizational consensus on its mission and brand, accurately communicate its brand to prospective students, and deliver a student experience based on that promise, it is likely to be able to attract and retain greater numbers of "engaged" students than those schools that fail to develop and communicate their brand. In general, engagement, by this logic, becomes one result of effective brand strategies and schools that participate in NSSE should see higher scores.

While branding may be an opportune way to represent an institution and capture the attention of prospective students, it often fails to reflect the complex activities and relationships that constitute a university. Because most colleges and universities function 
in a fairly decentralized way, many faculty are unaware that a brand exists, simply dismiss it as marketing, or openly resist it (Pulley). Lars Christensen and George Cheney argue that even when organizational participation occurs through telling the various corporate narratives, employees (faculty, in this case) don't feel the same level of commitment to the brand as the senior management (252).

Still, branding strategies have been embraced by many colleges and universities and proven successful in attracting students. Ultimately, branding practices by colleges and universities are the result of escalating competition and increasingly demanding consumers who are thinking "in terms of their educational experience and in terms of returns on investment in human capital" (Slaughter and Rhoades 12). Such practices now seem routine and often go unquestioned as market activities permeate through the academy.

In summary, the academic capitalist/knowledge regime points to a broad array of networks operating to link colleges and universities and their members to the new economy where neo-liberal values such as privatization, commercialization, and competition dominate. Branding supports the institution in the marketplace and is especially helpful in recruiting students. Furthermore, the expanding construct of student engagement associated with NSSE meshes well with the practice of branding and the marketing of an experience.

\section{Shifts in Power}

In the existing milieu of accountability, colleges and universities labor to make decisions regarding the operations of their institutions and to balance multiple demands 
that a complex network of constituencies—government, professional organizations, governing boards, media, student consumers, and alumni and donors-place on them. In sorting through these challenges, decision makers frequently look for quantitative evidence that appears objective to facilitate and justify specific decisions. While the data often appear neutral, embedded in it are various political assumptions and lines of thought that are the result of other layers of struggle. Whatever data are used, then, subtly advances a particular agenda, shaping priorities and, in turn, shaping everyday practices. In an interview with Jeremy Packer, cultural theorist Larry Grossberg describes the various forces in play this way:

The apparatus of education isn't formed by any one group's intentionality. So what we get out is the result of contradictions among the various fights within the economic sector, and then between the economic and other sectors, and the enactment of the battle between the conservative and liberal views of education, all of these things enter in, each with their own problems, problematic, solutions, etc. (45).

Ultimately though, everyday practices come to be governed from a distance by these larger forces. A point Foucault makes in discussing the management of prisons applies here: "power is not totally entrusted to someone who would exercise it alone, over others, in an absolute fashion; rather, this machine is one in which everyone is caught, those who exercise power as well as those who are subjected to it" 
(Power/Knowledge 156). Not only are management decisions caught in this "machine," so are assessment tools such as NSSE. These tools — and the metrics associated with them - are both a product of the machine, and have a role in constructing it, gradually generated shifting relations of power and altering practices.

Operating at a distance, those who embrace neoliberal assumptions have had several effects on practices throughout the academy. First, areas in which the academy has traditionally been autonomous, such as the classroom, are being eroded by pressures from policymakers to provide additional data for competitive comparisons, data that go beyond the accreditation process as evidence of institutional quality and facilitates processes of normalization. Advocacy think tanks that present themselves as being informed by research-based experts have succeeded in influencing both policy decisions and the public through reports that advocate strategies to make colleges and universities more responsive to the market. Their initiatives subtly establish new measures of quality for colleges and universities and add layers of monitoring and data collection that ultimately serve as a governing force for colleges and universities.

Second, the expanding definition of student engagement is re-defining educational practices to encompass the overall college experience. This broader notion is being incorporated into accountability tools (such as NSSE) that are being used to satisfy market demands. To the extent that colleges and universities respond to these increasing pressures for accountability, institutional practices - from classroom activities to the student services provided - will undoubtedly change, effectively giving the greater market power to shape the conduct of administrators and faculty from a distance. 
Furthermore, the expanding definition of student engagement shifts resources and gives more power to people who provide programs and services outside the classroom. Further, these out-of-class activities are often featured as a part of branding efforts to demonstrate a wider array of institutional attributes beyond the curriculum. Although academic programs are still central to universities, they now have to compete with more nonacademic initiatives for resources.

Finally, colleges and universities are turning to the practice of branding in order to compete. As competition for students and resources increase, investments are made in establishing a brand with the hope that it will make the institution more competitive in attracting students and additional resources. The goal of branding is to differentiate the institution and to deliver on the experience represented by the promise of the brand, a strategy that meshes well with the expanding construct of engagement. Andrew Wernick, in an article titled "Rebranding Harvard," makes the point that "every dimension of the institution has come to be pressed into the service of cultivating a public image in line with its management's chosen competitive strategy" (566). This is a significant organizational challenge, but delivering on the brand translates to increased revenue whether that means recruiting and retaining students, receiving contributions from satisfied alumni, or bringing research to the marketplace. However, it is important to emphasize that in a competitive market branding has a normalizing effect. As more institutions brand themselves in ways that external constituencies find attractive, the more colleges and universities look the same. 
These shifts in power in higher education, revealed through an examination of NSSE as a nodal point, reflect the neoliberal ideals circulating in the milieu of accountability. What has been made evident here are the layers of heterogeneous forces and tensions at work as competitive forces serve to normalize higher education in market terms. These efforts crowd out higher education's contributions to the public good that are not necessarily valued by the market. As examined in Chapter Four, the tools used to sort and normalize populations are not new. Furthermore, once created they have often been used for purposes other than their stated intent. Indeed, when one group creates a tool for their own purpose, it often gets used by other groups in ways consistent with the larger forces at work. 


\section{Chapter Four - Sorting Populations: Systems of Normalization in Higher Education}

All assessment tools, including the National Survey of Student Engagement (NSSE), have an implicit normalizing effect on the population being assessed, compared, and sorted. Evaluating educational quality is not, of course, a purely technical task; the metrics and methodologies one uses to make such assessments contain layer upon layer of choices and assumptions. Once established and used as a basis for making decisions about how to improve institutional practices or how to judge an institution's performance and compare it with others, such metrics and methodologies come to be an integral part of the governing apparatus. However, economic conditions, social changes, and technological innovations that alter power relations can result in the data generated by such assessment tools — and the associated layered systems of sorting, comparing, and normalizing—-having unforeseen effects.

For Foucault, normalization is a key characteristic of apparatuses of security that govern populations. In this case, the effects of normalization are acting on populations of colleges and universities and their members. Sauder and Espeland in their article "The Discipline of Rankings: Tight Coupling and Organizational Change" explain that normalization "functions paradoxically, by defining a class of subjects as the same and then using normative criteria to establish individual differences" (72). Foucault indicates that normalization produces

a whole range of degrees of normality indicating membership of a homogeneous social body but also playing 
a part in classification, hierarchization, and the distribution of rank. In a sense, the power of normalization imposes homogeneity; but it individualizes by making it possible to measure gaps, to determine levels, to fix specialties and to render the difference useful by fitting them one to another (Discipline and Punish 184)

Sauder and Espeland, in their work, examined the processes of normalization in its application to law school rankings and reiterated Foucault's focus on the processes of comparison, hierarchization, differentiation, homogenization, and exclusion (72).

Here, I contend that the knowledge generated through the sorting and normalization of populations is used for a variety of purposes, and how that knowledge comes to be used to regulate behavior reveals much about the power relations at work. For most of the twentieth century, professional organizations and associations within the academy controlled these sorting efforts, indirectly shaping the direction of higher education through the criteria they used. However, a combination of factors - from a dramatic increase in the number of people attending college, an influx of federal financial support to provide greater access to college, new technologies, and a subsequent shift in expectations - gradually complicated the terrain. Over time, the sorting tools and criteria developed by the academy came to be adopted by external constituencies for new purposes, including sorting colleges and universities in ways that were of interest to the market. NSSE, which emerged in response to this shift, is also being shaped by these emergent layered forces and relations. 
This chapter identifies some of the conditions that influenced the emergence of systems for sorting various populations — students, colleges and universities, and faculty - that were developed in higher education over the course of the twentieth century. The goal is to provide a foundation for more closely examining (in Chapter Five) how the discourse of student engagement surrounding NSSE morphs from an effort on the part of the academy to gain control of the conversation about collegiate quality to one in which the student experience is defined in market terms.

\section{Establishing Standards and Systems for Sorting Students}

Higher education, like all aspects of U.S. society in the late nineteenth and early twentieth century, experienced significant change as the nation shifted from being primarily rural to urban, from agricultural to industrial. The spread of railroads had transformed local markets dominated by craftspeople into national ones governed by large, vertically integrated corporations employing techniques of mass production. The desire of civic and business leaders to educate and train a new generation of workers for employment in an industrializing society prompted a shift in the university curriculum from one that emphasized theology to one that focused on science and rationality (Rudolph 40). Explicit evidence of this shift can be seen in the Morrill Federal Land Grant Act of 1862, which established land grant colleges by providing states with 30,000 acres of land for each senator and representative. The objective of the Act was to create universities that would address the needs of an industrializing economy:

to teach such branches of learning as are related to agriculture and the mechanic arts, in such manner as the 
legislatures of the States may respectively prescribe, in order to promote the liberal and practical education of the industrial classes in the several pursuits and professions in life (7 USC. Sec. 304).

Further, those benefiting from the changing economy pushed for an emphasis on research, an elevation of science over the humanities, and the professionalization of faculty. By the end of the nineteenth century, large corporations in the oil, railroad, and steel industries were not only employing large numbers of university graduates but were also financing research projects and new programs (Cohen and Kisker 115; Noble 168). In addition, personal philanthropy from industrial leaders like John D. Rockefeller and Leland Stanford resulted in the establishment of new comprehensive universities complete with professional and graduate schools. Another indication of the changes taking place was reflected in the increasing number of students attending college. In 1790, only 1,050 students were enrolled in institutions of higher education; by 1910 the number had risen to 354,000 (Cohen and Kisker 58; U.S. Census Bureau 876). In the process of these monumental changes, societal structures that had proved capable of governing in the past became inadequate and reformers seeking to establish a new order turned to the creation of "standards" as an organizing force.

The value of standards seemed obvious to the reformers who championed them: standards allowed one to make rational decisions by comparing similar phenomena to something known, thereby rendering the entire class of phenomena measurable. Initially, standard-setting efforts were driven by engineers and scientists seeking consistent ways 
for making basic measurements in science and technology, with the establishment of the U.S. National Bureau of Standards representing an important marker of the value placed on this effort. The technocratic-minded leaders at the Bureau of Standards soon attempted to expand their original charge from creating consistent "measures" for scientists and engineers to developing standard specifications for industrial products, arguing that "the modern view [is] that quality depends upon definite measureable properties" and that the organization should play a role in creating those standards (United States Dept. of Commerce and Labor 6). Although the practical messiness of making value-laden choices placed limits on what role the Bureau of Standards could play in setting commercial standards, the technocratic spirit of standardization informed a wide range of reform efforts, including those in higher education.

\section{Four Options for Sorting Students}

How to proceed in establishing new educational standards was debatable. For example, in 1901, in an attempt to establish a consistent set of admissions practices, the College Entrance Examination Board (CEEB) - the organization through which the SAT and other standardized tests would eventually be administered —advocated the use of standardized subject tests to generate data that colleges wanted to make admissions decisions. As this notion was considered, it became clear to educators that any criteria used to screen students had significant implications for the future of higher education in the United States. As Nicholas Lemann explains in The Big Test: The Secret History of the American Meritocracy, what emerged were "four distinct ideas about the future of 
education, each implicitly leading to a different kind of new social order... and competing with each other" (21).

One approach to education, reflected in what was known as the Pennsylvania Study, supported by the Carnegie Foundation for the Advancement of Teaching, took a disciplinary approach. In their view, American schools needed stricter, more uniform admissions standards based on achievement. Their research attempted to identify what students were learning in high school. According to Lemann:

The idea animating the Pennsylvania Study was to establish a body of material that all students in high school and college should be required to master, test them on it and ruthlessly weed out the student population on the basis of the test results. Then the United States could become a technocracy, led by a coterie of college graduates who would be highly skilled experts (23).

An opposing project (also funded by the Carnegie Foundation for the Advancement of Teaching), one that fostered educational innovation and little standardization, was known as the Eight-Year Study. This effort was built on the ideals of progressive education whose proponents "believed that schools should promote the individual blossoming of each student as a creative thinker and as active, skeptical citizen rather than treating young people as drones whose empty heads should be filled with prescribed material in a disciplined environment" (Lemann 21). Organized by the Progressive Education Association, this project encouraged a partnership between thirty 
high schools and 284 colleges where traditional college entrance requirements would be ignored thus freeing high schools to explore and experiment with more imaginative teaching strategies (Bullough 169; Rudolph 473-479). While the results of this study revealed greater college success for the students involved, the critique of the project, rested in its failure to answer a standardizing question: "what ought an educated man know" (Rudolph 474)?

A third view endorsed IQ testing — which saw significant use during World War I to choose officer candidates - as the key to effective screening. Those who supported this initiative saw the test as a way to sort and exclude American children, providing high scorers with the best education and average or low scorers with something less. Contrary to the standard-setters who "wanted to reward students who had demonstrated a mastery of a body of knowledge; the IQ testers wanted to reward pure inherent brainpower, as they believed it was revealed by IQ test scores" (Lemann 23). Their goal was to reserve higher education for the most intelligent, ensuring that smartest people would become leaders in society.

The fourth position argued against the use of standards for the purpose of excluding students and advocated for expanding the number of students going to college. This project called the Iowa Every-Pupil Testing Program and developed by a group of scholars at the University of Iowa, advocated administering achievement tests to public school children. Their purpose, unlike the standard setters, was to identify areas where students needed special attention and where efforts could be directed toward their improvement. According to Lemann, these test results were not to be used in order to 
select the best students, or to force schools to adhere to specific standards. "That would be excellent and beneficial for one particular type of boy or girl...namely, those of superior bookish ability... [but] those same standards, because of their uniformity and rigidity, are thwarting and damaging to all other kinds and degrees of capacity" (25).

At a time when American higher education was shifting from being primarily a local institution to a national one, the competition between these rival philosophies mattered. In Lemann's words:

So whoever won would score a highly consequential victory-would get to configure the basic form that life took for most Americans for the rest of the twentieth century.... It was like a slow motion, invisible Constitutional Convention whose result would determine the American social structure (26).

The choice of a screening tool for admission into college, in effect, would ultimately determine which philosophy took root and how power and wealth would ultimately be distributed in society.

\section{Scholastic Aptitude Test (SAT): A Mechanism to Differentiate and Compare}

A significant step in the direction of a standard screening tool occurred in the 1920s when some colleges and universities began using a version of the IQ test that the Army had developed during World War I, which evolved into the SAT. By 1933, the developers of the SAT had enough data to make the claim that the instrument could be used as a predictor for academic performance, providing those who embraced the 
ideology of meritocracy with a tool for sorting students. However, the use of this tool would also have implications for how students viewed colleges and universities.

The intentions of those who adopted the SAT appeared to be straightforward. Harvard, for example, had recently begun to award scholarships based solely on academic ability, not social standing or need (Conant 129) and decided that the applicants for this scholarship would be required to take the SAT as well as several achievement tests (Conant 130-134). Soon after, leaders in higher education began discussing the establishment of a national testing agency to administer all standardized educational tests. The creator of the SAT, Carl Brigham, argued against the establishment of a national agency, warning "that the very creation of powerful machinery to do more widely those things that are now being done badly will stifle research, discourage new developments, and establish existing methods, and even existing tests, as the correct ones" (Lemann 40). However, at the same time, a technological advance emerged — the Markograph machine — making use of standardized tests almost irresistible. This machine could electronically read pencil marks to determine if the answers entered on a separate form were correct. In 1936, when it went on the market it "could score tests 10 times faster than manual methods - and with greater accuracy" (IBM). This equipment made mass testing possible and paved the way for accumulating a large volume of data that could eventually be used to establish statistical information about the population of aspiring college students. Soon after, the Educational Testing Service (ETS) was established and testing became a governing force, cementing the practice as a requirement for college admissions and the distribution of financial aid going forward (Lemann 343). 
The ease with which data could be processed also opened the door for others to manipulate it for their purposes. In particular, SAT scores, originally embraced to help universities differentiate between students, eventually came to be used in college guidebooks and, as a result, helped students to compare and sort universities. One early college guide, The Gourman Report: Ratings of American College, made use of SAT scores in a somewhat roundabout way: Gourman calculated a score for each university and claimed that this number correlated with the SAT score of a student likely to flourish at that institution. To obtain a university's score, Gourman first gave a letter grade to the institution's administration, student services, general operations, and faculty. He then converted that grade to a numeric value $(D=200, C=400, B=600, A=800)$ and averaged those scores to produce a SAT-like number. Gourman encouraged students to select a college by identifying a school having a score that matched their SAT score (x). A student receiving a 500 on the SAT should, according to Gourman, attend a college with a score of 500. Not surprisingly, few people used this guide in the way that Gourman had hoped and later editions (including some published by Princeton Review and Random House in the 1990s) dropped that approach. (Selingo).

While Gourman's goal was to match students' abilities with institutions of a particular caliber, his effort reframed how such scores could be used. A college that admitted a cohort of students having an average SAT score of 600, for example, could be assumed to be more intellectually challenging than one admitting students with an average score of 500. As a result, the data originally generated to help colleges differentiate between students gradually came to be used by students to compare and 
evaluate a school's worth. For colleges and universities this has resulted in a governing force manifested in an increased effort to recruit students with high test scores.

In summary, the process of using standards to sort populations in higher education emerged at a time when reformers were attempting to standardize numerous aspects of society for the first time. However, over the long term, standards developed for one purpose came to be used for other purposes. In this case, tools to sort students for college admission based on preparation and merit eventually came to be used as measures of educational quality — both as a result of changes in power relations and as a force facilitating those changes.

\section{Sorting of Institutions}

While systems in higher education were being developed to sort prospective students based on their performance on standardized tests, other initiatives emerged that led to systems for sorting institutions. In each of the cases examined here, as in the case of the SAT, the initial effort ultimately led to the data being used for another purpose, having an unintended governing effect. For example, one project attempted to evaluate how well undergraduates were prepared to do graduate work, which led to an assessment of specific academic programs. Another project involved an effort to create a system of accreditation - a sorting of institutions based on their ability to meet particular standards - that became the basis for establishing a wide range of institutional practices. Yet another project led to the emergence of the Carnegie Classification, a system that was created originally for the research purposes of the Carnegie Foundation but was soon embraced by others for a variety of uses. 


\section{Systems of Classification}

Early in the century, leaders of the exclusive Association of American Universities (AAU) were looking for a way to identify what they considered talented students to do graduate work. The strategy they adopted was to conduct an assessment of undergraduate programs and to identify those institutions capable of producing students qualified to be admitted to an AAU graduate program. However, the leadership of the AAU was hesitant to undertake the effort as they did not want their approval to to be construed as an endorsement and they did not want the AAU to serve as an accrediting body for colleges and universities (Slate 36). Hence, in 1911, when the United States Bureau of Education proposed conducting a quality assessment of undergraduate education, the AAU supported the effort. Having one of the Bureau's researchers conduct the evaluation was seen as preferable, with leaders of the AAU believing someone associated with a federal agency would be more objective than anyone associated with a particular university (Webster 502).

To classify universities, the researcher selected for the job, Kendric Babcock, assessed institutions based on how well the alumni of those universities performed in prestigious graduate programs. In order to make this evaluation, he visited campuses with large graduate programs and met with and interviewed presidents, deans and graduate committees. He also examined admissions practices and reviewed the records of several thousand students who took courses within the last five years of the project. In the end, Babcock, classified 344 institutions based on a system of five levels of quality. For example, Class I included institutions "whose graduates would ordinarily be able to take 
the masters degrees at any of the larger graduate schools in one year after receiving the bachelor's degree..." (Webster 503). Fifty-nine colleges and universities were in this group. At the opposite end of the scheme, in Class Five, were forty schools he identified as being “approximately two years short of equivalency with the standard bachelor's degree of a standard college..." (Webster 503).

Not surprisingly, this report was not well received by institutions that were rated poorly. In fact, controversy kept the report from ever being officially published. Those who questioned the results focused their critique on the methodology employed. For example, the Chancellor of Syracuse University charged that Babcock had never even been on campus and that no one there had been aware that the classification project was being done. Others made similar claims. The Commissioner of Department of Education downed played the controversy, explaining that "it was 'unfortunate' that the designations 'Class I' and 'Class II,' and so on were used and that the word 'classification' appeared on the title page" (Webster 506). He also acknowledged that the results were incomplete and tentative, "adding that if the Bureau of Education received requests from the proper officials of any college that was displeased with its rating, the Bureau would work towards having the rating corrected" (Webster 506). However, outcries continued, resulting in "an Executive Order banning the distribution of Babcock's classification" (Webster 507).

Even though the Bureau's report was not endorsed, key decision makers saw the information contained in it as valuable. For example, European universities were pressing for some way to assess the preparedness of American students. Because of the elite status 
of the AAU, many European universities proposed simply using graduation from an AAU school as a pre-requisite for admission into their graduate schools. Leaders of the AAU, however, saw this as unwarranted since there were many excellent undergraduate programs in the United States that were not at AAU member schools. Therefore, although the AAU did not want to bear the "onus of a classification that would almost inevitably awaken opposition on the part of disqualified," the organization reluctantly developed a list of schools whose graduates could be considered sufficiently prepared for graduate study (Slate 37). The list, known as the "AAU Accepted List," was formed using both Babcock's classification system and information compiled by the Carnegie Foundation for the Advancement of Teaching, with the latter information having been gathered to determine which institution's faculty would be eligible for their pension plan. The AAU Accepted List ended up carrying significant weight as a quality indicator of undergraduate programs and was a topic of heated discussion at the AAU annual meetings the middle of the century (Slate 37).

While the AAU was evaluating how well academic programs were preparing undergraduates for graduate school, reformers in higher education were critiquing the general quality of undergraduate education. For example, in 1908, Abraham Flexner wrote a critique titled The American College: A Criticism in which he argued that the current system of higher education was deficient in three main ways: the standards used for admissions failed to measure what was important, the curriculum of many undergraduate colleges lacked coherence; and graduate education and research priorities had overtaken the importance of undergraduate teaching. 
To Flexner and other progressives of the time the main purpose of colleges and universities was to prepare undergraduate students for jobs in a complex economy, and he argued that graduate education and research priorities had overtaken the importance of undergraduate teaching. Indeed, he saw most universities as placing a priority on attracting large numbers of students rather than on offering a quality educational experience (Flexner, The American College 216). He believed that the practice of admitting as many students as possible stood in the way of a quality education:

On this point plain speech is necessary. Efficient teaching is utterly irreconcilable with numerical and commercial standards of success. The colleges now want numbers; they must have and keep them, more or less regardless of quality. So elaborate are their equipments and appointments, so costly the maintenance of the plant, that a temporary fluctuation in tuition fees is a serious matter. There arises thus a spirited competition for students (229230).

If the main focus was on teaching, Flexner argued, enrollments would have to be limited in order to ensure teacher student contact. Accordingly, he indicated that institutions should admit no more students than they could effectively teach, suggesting that this be one of the standards all universities should meet.

Flexner's evaluation of higher education led those who shared his vision to enlist him in reform efforts of their own. Indeed, the Carnegie Foundation asked him, in 1910, 
to conduct an evaluation of medical schools in the United States and Canada. This effort turned out to be one of the first to evaluate institutions of higher education on a set of established criteria that ultimately reduced these complex institutions to a set of statistics that could be used for comparisons. In executing the assessment, Flexner examined 150 medical schools, reporting on the number of students, entrance requirements, teaching staff and rank, resources available for maintenance, and lab facilities (Flexner, Medical Education 318). The Flexner Report, as it became known, had far reaching impact. Many of the substandard schools were closed or merged with others, while borderline schools were propped up with funding from the Rockefeller Foundation. Among other things, the report lent support to the notion that individual colleges and universities could be evaluated in terms of an established set of standards so as to ensure that a minimum standard of quality was being met (Flexner, Medical Education 185-337).

Meanwhile, those who sought to advance Flexner's vision and improve the performance of undergraduate education ran into difficulty. For example, one organization, the National Association of State Universities (NASU, now the Association of Public and Land-grant Universities, APLU), formed a standards committee that initially focused on developing meaningful admissions criteria but soon broadened its mission to classify institutions according to "the efficiency of their undergraduate courses" (G. P. Benton 44). However, after the release of the controversial Babcock report that had been commissioned by United States Bureau of Education, the members of NASU expressed concern about establishing a classification scheme and decided instead to simply lay out the "facts," leaving interpretation to others: 
The difficulty of finding criteria of judgment is obvious. Per capita cost of education, per capita endowment, success of graduates, average salaries paid, etc., are all significant but no one of them is necessarily conclusive....It would seem best, therefore, not to attempt a classification into groups, but to publish a list of institutions giving all the objective facts and allowing the public to draw its own conclusions (G. P. Benton 44-45)

Of course, what facts to include and what information to leave out had implications and could potentially give some institutions an advantage over others.

Another classification scheme, based on a different strategy to categorize colleges and universities, emerged much later (in 1970) when the Carnegie Foundation for the Advancement of Teaching sought to establish a classification system for the purpose of advancing its own quantitative educational research priorities. Perhaps because this system was created for the Foundation's own research efforts, their classification of institutions generated little controversy. Its impact, however, has had far-reaching consequences as decision-makers outside the Foundation have embraced the classification scheme for a wide range of other purposes, some at odds with the original intention of the system (McCormick and Zhao 52).

The organizing structure of the Carnegie Foundation's system was to classify institutions by type. Through its Commission on Higher Education, the Foundation gathered data collected by other organizations, such as the Department of Education's 
Integrated Postsecondary Education Data System (IPEDS), National Science Foundation, and The College Board, and considered information such as the "type and number of degrees awarded, federal research funding, curricular specialization, and (for undergraduate colleges only) admissions selectivity and the preparation of future $\mathrm{PhD}$ recipients" (McCormick and Zhao 52). The classification system, created by Clark Kerr, architect of California's 1960 Master Plan for Higher Education, then grouped schools "into meaningful, analytically manageable categories" in order compare and contrast institutions by type (McCormick and Zhao 52). The outcome was a system that organized institutions by type, level of degree, and specialization:

1. Doctoral-Granting Institutions

1.1 Heavy emphasis on research

1.2 Moderate emphasis on research

1.3 Moderate emphasis on doctoral programs

1.4 Limited emphasis on doctoral programs

2. Comprehensive Colleges

2.1 Comprehensive colleges I

2.2 Comprehensive colleges II

3. Liberal Arts Colleges

3.1 Liberal arts colleges-Selectivity I

3.2 Liberal arts colleges-Selectivity I

4. All Two-Year Colleges and Institutes

5. Professional Schools and Other Specialized Institutions 
5.1 Theological seminaries, bible colleges, and other institutes offering degrees in religion

5.2 Medical schools and medical centers

5.3 Other separate health professional schools

5.4 Schools of engineering and technology

5.5 Schools of business and management

5.6 Schools of art, music, and design, etc.

5.7 Schools of law

5.8 Teachers colleges

5.9 Other specialized institutions (Carnegie Commission on Higher Education, Dissent and Disruption 121-125)

The Carnegie report New Students and New Places: Policies for the Future Growth and Development of American Higher Education, the first to use the classification system, included a discussion about the future of higher education and indicated that there was "no need whatsoever in the foreseeable future for any more research-type universities granting the $\mathrm{PhD}$ " (5). The authors suggested "preserving and even increasing the diversity of institutions of higher education, by type and by program, resisting homogenization" (9). However, the system itself has had a homogenizing effect as institutions have sought to "move up" in the classifications and be included as a research university (McCormick and Zhao 52). Part of the drive to move up, of course, is that becoming a research university is what is rewarded both in terms of institutional prestige and financial support. 
Ultimately, this classification system emerged as another sorting mechanism shaping the practices of colleges and universities from a distance. It is now used by foundations, associations, news magazines, government agencies, and others for purposes ranging from grant funding to various ranking initiatives. NSSE, for example, uses this system to organize and classify its results. Furthermore, due to its wide use as a decisionmaking tool, the system carries authority, and institutions pay close attention to how they are classified. For example, in 1994, when the Carnegie Foundation re-classified approximately 400 institutions — which it does periodically to stay abreast of changesBerea College was shifted from a Comprehensive II to a Baccalaureate I institution, reflecting changes Berea had made to its practices. However, the change had an unintended consequence with Berea moving from a regional to a national category in "America's Best Colleges," the well-known ranking scheme produced by U.S. News and World Report. As a result, Berea plummeted in the rankings and went from being one of the best regional universities in the South, to the being unranked in the category of national liberal arts colleges.

Knowing it could not compete with the more selective national liberal arts colleges and still garner the good press it had receive from the rankings, Berea appealed. ...Carnegie agreed to reclassify Berea downward as a Baccalaureate II institution, based primarily on its mission of serving low-income students in Appalachia. U.S. News then put Berea back into its less competitive regional 
category. And in the September 1997 rankings, Berea once again emerged as a top liberal arts college in the South (Machung 12).

The expanded use of the Carnegie Classification system has had a strong governing influence over institutions, with schools and colleges making operational decisions based on their position or desired position in such schemes. As always, the placement of institutions within such a classification system matters because powerful actors such as funding agencies, faculty, prospective students, and potential employers cannot help but to be influenced by the results.

\section{Governing Practices Emerging through Accreditation}

Accreditation schemes to determine whether an institution met a minimum level of quality emerged and operated in parallel to these various classification systems that emerged to categorize colleges and universities. Six regional accrediting agencies ${ }^{7}$ were well established by 1923 and their criteria for accreditation eventually became a benchmark that structured governing practices at the institutional level. Various groups were also formed to accredit specific academic programs, such as the American Association of Teachers that accredited teacher education programs. Strictly speaking, these accreditation processes were voluntary, but as a marker of quality it was difficult to attract students without it. However, the standards to which universities were held were not particularly onerous. For example, the North Central Association required that faculty

\footnotetext{
${ }^{7}$ New England Association of School and Colleges (1885), Middle States Association of Colleges and Schools (1887), Southern Association of Colleges and Schools (1895), North Central Association of Colleges and Schools (1895), Northwestern Association of Schools and Colleges (1917), Western Association of Schools and Colleges (1923).
} 
have the equivalent of a master degree from a member institution, adequate laboratories and libraries, and be able to prepare graduates for advanced degrees (Brubacher and Rudy $358)$.

Over the course of the 1920s and 1930s, the use of accrediting systems as a way to sort institutions and programs into two categories - those meeting a minimum set of standards and those failing to do so-expanded. Furthermore, most accrediting organizations came to use same general process: specific criteria for evaluation were established, the institution or unit conducted a self-study, and an outside team visited to examine the evidence and determine if the prescribed standards were met (Cohen and Kisker 262). The importance of accreditation also increased over time, with some professional associations restricting membership to those who had degrees from an accredited program (Altbach, Berdahl and Gumport 264). In other situations, students had to be graduates of an accredited program in order to apply for occupational licensure (Cohen and Kisker 168).

Accreditation systems were not without opposition. In the 1930 s, some administrators argued that the standards were becoming too rigid and that some of the more quantitative assessments missed the valuable qualitative attributes of an institution (Brubacher and Rudy 358). Coupled with this charge was that accreditation discouraged experimentation and limited creativity. By the middle of the century, the regional bodies responded by revising their criteria to capture how well institutions were achieving their missions, providing some room for institutions to exercise autonomy in defining their purpose (Finkin 91). Nonetheless, presidents at numerous schools continued to feel that 
accrediting efforts were costly, inefficient, and a duplication of effort, forcing institutional decisions to be made a particular way in order to satisfy overly rigid requirements (Brubacher and Rudy 360).

One response to these concerns was to construct another lay of control—one that operated on the accrediting organizations. In particular, shortly after World War II, a group of presidents established the National Commission on Accrediting (NCA). The goal of this organization was to sanction accrediting agencies and to limit the number of specialized agencies by accepting only one agency for any discipline (Brubacher and Rudy 360). Almost simultaneously, the regional accrediting agencies established the Federation of Regional Accrediting Commissions (FRACHE) to coordinate their business practices. These two organizations eventually merged in 1975 but the resulting organization, mired in conflict over priorities, disbanded in 1993. By that time, however, accrediting practices had come to be systematically embedded in the criteria for assessing a wide range of institutional operations and required for schools before their students could receive financial aid from the federal government. Soon after, therefore, a new association, the Council for Higher Education Accreditation (CHEA) emerged as the sole organization dedicated to governing the process of accreditation, with its major function being to ensure academic quality and improvement. Today, CHEA works with the U.S. Department of Education, which recognizes and gives authority to accrediting agencies and specifies the standards on which to base accreditation (Finkin 106).

The system of accreditation currently in place, therefore, now functions as a powerful governing force embedded in several layers of organizational and bureaucratic 
actions that are largely invisible to most observers. Through the interpretation and implementation of these standards, these bodies wield significant yet subtle power over a host of institutional practices such as eligibility for financial aid, curricula design, admissions practices, faculty credentials, and the design of facilities. Furthermore, as accreditation has become a requirement for universities to receive governmental aid, these "voluntary" systems of accreditation are something much less than voluntary. To the extent that universities manage their practices to satisfy their accreditation requirements, accreditation then plays a role in shaping decisions affecting those practices.

\section{Sorting Faculty and Graduate Programs}

As with accreditation processes, the sorting of students and undergraduate programs, the sorting of faculty, and in turn, the evaluation of graduate programs evolved over time from within the academy. In addition, these efforts, like the others, also came to serve a variety of purposes - from, in this case, hiring new faculty to funding allocations - reflecting and facilitating shifts in power relations.

\section{Mobilizing Ranking Systems within the Academy}

In 1924, to simplify and rationalize the process of hiring new faculty, the President of Miami University (Ohio), Raymond Hughes, sought to identify graduate schools with outstanding programs in specific disciplines. All things being equal, $\mathrm{PhDs}$ produced by these programs would be given preference in the university's hiring decisions. To conduct this assessment, he requested the faculty at Miami to provide the names of twenty to sixty well-known scholars in their respective disciplines. These 
scholars were then sent a survey and asked evaluate the graduate programs in their discipline at thirty-six schools. In the end, the survey was sent to forty evaluators in each discipline (Hughes 4).

This effort to assess graduate programs based on reputation established a precedent. The evaluators assigned a numerical rank based on "informed opinion," setting up a structure for comparisons and competition. For example, the evaluators were asked to rank the institutions "as they stand in your esteem at the present time for graduate work in your subject. If several rank equally well, give them the same number" (Hughes 5). Finally, Hughes focused only on the nation's leading institutions, ultimately privileging some programs and institutions over others (Lawrence and Green 10). The final report included "(1) the names of the professors in the discipline who returned the ratings; (2) the tabulation of the combined ratings returned; (3) the staffs of the graduate schools listed" (Hughes 6).

If this tabulation of graduate programs for the purpose of screening faculty hires had remained within the confines of Miami University, reaction to it would have been minimal. However, Hughes explicitly saw the system as a way to prescribe behavior and influence the practices of graduate schools and desired to see the results disseminated. He also believed that the results of his study would prove useful to other institutions as well as to those planning to do graduate work, and suggested such an effort be replicated every three years by a professional association.

The critics of this effort, though, saw the study as politically naive and methodologically flawed, with the potential of doing more harm than good, and 
suggested that if students wanted information about graduate school, they should ask a professor knowledgeable in the subject. In response, Hughes argued that the study may not be "exactly correct or of very great significance," but that it did offer the opinions of twenty to forty professors and "their combined opinions should have more weight than the opinion of any one single professor" (6). Critics, though, believed the evaluation overall was too broad. Instead of evaluating only graduate programs in chemistry, for example, critics suggested that it would have been more helpful to differentiate between sub-disciplines like organic chemistry, physical chemistry, etc. Hughes's reply was that "it proved impossible in this study to make any such differentiation, but in a more comprehensive study certainly this should be made" (6). To those who suggested that rater bias may have influenced the results, Hughes indicated that while there was some evidence to support this assertion, it was not significant enough to impact the results.

Despite the weaknesses in this study, it served as a decision-making tool where none previously existed. On one level, those who did not trust the data on which the study was based, did not have to use its results. On another level, though, the use of the data could not be controlled, and those who found the results useful wanted more data and studies like this to be updated and expanded. Indeed, ten years later, the America Council on Education (ACE), a prominent organization that played a significant role in shaping higher education policy, funded Hughes to examine even more doctoral-level universities. Two decades after that, Hayward Keniston at the University of Pennsylvania executed a similar reputational project, comparing both doctoral program quality and faculty production at Penn to that of other leading institutions. In this case, the evaluators, 
department chairmen from schools who were members of the AAU, were asked to identify the top five departments in their field. Keniston also compared his aggregated data and rankings to Hughes results, highlighting the changes that had taken place over time (Lawrence and Green 5).

Relying on the judgment of scholars recognized as leaders in their discipline, these reputational studies transformed institutions and programs into describable objects based on the rank they were assigned. Although the approach pioneered by Hughes and adapted by Keniston involved the academy assessing itself, there was no way to limit the use of these data. External constituencies found these reputational rankings useful. The National Science Foundation (NSF), for example, began to use them to make funding decisions.

Initially, officials at the NSF considered commissioning a private research firm to rank departments, which would have moved control of the ranking outside the academy. ACE saw that option as untenable as Allen Cartter, an ACE vice president, explained in an interview with researcher and author Patrick Dolan:

Logan Wilson and I hit the ceiling and alerted him (Mr.

Bolt, Director of NSF) to the fact that there had been a long-standing position of the Association of Graduate Deans that nobody ought play around with evaluating the graduate programs who was not themselves responsible to the institutions themselves; either the AAU or some other group. The deans always said that anyone who is going to 
accredit us or rate us has to be responsible to the institutions. We don't want any outside body doing this. At that point I think we convinced Mr. Bolt that if it were going to be done, it ought to be done by a group like the Council of Graduate Schools or the American Council on Education or some other group (26).

Cartter then approached the NSF with a proposal and a budget of $\$ 105,000$ to undertake a project to assess "all major disciplines, including social sciences and humanities" (Dolan 27). In expanding the scope of the project, Cartter also solicited support from other governmental agencies, including the National Institute of Health (NIH) and the Office of Education. In the end, the NSF agreed to provide $\$ 75,000, \mathrm{NIH}$ provided $\$ 15,000$, and the Office of Education, $\$ 25,000$ - just enough to demonstrate support for the project but not enough to reflect a federal endorsement of the results (Dolan 27). The project eventually conducted by Cartter, An Assessment of Quality in Graduate Education, ending up having three goals: (1) to bring earlier studies up to date, (2) to expand the reputational studies "to include all major universities in United States" and, (3) to understand as much about the problems associated with this type of project in order to make improvements going forward (3).

Although ACE desired to retain control of the study, the goals of the leading funder, the NSF, carried significant influence. To illustrate, NSF pushed to have the results of the study be a numerical ranking reflecting the quality of graduate departments at universities affiliated with ACE. Around Washington, groups such as the Council of 
Graduate Schools were reluctant to accept this format, but they eventually capitulated and ACE provided the results as a numerical ranking (Dolan 27).

This study was more representative than previous reputational studies. The survey was sent to the 100 institutions that were members for the Council of Graduate Schools in 1961 as well as an additional six schools that had awarded "100 or more doctorates (spread over three or more fields) in the preceding decade" (Cartter 12). In total, 1,663 programs in 29 disciplines were rated, with broader representation among the raters than in either of the Hughes and Keniston studies. Cartter argued that his network of raters, which included "department chairmen, distinguished senior scholars, and knowledgeable junior scholars who had completed their formal training not more than ten years earlier" (Cartter 12) and represented:

what in a court of law would be called "the testimony of expert witnesses"- those persons in each field who are well qualified to judge, who by training are both knowledgeable and dispassionate, who through professional activities are competent to assess professional standards, and who by their scholarly participation within their chosen fields have earned the respect of their colleagues and peers (8).

This effort also included a layer of quantitative analysis over what, at its core, was purely subjective. Evaluators were asked to rate each program in their own area of study on two parts: "the quality of graduate faculty and effectiveness of the doctoral program" 
(Cartter 12). The forced-choice responses for the rating of the quality of graduate faculty included "distinguished," "strong," "good," "adequate," "marginal," and "not sufficient to provide acceptable doctoral training," with raters instructed to limit the number of schools they scored as "distinguished" to five. Response options for the second part, effectiveness of the doctoral program, were "extremely attractive," "attractive," “acceptable," and "not attractive." These subjective responses were later quantified using correlations and other statistical tools, with the resulting numbers displayed to two decimal places. In addition, raters were asked to provide biographical data and an assessment of time spent on various professional activities in order to ensure satisfactory and reputable representation (Cartter 12).

In an effort to demonstrate the objectiveness of this study, peer ratings were compared with other quantifiable indicators like number of award recipients, quantity of faculty publications, faculty salaries, awards, and library holdings. Cartter concluded that "if one were to include enough factors in constructing a so-called objective indexallowing for variations in institutional size and a university's commitments to certain fields of study — the results of our subjective assessment would be almost exactly duplicated" (Cartter 118).

The results of this project had real consequences. The NSF used it as a decisionmaking tool for distributing funding to different academic programs. In particular, program officers desired to create "steeples of excellence" in various disciplines, and to do so, funneled most of the available funds to the programs ranked the highest (Cole 185). A review of Cartter's project that appeared in Physics Today in 1966 written by 
Ralph A. Sawyer, acting director of the American Institute of Physics, indicated that the results of this study would not only support "steeples of excellence" but would also allow program directors to identify second-tier schools that could move up and deserved to receive more funding (76).

When ACE sponsored another rankings study in 1970, effectively following-up on Cartter's pledge to do update the survey within five years so that rankings in his study did not become solidified, the new project leaders, much more aware of the influence of these rankings, appeared to wrestled with the notion that their project was an assessment of quality and ended up omitting the word "quality" from the title of their study (Lawrence and Green 13). In addition, they presented their results as range of scores instead of as absolute numbers hoping to encourage readers of the report to consider the results not as a ranking system per se, but instead as indicators of a range of quality (Lawrence and Green 13).

However, preventing people from aggregating the results and creating a rank order of institutions proved impossible. Efforts by universities to improve their reputations were also inevitable, resulting in the study ultimately shaping the practices of those institutions. Such aggregated information, framed as the product of an influential organization like ACE, provided instant credibility and effected policy decisions both internally within institutions and in funding decisions made by the government. As long ACE produced data that could be used to create a ranking, people would use the information in that way in order to make comparisons (Lawrence and Green 14). 
The most biting criticism of ACE's approach came from those who recognized that reputational studies avoided the need for anybody to reach agreement on or define the goals of higher education. In particular, Patrick Dolan, the author of The Ranking Game: The Power of the Academic Elite, vehemently criticized the ACE studies, arguing that the resulting resource allocation, disciplinary priorities, and faculty selection were all negatively impacted as institutions used these flawed results as a decision-making tool. He condemned the statistical manipulation of personal opinion, and further argued that rankings favored elite institutions, prioritized graduate education over undergraduate education, and diminished the value of interdisciplinary efforts thus obstructing real improvement. In closing, he maintained that rankings are clearly based on the narrow assumptions and elitist structures that so dominate the present direction of higher education in the United States. As long as our most prestigious source of information about post-secondary education is a vague popularity contest, the resultant ignorance will continue to provide a cover for the repetitious aping of a single model. The quickest way to achieve qualitative diversity is to clearly state some legitimate aims for higher education and to measure the present institutions against these criteria. We could then have an open and honest picture of successes and failures, with the opportunity to force both the academic 
professionals and the institutions themselves to generate some real alternatives. Until then, all the attempts to change higher education will ultimately be strangled by the "legitimate" evaluative processes that have already programmed a single set of responses from the start (81).

Partly due to such criticism, ACE announced that they would not continue conducting graduate school rankings (Lawrence and Green 14). The National Research Council assumed that responsibility. However, by that time, a shift from the direct disciplinary-level evaluation of Hughes to something significantly more complex had occurred. The network in operation had expanded to include federal agencies, more universities, and more evaluators. Far more resources were also in circulation and being directed based on the results of the ACE studies. In addition, those results, presented as comparison statistics, were beginning to be used internally by institutions hoping to alter their practices and improve their rankings in the eyes of state and federal agencies, businesses, students, and prospective faculty.

\section{Advancing Students as Consumers}

While practices for sorting and assessing students, programs, and institutions were evolving, the milieu in which these assessment tools operated was becoming significantly more complex, as was the scale and scope of American higher education in general. By 1945, for example, the number of students enrolled in higher education had risen to $1,677,000$, a significant increase from the 63,000 that had been enrolled seventy-five years earlier. In addition, the number of faculty had increased from 5,000 to 150,000 
while the number of institutions grew from 250 to 1,786 (Cohen and Kisker 106). These shifts in scale and scope were followed by other important changes, including Cold War and Great Society policies that pumped large amounts of federal dollars into higher education, which facilitated its continued expansion. However, subsequent changesincluding the demise of in loco parentis (the notion that colleges and universities operated in place of students' parents), and the increased marketing of college guidebooks (which sorted colleges and universities by criteria outside their control)_ empowered students and positioned them as consumers of their education. In addition, a demographic shift associated with the peak of the baby boom entering adulthood put an end to the period of expansion in higher education and increased competition for students. A general resurgence of those who supported free market ideals complicated matters further. These changes resulted in a milieu of accountability that challenged the academy's control over what constituted a quality education and gave rise to the network of forces that facilitated NSSE's creation and rapid dissemination.

\section{Shifts Reflected in Policy}

A policy decision that opened the door to mass higher education and dramatically increased the level of federal funding directed toward the nation's colleges and universities occurred during World War II. In particular, the Servicemen's Readjustment Act of 1944 (commonly referred to as the GI Bill of Rights) facilitated the largest single influx of students into higher education ever, offering those who served in the armed forces technical training or a college education at no cost and with a living stipend for up to 48 months depending on their length of service. Almost eight million took advantage 
of this policy, with 2.2 million of them choosing to attended college (Greenberg, The GI Bill of Rights).

If the GI Bill increased federal involvement in higher education, the U.S. response to the Soviet Union's launch of Sputnik in 1957 raised that participation to a new level. Seeing Sputnik as a threat to national security, the nation's leaders expressed concerns about the lack of rigor in science education in America and prompted Congress to pass the 1958 National Defense Education Act (NDEA). This bill not only directed resources toward science and engineering programs but also to programs such as area studies and foreign languages and, provided incentives to students for becoming math and science teachers (Gladieux and Wolanin 9). While the bill was intended to be temporary and to focus on producing scientific knowledge, it became enduring legislation in the form of the Federal Perkins Loan Program to help financially needy students fund their education.

By the 1960s, therefore, national security interests were reinforcing the meritocracy-based structures in place, such as the IQ-based tests used as part of the admissions process. Increasingly, access to college was no longer seen as something only for the privileged but for all capable students, and a sequence of additional legislation further reinforced the trend by supporting students with financial need. For example, in 1964, the Johnson administration passed that the Economic Opportunity Act, the genesis of today's federal work-study program, giving colleges and universities federal funds to provide financially needy students with part-time employment while working toward their degrees. Then, Congress passed the landmark Higher Education Act (HEA) of 1965 "to strengthen the educational resources of our colleges and universities and to provide 
financial assistance for students in postsecondary and higher education" (20 USC 1001 et seq). This legislation provided government insurance on student loans (the Guaranteed Student Loan Program) and federally funded scholarships for undergraduate studentsEducational Opportunity Grants (EOG) — again, to be distributed to financially needy students. Standardized testing, which had become a key component of the admissions process at most colleges and universities, also became an essential element in the system of funneling financial aid toward promising students.

With the scale and scope of American higher education expanding rapidly, colleges and universities experienced significant change, including changes in the power relations between institutions and their students. Much of the pressure for change was coming from the larger population of students making new and varied demands. Initially, those demands had less to do with policies guiding higher education and more to do with national policy decisions. In a wave of student activism fueled by opposition to the Viet Nam War, protests in the late 1960s and early 1970s garnered national attention. Those protests also led to and became integrated with calls for a variety of national reforms on issues ranging from the environment and free speech to racism and women's rights. Large numbers of students participated in rallies and sit-ins, blocked building entrances, and picketed in an effort to express their dissatisfaction both with institutional decisions and American life. According to a report titled Dissent and Disruption: Proposals for Consideration by the Campus, authored by The Carnegie Commission on Higher Education, almost a quarter of all institutions experienced "disruptive protests" (28-29). 
According to anthropologist Michael Moffatt, author of Coming of Age in New Jersey: College and American Culture, these protests empowered students nationally and led to colleges around the country renouncing the philosophy of in loco parentis, giving students more choices and more freedom over their personal behavior (35). At the University of Maryland, an institution where significant protest took place, the administration adopted a two-pronged approach, developing tougher disciplinary procedures but, at the same time, making "an effort to be more open to the views of students and faculty and to involve them increasingly in the operation of the university" (University of Maryland Libraries).

The systematic evaluation of faculty by students emerged during this period. Initially, students simply began to express opinions about the quality of teaching they were experiencing but built a more structured evaluation system over time. For example, in Saints and Scamps: Ethics in Academia, Steven Cahn notes that on many campuses, students began publishing course evaluations, much to the disdain of the faculty who questioned how students, who knew little about the subject matter, could adequately judge faculty teaching. These evaluation practices, however, were eventually incorporated into the university's routine (Cohen and Kisker 246; Cahn 41) and, in many universities act as a governing force in the behavior of faculty who seek high scores for tenure and promotion.

Another indication of students' expanding influence was the signing of the twenty-sixth amendment in 1971, lowering of the voting age to 18 , a response credited specifically to Vietnam War protests. Senator Edward Kennedy offered persuasive 
testimony on behalf of the youth of America in his remarks to the Senate Subcommittee on Constitutional Amendments:

We know that there is already a high incidence of political activity today on campuses and among young people generally, even though they do not have the franchise. None of us who has visited a high school or college in recent years can fail to be impressed by their knowledge and dedication. By granting them the right to vote, we will demonstrate our recognition of their ability and our faith in their capacity for future growth within our political system.

Changes in the structure of financial programs further empowered students in the early 1970s. At the time, institutions were facing increased fixed costs due to their growth as well as declining federal research spending and state appropriations. As a result, colleges and universities looked to the government to provide more undergraduate financial aid. However, the question was raised as to whether those resources should be channeled through the schools or directly to students. If students received the funding, their priorities would ultimately have more influence on institutional decisions than if the money went directly to the institutions themselves. As Gladieux and Wolanin explain in Congress and Colleges:

An argument for student aid was that putting greater purchasing power in the hands of students would make institutions more responsive to market pressures, therefore 
more diverse, flexible and change-oriented. Advocates of institutional aid, on the other hand, maintained that the diversity of the entire system would be jeopardized without basic support to insure the survival of all its elements, and that individual institutions would be less capable of change and innovation without such support (43).

In the end, the 1972 Amendments to the Higher Education Act resulted in the Basic Educational Opportunity Grant (BEOG), later re-named the Pell Grant, which provided a base for students' financial aid packages. This aid, in contrast to campusbased aid, where institutions decided who received funding, was awarded directly to qualifying students regardless of their choice of institution. In addition, changes in legislation also made grants available to students attending private colleges, making those colleges more affordable to capable but less privileged students as well (Wilkinson 57). In addition to giving students more purchasing power, legislation that awarded financial aid directly to students, also changed the relationship between students and institutions in other ways: colleges and universities began to see raising tuition as a way to increase revenue. One result has been an escalating spiral of increased financial need and increasing tuition (Wilkerson 57; Gladieux and Wolanin 43). To illustrate, in 1965, when the first baby boomers started going to college, the average cost was just under $\$ 7,000$ at private schools and just under $\$ 2,000$ at public institutions (dollars adjusted for inflation to 2006) (Howe and Strauss 52-53). Yet, in the decade from 1977-1986, college inflation rose at an average rate of nearly one and a half times general inflation; in 1986 
the college inflation rate was over four times that of the general inflation rate (8.09 percent compared to 1.61 percent), one of the highest rates in more than twenty years (Kantrowitz). Meanwhile, federal financial aid legislation continued to expand. In 1978, the Middle Income Student Assistance Act (MISAA) eliminated income restrictions for the Guaranteed Student Loan Program, making students from middle (and upper) income families eligible to receive these loans. The result was a threefold increase in the number of Guaranteed Student Loans awarded (Forest and Kinser 301).

All of these changes resulted in students being perceived (and students perceiving themselves) as consumers of their education. A demographic shift and factors such as more students having college-educated parents — and, hence, more capable of guiding students in their decisions_-resulted in institutions having to be more competitive in attracting students with tuition dollars. Specifically, in the early 1980s, the children of baby boomers - the wave of students that historians Strauss and Howe describe as Gen Xers-were beginning to go to college. At the time, the population of college-age students was shrinking and the competition for students escalating (Thacker 13). Hence, with parents much more savvy about how to navigate the educational system, these students—described by Strauss and Howe as "pragmatic, survivalist, and marketsavvy"- arrived at college seeing themselves as pursuing their education for the primary purpose of future financial gain (171). Indeed, Derek Bok, in his book titled Our Underachieving Colleges, points out that between 1970 and 2001, the percentage of freshmen who rated "being very well off financially" as a reason for attending college 
rose from 36.2 to 73.6 percent, while the percentage of those who wanted to "acquire a meaningful philosophy of life" fell from 79 to 39.6 percent (26).

As the relationship between universities and undergraduate students shifted more toward that of consumer and producer, a range of technologies and strategies, such as college guides, commercial ranking systems, and more sophisticated forms of marketing colleges, emerged. Legislation also facilitated this shift by mandating that universities make more information about their institutions available to students and, indirectly, to the college guides that packaged that information for students. When, for example, the Higher Education Act was re-authorized in 1976, new provisions required institutions that accepted funding to provide consumer information about financial aid programs as well as academic progress rates and job placement rates.

\section{The Sorting of Colleges and Universities for Consumers}

Public access to more information about colleges and universities allowed companies that marketed college guides, which positioned themselves as neutral sources of information about the universities and colleges, to become an even more important source of information for prospective students (Hossler and Foley 22). For example, guides such as Peterson's Guide for Four Year Colleges and Barron's Profiles of American Colleges provided students with similar information about each institution so that they could easily compare colleges and universities in which they were interested. In practice, then, these guides served as a powerful force shaping a student's image of various universities and facilitating assessments based on kinds of information that a 
student might be interested in, which was not necessarily what those in the academy valued.

The type of information each guide included and how it was presented mattered. One guide, Hawes Comprehensive Guide to Colleges, first published in 1978, directly positioned students and their families as consumers of higher education and sought to include data that addressed three common concerns of students - will I fit in and be successful, can I afford it, and, can I get in? The guide used the following indicators of quality:

1. "Social Prestige" rating: based on "the number of graduates in the current edition of the Social Register."

2. "Social Achievement" rating: based on "the extent to which colleges have educated graduates who themselves have achieved high status."

3. "Best Buy," "Better Buy," or "Good Buy" Rating: based on "the college's total expense per academic year."

4. "Faculty Salaries" rating: provides data about faculty salaries based on the notion that "a college with higher faculty salaries will in general attract more highly qualified professors."

5. "Admissions" rating: based on whether the college's admissions standards are "hard," "selective," or “easy" (xi-xii).

Hawe's effort re-framed what was mean by a quality education in a way that reflected the information that students and parents wanted, but it left educators questioning whether such ratings accurately measured institutional quality (Lawrence and Green 43). 
By the 1980s, commercial college ranking systems that sorted and compared institutions on a variety of criteria became popular, with the most well-known and frequently cited evaluation being “America's Best Colleges” produced initially in 1983. Other systems ranked schools based on criteria such as quality of life, sports team performance, and community service, acquiring their data from numerous sources. These ranking systems eliminated the layer of interpretation that students brought to the comparison task and presented educational quality as even more objective and measurable than the college guides.

Because these simple ranking systems proved to have a powerful influence on perceptions, colleges and universities began to look for ways to move up in the rankings. Some even provided misleading information in an effort to improve their standings. A revealing Wall Street Journal story, "Colleges Inflated SATs and Graduation Rates in Popular Guidebooks; Schools Say They Must Fib to U.S. News and Others to Compete Effectively," published in 1995 explained that ranking organizations take the information provided to them by colleges at face value and do not check other sources for accuracy. By comparing these data to similar data provided to debt-rating agencies, where lying violates laws and subjects schools to potential legal penalties, journalists uncovered numerous discrepancies, and some schools were soon squirming in their efforts to explain the differences (Stecklow). College and university administrators, while they often object philosophically to the rankings, might be considered accomplices in this activity because they provide the data to $U$. S. News for the assessment. However, many institutions, don't 
feel like they have a choice. One school that attempted to boycott the U.S. News rankings by not providing the data plummeted on the list that year (Machung 9).

Several researchers argue that rankings systems inherently privilege some populations over others (McDonough, Antonio, Walpole, and Pérez 515). For example, Machung charges that the U.S. News rankings tend to privilege private schools over public institutions. According to her statistics, in 1998, eighty percent of U.S. college students were enrolled in public universities, yet that year, there were no public schools represented in the top tier in any U.S. News category. In her analysis, they subtly invalidate public higher education because they are based on characteristics more representative of private institutions, i.e. "continuous undergraduate enrollment, high graduation rates, high spending per student, and high alumni giving rates" (4). Such ranking systems, then, are a powerful system of control highly influenced by consumers that frame higher education as a private good. This system privileges a small percentage of institutions (and individuals) over others but governs the practices of many colleges and universities in the U.S.

The creation of NSSE was, in part, a response - a form of resistance — against the growing power and influence of commercial rankings. NSSE's goal was to create a new measure of quality, one linked more directly to learning. From one perspective, then, NSSE is an effort by the academy to take control of how collegiate quality is to be defined by identifying the practices that should be assessed, compared, sorted and, in the end, normalized. In the existing milieu of accountability, however, market choices are still the ultimate arbiter of quality. Indeed, the neoliberal assumption that the market 
should be the only force governing social institutions, has come to be taken for granted by many, including policymakers. Any significant resistance would have to challenge this assumption. NSSE, however, as examined in Chapter Five, failed to do that. While NSSE is being used on many campuses and successfully contributing to changing practices, much of its use lies in helping institutions position themselves to compete in the market. 


\section{Chapter Five - Governing Assessment}

When the National Survey of Student Engagement (NSSE) emerged it was as a form of resistance against the commercial rankings that listed the country's colleges and universities in order of their perceived quality. Like many in the academy, the creators of NSSE argued that the criteria underlying these rankings were not a good measure of institutional quality and therefore had little meaning. Still, these reputational systems wielded significant influence and were driving institutional practices as schools made changes to move up on the coveted ranking lists. Thus, the creators of NSSE set out to design an instrument that would be more useful in evaluating and improving institutional practices and change the conversation about collegiate quality. As a result, when NSSE was introduced, it had significant appeal within the academy. At the same time, however, by serving as a measure of collegiate quality based on the fluid concept of engagement, I contend that NSSE did little to buffer institutions from market pressures. Indeed, NSSE's emphasis on measuring student engagement encourages colleges and universities to direct more resources toward those parts of the institution that contribute to the student experience in areas outside the academic disciplines. In addition, the data generated by NSSE — which reflect how colleges and universities are viewed through the eyes of students - support corporate strategies such as branding, which allows institutions to be even more responsive to students as consumers.

More specifically, scholars of higher education created and promoted NSSE as a way for universities to improve the traditional assessment process by surveying students about their educational experience. Theoretically, each college or university could use the 
responses of students as evidence of what was being done well, what could be improved, and where to commit resources. At the same time, NSSE's creators were sensitive to market pressures and the desire of neoliberal-leaning policy makers to make college and universities more accountable to students as consumers. This sensitivity is evident in the criteria they established for choosing items to be included on the survey: "(1) Is the item arguably related to student outcomes as shown by research?; (2) Is the item useful to prospective students in choosing a college?; and (3) Is the item straightforward enough for its results to be readily interpretable by a lay audience with a minimum of analysis" (National Survey of Student Engagement Our Origins and Potential)?

This sensitivity to market forces resulted in a survey that did little to challenge the underlying power relations in the existing milieu of accountability. In such a milieu, where education is framed as a private good to be governed by the choice of consumers, the power of the academy to influence the direction of higher education is limited. As well, in the absence of policies that entrust the academy with more power, the ability of instruments such as NSSE to make a difference is also limited. Although taking control of the measures used to assess educational quality could be significant, that shift in control did not happen with NSSE. Indeed, in this milieu where the market is the dominant governing force, the data generated by NSSE that are useful for making higher education more responsive to consumers are privileged.

This complex dynamic warrants an investigation into the discourse that surrounded the creation of NSSE, its marketing, and the use of the knowledge it generates as it operates in the existing milieu of accountability. As with most technologies, NSSE's 
meaning is context dependent (Mitcham 152). Cultural theorist Jennifer Slack makes this point arguing that "technology has no absolute identity; it is rather the ongoing production of identity empowered and empowering in articulated social relations" (338). While the technology may become stationary or stable for a time, it is "always open to redefinition as the relations among social forces change and as new social forces come into play" (Slack 338). NSSE, rooted in the fluid notion of engagement, is especially able to be used in ways that conform to various patterns of social relations. Although policy makers, consumers, and administrators are all interested in the knowledge produced by NSSE as a measure of collegiate quality, each has different goals in mind. Policy makers may link results to funding, student consumers may use the information for the purpose of college selection, and administrators are interested in using the results to aid in improving practices and to compare their institutional scores against others to evaluate overall performance. Furthermore, when influential organizations like the Carnegie Foundation for the Advancement of Teaching, the Lumina Foundation, Pew Charitable Trusts, and the Spencer Foundation endorse or fund a project like NSSE, regardless of their reasons, the survey instrument and the notion of student engagement itself takes on greater authority.

In general, then, I argue that as NSSE was developed, marketed, and disseminated in the existing milieu of accountability, the discourse of student engagement surrounding NSSE morphed from an effort on the part of the academy to gain control of the conversation about collegiate quality to one in which the practices of colleges and universities are being (re)defined in market terms. On campuses, these shifting forces are 
(re)shaping power relations and the practices of colleges and universities and their members.

\section{Student Engagement as an Object of Knowledge}

Early in twentieth century, the study of higher education administration emerged as a scholarly discipline in support of teaching and learning. While its research agenda was varied and ranged in topic from understanding the role that colleges and universities play in society (Stewart 894) to examining the effects of interpersonal relationships in the classroom (Katz 365), it was understood in the context of contributing to the academic endeavors of the academy and supporting higher education as something more than vocational training. When this discipline emerged, faculty generally saw themselves as being responsible for the development of students' intellects and believed that little learning took place outside of class. Nevitt Sanford captures this notion in a chapter titled "Higher Education as a Field of Study," where he portrayed the faculty as believing that the highest development is to be brought about by what teachers consider to be educational means, by what goes on in the classroom and in the teacher-student relationship, rather than by extracurricular activities, psychological services, or the chance to "grow" willy-nilly in a pleasant environment. Since development through disciplined learning is likely to be difficult or even painful, and since college students are often resistant to such development, 
the educator is naturally opposed to anything that might offer the students a chance to escape (40).

While scholars in the field of higher education research agreed that learning and knowledge production was the priority in the academy, they also argued that an essential element in support of learning was student involvement-including involvement outside of class. As institutions competed for students, the influence of these scholars and the emphasis that colleges and universities placed on out-of-class learning increased as well. As institutions expanded their efforts to engage students beyond the classroom, tensions have risen between faculty and student affairs professionals, who are now seen to be vying for scarce resources, including the students' time, especially as more professional staff are being hired to deliver these new programs and services. In Academically Adrift: Limited Learning on College Campuses, scholars Richard Arum and Josipa Roksa, citing a study by sociologist Gary Rhoades, indicate that these positions now "comprise nearly 30 percent of the positions on campus" (12). This investment reflects a greater concern for students' overall college experiences and as Arum and Roksa argue "has implicitly deemphasized the role of faculty and faculty instruction" (12). To complicate this scenario further, in the milieu of accountability, where student consumers are privileged, it is the out-of-class experiences that provide greater opportunities for institutions to differentiate themselves, providing the platform for marketing and branding. This of course translates to increased revenue for the institution and gives unspoken power to this broader educational experience. Consequently, in this milieu where the market is a significant governing force, the 
expanded concept of student engagement to include out-of-class experiences results in a system of higher education that channels resources to these activities to be even more responsive to the market.

\section{$\underline{\text { Reform and Expert Knowledge }}$}

That NSSE might help universities be more responsive to consumers was not the expressed intent of those who created the survey. In 1998, when the Pew Charitable Trusts assembled a group of leading scholars in higher education research to develop a new assessment instrument, its stated aim was to create an alternative to reputational ranking systems. This use of experts is consistent with Nikolas Rose's explanation of the role of expertise - " "authority arising out of a claim to knowledge, to neutrality, and to

efficacy" - in support of liberal reforms in the nineteenth century (Governing "Advanced" Liberal Democracies 39). He argues that expert thought and the "rise of expert figures" played a significant role in justifying societal reforms, replacing the governing authority of the state with the authority of the expert (39).

In the case of the NSSE design team, the task was to create a survey instrument that would produce "valid, reliable information directly from students about the extent to which they engage in the kinds of educational practices that the research shows are associated with powerful learning outcomes" (Edgerton and Ewell). This team was to develop the survey instrument, "test its utility and feasibility, [and determine] a strategy for its administration" (National Survey of Student Engagement Our Origins and Potential). Ultimately, this team also controlled what knowledge would be acquired and how it would be presented. 
In terms of their credentials as experts the members of the NSSE design team were regularly referred to as "educational leaders" and "national experts." The group included Peter Ewell, Alexander Astin, Gary Barnes, Arthur Chickering, John Gardner, George Kuh, Richard Light and Ted Marchese, all highly respected scholars within the field of higher education research (Edgerton and Ewell; National Survey of Student Engagement Our Origins and Potential). The team also represented some of the most prolific writers in the field and the recipients of numerous national honors. For example, Alexander Astin has authored 21 books and more than 300 articles about higher education. He is also been elected as a member of the National Academy of Education. John Gardner has examined and written about the first-year college experience and has been recognized by numerous professional organizations. In 2002, he received the American College Personnel Association's (ACPA) lifetime achievement award. Richard Light is the Walter H. Gale Professor of Education at Harvard and has published seven books. He won the Stone Award for the best book on Education and Society for his most recent book Making the Most of College. And, finally, George Kuh, who is the spokesperson for NSSE has more than 300 publications on topics related to student engagement and improving the undergraduate experience. In addition, their expertise is seen in the recognition they have received from their peers. In 1998, four of them were identified in Change magazine, the journal of the American Association for Higher Education (AAHE), as leaders in high education. More specifically, Alexander Astin, Peter Ewell, and John Gardner were three of only eleven identified by their peers as "agenda setters in higher education" (Chronicle of Higher Education). 
Several also had experience constructing assessment tools, and their previous instruments served as the foundation for NSSE. For example, the College Student Experiences Questionnaire (CSEQ) was designed by Bob Pace and administered by the Indiana University Center for Postsecondary Research under the direction of George Kuh. Alexander Astin founded the Cooperative Institutional Research Program (CIRP) which began in 1966 and is the longest-running longitudinal study about the behaviors and attitudes of incoming college students in the nation. Student and alumni surveys administered by the University of North Carolina system, where Gary Barnes was affiliated, also contributed to the experience base of the team.

While the credentials of the NSSE design team gave the instrument immediate credibility in the higher education research community, they all were entrenched in a single body of work, citing each other in a circular fashion. Scholars such as Shanteau et al. call this "between expert reliability" and suggest that it could result in a failure to challenge assumptions that outsiders might. In addition, they claim that it can lead to hasty decision-making (256). Donald T. Campbell referred to this as disciplinary ethnocentrism, "that is, the symptoms of tribalism or nationalism or in-group partisanship in the internal and external relations of university departments, national scientific organizations, and academic disciplines" (328). It is also safe to say that the group resembled an old boys' network - in this case, an exclusive group of scholars who assisted one another and benefited from the relationships with each other. In the case of NSSE, no one appeared to question the underlying assumption that student engagement 
could be a proxy for quality, or whether this description of their goal actually matched what they were attempting to do.

The team, however, was not without disagreement. For example, Peter Ewell argued from the beginning that the NSSE benchmark results should be made public in order to directly address the charge that colleges and universities are not transparent when it comes to performance, a point he reiterated in the "Forward" of the 2007 NSSE Annual Report (National Survey of Student Engagement, Experiences That Matter). Alexander Astin lobbied for the survey to be longitudinal as he believed comparing responses of students over time would give the entire project more value (Astin email correspondence). These disagreements, while significant, did not occur at the level of fundamental goals and assumptions.

In designing the survey, the design team drew on several decades of scholarship examining numerous facets of higher education. In fact, NSSE's creators often make the point that "NSSE is credible because it rests on an extensive body of researchempirically linked to student learning” (National Survey of Student Engagement, Experiences That Matter). According to NSSE's 2003 annual report, several foundational works they built from included Nevitt Sanford's 1,000-plus page edited volume titled The American College: a Psychological and Social Interpretation of the Higher Learning, which examined higher education as a field of study and the effects of a college education on students. Topics included the role of the college professor, peer group influence, and level of academic effort exerted by students to name only a few. Similarly, another volume, How College Affects Students, written in 1991 by Ernest Pascarella and 
Patrick Terenzini, offered an extensive literature review investigating student development in college across a broad range of variables including cognitive skills and intellectual growth, psychosocial change and the quality of life after college (National Survey of Student Engagement, Converting Data into Action).

Other research that influenced NSSE's development included a project that emphasized the essential role of colleges and universities in encouraging civic engagement. In an influential report from a study group sponsored by the National Institute of Education to examine the conditions of American higher education in 1984, the authors highlighted the idea that education in the United States must be deepened "so as to provided increased opportunities for intellectual, cultural, and personal growth for all our citizens" (Study Group on the Conditions of Excellence in American Higher Education 2). The authors of that report organized their recommendations around three themes: involving students in the learning process, establishing and communicating high expectations, and assessing how well both classroom and institutional objectives have been met (15).

Another body of research that influenced the design team included the work of Arthur Chickering and Zelda Gamson who identified seven principles of good practice in undergraduate education focusing specifically on the collaborative roles of faculty and students in the learning process. Chickering and Gamson maintained that an effective educational experience

1. Encourages contacts between students and faculty.

2. Develops reciprocity and cooperation among students. 
3. Uses active learning techniques.

4. Gives prompt feedback.

5. Emphasizes time on task.

6. Communicates high expectations.

7. Respects diverse talents and ways of learning (3).

Given that Alexander Astin was on the design team, it is no surprise that NSSE would also address the role of student involvement in out-of-class activities in a manner consistent with his theory of involvement. Astin argues that learning happens through student involvement—whether in classes, co-curricular groups, or social activities—and contributes to student growth ("Student Involvement" 302). Astin's idea of student involvement was examined further by George D. Kuh, John H. Schuh, Elizabeth J. Whitt and their associates in Involving Colleges: Successful Approaches to Fostering Student Learning and Development Outside the Classroom. They collected data for fourteen institutions through campus interviews, observation, and document analysis to study enhanced out-of-class experiences. (27).

What can be seen in these various research efforts-which are manifest in NSSE's focus on student engagement —is an attempt to bring together a variety of learning practices, including a broad range of out-of-class activities, under the umbrella of the overall college experience. The authority of the design team, rooted in their experience and scholarship, enabled them to construct a vision of student engagement that had wide appeal. At the same time, some of those involved in NSSE's design recognized that establishing NSSE as the standard for assessing quality had implication 
for the flow of resources within universities. Astin, for example, made the point that "if an institution commits itself to achieving maximum student involvement, counselors and other student personnel workers will probably occupy a more important role in institutional operations (Astin, "Student Involvement” 305).

\section{(Re)constructing Student Engagement}

The NSSE instrument was designed based on several pre-existing surveys rooted in the scholarship that broadly defined the college experience. However, NSSE reflected a change. While previous surveys were primarily for the purpose of assessing the practices of students, NSSE shifted the focus to students assessing the practices of colleges and universities. It did so by linking their experiences to evidence of collegiate quality:

Student engagement represents two critical features of collegiate quality. The first is the amount of time and effort students put into their studies and other educationally purposeful activities. The second is how the institution deploys its resources and organizes the curriculum and other learning opportunities to get students to participate in activities that decades of research studies show are linked to student learning (National Survey of Student Engagement, About NSSE).

This change positioned NSSE to be used not only for assessment processes internal to the academy, but also as an accountability tool for external audiences. After all, unlike 
surveys that attempt to assess what students have learned which is highly context dependent and requires significant interpretation, NSSE mainly asks about what the students have experienced. The focus is placed on whether the university has been successful in facilitating or providing those experiences.

The surveys on which NSSE is based explicitly avoided placing the focus on the activities of the college or university. For example, the survey most often referred to as NSSE's precursor is the CSEQ which was initially created in 1979 and revised in 1990 and 1998. Focusing on students' efforts in their academic pursuits, this instrument asks students about their participation in meaningful learning activities, their perceptions of the institution's emphasis on academic priorities, and to evaluate their personal progress toward academic gains. The premise of this survey was focused on the notion that students' were responsible for their learning. Robert Pace explained his rationale for the instrument in this way:

One motivation for my desire to measure student effort was the recurring rhetoric about accountability that always blamed the institution for outcomes. If students don't graduate it is the college's fault. If they don't learn it's the teacher's fault. If the graduates don't get good jobs, the college is to blame. If you don't benefit from going to college it's their fault. This assumes that the student is buying a product when actually the student, at a later point in time, is the product. So, the other side of accountability 
is the quality of effort students invest in using the facilities and opportunities the college provide (28).

He went on to explain that "there would be no statements of opinions or of likes and dislikes or students' satisfaction or dissatisfaction. Statements of that sort are not indicative of action or effort" (29).

Where Pace explicitly avoided asking questions in terms of student satisfaction, NSSE has two questions that emphasize students' overall satisfaction with their institutions: "Overall, how would you evaluate the quality of academic advising you have received at your institution?" and, "how would you evaluate your entire educational experience at this institution" (National Survey of Student Engagement, The College Student Report)? These questions are consistent with the perception of students as consumers.

In addition, a closer look at the two survey instruments reveals several questions that originated in the CSEQ and appear in NSSE in a slightly different form. The change in language is consistent with a shift from measuring student practices to measuring the practices of colleges and universities, shifting the responsibility for learning from students to faculty and administrators. For example, both instruments include questions about a student's progress, but they ask the question in slightly different ways. The CSEQ places the focus on students; NSSE places it on the institution. To illustrate, the CSEQ asks 
In thinking about your college or university experience up

to now, to what extent do you feel you have gained or

made progress in the following areas (emphasis added)?

In contrast, NSSE asks

To what extent has your experience at this institution contributed to your knowledge, skills, and personal development in the following areas" (emphasis added)?

The CSEQ is asking the student to evaluate their own progress, whereas NSSE is asking about the collective behaviors of the institution that could have contributed to student gains/experiences.

In another case, both instruments attempted to determine how frequently students participated in specific academic activities. The CSEQ asks

In your experience at this institution during the current school year, about how often have you done each of the following (emphasis added)?

And, NSSE asks

During the current school year, how much has your coursework emphasized the following mental activities (emphasis added)?

Again the CSEQ asks about the students' involvement in these experiences, while NSSE's has the student assessing whether the institution/instructor has provided these kinds of activities for students. 
In a final example, both surveys include questions that ask students to evaluate the degree to which the university emphasizes various components of an education. In the CSEQ, the question is framed in terms of goals that lay at the core of any college's or university's mission:

Thinking of your experience at this institution, to what extent to do you feel that each of the following is emphasized?

- Emphasis on developing academic, scholarly, and intellectual qualities

- Emphasis on developing aesthetic, expressive, and creative qualities

- Emphasis on developing critical, evaluative, and analytical qualities

- Emphasis on developing an understanding and appreciation of human diversity

In NSSE, the question focuses on the institution's role in providing support:

To what extent does your institution emphasize the following?

- Providing the support you need to help you succeed academically

- Encouraging contact among students from different economic, social, and racial or ethnic background 
- Helping you cope with your non-academic responsibilities (work, family, etc.)

- Providing the support you need to thrive socially

The difference in the wording of these questions reflects NSSE's sensitivity to the notion that the knowledge it produces could be used to address accountability concerns outside the academy. In fact, during the design phase, the survey instrument went through several drafts and was reviewed by various constituents who were considered potential users. It is no surprise that representatives from the American Council on Education (ACE), accrediting agencies, and selected colleges and universities would be asked to review the instrument. What was unusual was to have media representatives from U.S. News and World Report and other outlets review and comment on drafts of the survey (National Survey of Student Engagement, Our Origins and Potential). Including them in the review process reflected the design team's desire to provide knowledge that consumers of higher education would see as useful.

\section{Governing through Normalization}

The way in which the data generated by NSSE is packaged and presented is helpful for internal assessment processes controlled by the academy but it is also structured for easy use as a tool for making competitive comparisons. The data are organized around five "national benchmarks of effective educational practice:" academic challenge, active and collaborative learning, student-faculty interaction, supportive campus environment, and enriching educational experiences (National Survey of Student Engagement, Benchmarks of Effective Educational Practices). According to NSSE, each 
of these categories represents an aspect of the college experience that, taken together, provides a comprehensive way of understanding and operationalizing effective educational practices. In much the same way that the general concept of student engagement can be seen as an unassailable virtue open to a range of interpretation, so can each of the benchmarks. Indeed, the phrase "national benchmarks" indicates that NSSE hopes to see these measures used for making national comparisons. Ultimately, NSSE has positioned their benchmarks of effective educational practice as the new de facto standard for practices in higher education.

The dissemination of NSSE, then, can be explained by a combination of factors. First, it generates data that can be used as evidence in satisfying traditional assessment processes. However, it also generates data that can be used by external constituencies to compare colleges and universities and by schools themselves to benchmark their performance on the measures that matter to those constituencies. Finally, some of the practices used by NSSE to facilitate the use of its survey draw on the pressure colleges and universities feel to perform well on market comparisons. In viewing the overall process involving governance at a distance, once can see the following mechanisms at work.

\section{$\underline{\text { Homogenization and Exclusion }}$}

If the data generated by NSSE were used only for assessment purposes, faculty and administrators would have significant flexibility in how to interpret the results and take action aimed at improving practices. However, to the extent that the NSSE

benchmarks are used by external constituencies - including prospective students and state 
legislators - to compare institutions, much of that flexibility disappears. Furthermore, as the NSSE benchmarks come to be seen as standard measures of educational quality, institutions will feel increased pressure to make their results public. Indeed, an early concern expressed by members of the academic community early was that use of NSSE as a comparison tool could "create pressure to homogenize curricular practices" (National Survey of Student Engagement, Our Origins and Potential). The main concern was that defining educational quality in terms of questions that NSSE asks (and in terms of the responses that students provide) could restrict or limit alternative expressions. Because NSSE does not prescribe universities to teach specific content it appears to offer flexibility and opportunities for creative instruction and programming. Still, the activities and conditions outlined under each benchmark do imply specific strategies for engaging students. For example, under the "Active and Collaborative Learning" benchmark students are asked how often they have: "made a class presentation, asked questions in class or contributed to class discussion, worked with classmates outside of class to prepare assignments, and discussed ideas from readings or class with others outside of class" (National Survey of Student Engagement, Benchmarksof Effective Educational Practices). Over the long term, as universities take steps to ensure that these practices are in place, other equally effective activities will receive less attention and come to be seen outside the norm. In short, the activities being measured by NSSE become the norm and other possible practices that could still be meaningful such as role-playing, building a model or mobile that represents a complex theory, creating a concept map, or making an 
ethnographic observation will be left out of what is considered effective practice. NSSE, then, becomes a tool for normalizing practices.

In addition to homogenization, other normalizing practices identified by Foucault include exclusion, comparisons and hierarchy, and differentiation all of which are evident in the dissemination of NSSE. For example, as NSSE has grown in popularity, the pressure on universities to use NSSE as an assessment tool and to make the results public has been exerted, in part, by exclusion. Early on NSSE's commitment to keeping the results of individual colleges and universities private so that schools would be comfortable using the instrument facilitated its dissemination. Today, barely a decade later, more than 1,400 baccalaureate granting colleges and universities have administered the survey (National Survey of Student Engagement, Major Differences 7). However, in the existing milieu of accountability, in which transparency for the sake of facilitating consumer decisions is valued, it is difficult to keep NSSE results private. As NSSE becomes a standard measure of effective educational practices, policy makers, higher education associations, and consumers, increasingly expect colleges and universities to administer the survey and make the results public. Indeed, in some state systems, participation in NSSE is now required and the data are then used in system-wide decision making. In this scenario, a campus that does not administer NSSE faces consequences of failing to provide required data. Furthermore, as more schools respond to this pressure and publicize their results, those that don't risk being excluded in the competition for resources controlled by external constituencies, including students who use the NSSE data directly or through other mechanisms. That, of course, is the ultimate exclusion. 


\section{Comparisons and Differentiation}

Even though NSSE does not produce rankings or make the data associated with specific schools public, it does generate knowledge that allows institutions to compare themselves with others. These data contribute to processes of comparison and differentiation. In the series of reports that NSSE provides to each institution, colleges and universities can see how they perform in relation to other schools of a similar type. (If the sample size is large enough, comparisons can also be made by school, department, or major field of study within one institution.) For example, the Frequency Distributions Report shows how many students answered each question — as a raw number and a percentage — broken down by their response. The same data are aggregated and appear for selected peers, schools in the same Carnegie Classification, and all NSSE participants for that year. Two columns of data appear for each category of school— the count and the percent of students who responded to each response option. Separate distributions appear for first-year and senior students (National Survey of Student Engagement, Frequency Distributions). To illustrate, an institution could learn that thirty-five percent of their first-year students have never made a class presentation compared to forty percent at selected peer institutions, thirty percent at schools in the same Carnegie Classification, and twenty-seven percent at all NSSE institutions.

NSSE also synthesizes these data to form the five benchmarks that are reported on in the Benchmark Comparisons Report. Here, individual institution mean scores are compared to five groups: "selected peers, schools in the same Carnegie Classification, all NSSE participants for that year, institutions with benchmarks in the top fifty percent of 
all NSSE institutions, and institutions with benchmarks in the top ten percent of all NSSE institutions" (National Survey of Student Engagement, Benchmark Comparisons). In this case, an institution might learn that the level of academic challenge experienced by its first year students is lower or higher than the challenge provided to the average student in these other groups. It is also possible to construct customized reports using the NSSE Report Builder. This tool allows one to generate comparison reports based on factors such as Carnegie Classification, enrollment size, gender, major, race, or first-generation status, allowing one to review "normative patterns of engagement" in a variety of ways (National Survey of Student Engagement, Report Builder).

Hence, even when NSSE data are not released to external audiences in a way that makes comparisons easy, NSSE still differentiates and makes distinctions among schools. On one level, because the information NSSE produces is aggregated and no individual institutional results are publicly provided, it is not possible to make specific school-toschool comparisons making efforts to rank colleges and universities difficult based on NSSE data alone. However, the "Benchmark Comparisons Report" sets up a hierarchy by displaying the mean difference between an institution and its peer groups and indicates the degree to which an institution is performing above or below the mean (National Survey of Student Engagement, Benchmark Comparisons 2). This practice reflects levels of performance - from high to low_ and situates an institution in the context of the norm. The intent of providing this information is to enable institutions to benchmark their practices (and the experiences of their students) against those associated with other schools in the same category and not for outsiders to use as a mechanism of 
accountability. However, even when the data are not used by external constituencies to make comparisons, they support the internal use of competitive comparisons.

Another example of a differentiating effect based on comparison also occurred as a result of NSSE's Documenting Effective Educational Practices (DEEP) research. In collaboration with AAHE, NSSE selected twenty institutions that had higher-than predicted scores on the benchmarks to investigate and document their educational practices. The project was funded by the Lumina Foundation for Education and the Wabash College Center of Inquiry in the Liberal Arts which was created with a grant from The Lilly Endowment. The schools that were selected were seen as representative of higher education in the U.S. - in the sense that they were diverse in size, selectivity, mission, location, and student characteristics — and hence, could serve as models for other institutions. According to the text documenting the research, Student Success in College: Creating Conditions that Matter, "other colleges and universities will be able to identify philosophical underpinnings and educational policies and practices that they can adapt in order to enhance their educational effectiveness" (Kuh, et al 14-18).

This project, perhaps unintentionally, served to boost the reputations of these twenty institutions and set them apart from all others, even from other schools that met the same criteria but were not selected to participate in the study. In fact, some schools used their involvement in the study to promote themselves. For example, Longwood University issued a news release "Longwood University Among Few Chosen for National Education Study" (Longwood University). Similarly, the University of Kansas issued a news release at the conclusion of the project that began: "In a new report on best 
college educational practices, researchers lauded the University of Kansas as an "engaging public research university" and noted that "many other colleges and universities will benefit from learning about KU's policies and practices" (Cohen). An enhanced reputation, of course, translates to a more competitive position in the marketplace.

In addition, in the existing milieu of accountability as calls for transparency and public disclosure get louder, policymakers could establish a standard score they see as an acceptable level of quality and require universities to publically release their results. In fact, some states are moving in this direction, and schools could find themselves responding in the same way that some have responded to the rankings. That is, escalating pressure to provide evidence of quality could lead some institutions to focus their efforts on increasing scores in order to be recognized but doing so more in a manner of gaming the system than making significant reforms (McCormick, "Toward Reflective Accountability" 97). As Sauder and Espeland point out: "pitting one person's or one institution's performance against all other is a central and deeply consequential aspect of the discipline imposed by processes of normalization" (73).

\section{Prescribing the Student Engagement Message}

Part of the normalizing process associated with NSSE involves a strategy for prescribing how the survey data should be used and how student engagement should be talked about across all sectors of higher education. As with the decision to adopt the survey, the decision to implement these strategies is not simply a reflection of the survey 
as an agent of change. It is also a reflection of the pressure placed on universities to compete with other institutions for resources.

That said, to the extent that NSSE is viewed as a tool that measures what external constituencies value, it has normalizing power. For example, as part of the report packet, colleges and universities are provided with a publication titled Using NSSE Data, which offers a variety of strategies to incorporate the data into institutional practices and highlight several approaches for communicating results. In addition, the document gives multiple examples of how various institutions are using NSSE in specific improvement efforts that align with the benchmarks or in other initiatives linked to accreditation (9). NSSE gives examples of how some universities are using the data because it promotes the dissemination of the instrument by demonstrating what uses are possible. It is an effective strategy because, at some level, seeing numerous examples of what other schools are doing can have a shaming effect on administrators for not keeping up with what administrators in other institutions are doing.

NSSE also provides a guide that directs administrators on how to interpret their data. This process shapes the conversation about how to understand what NSSE measures, which also had a normalizing effect. In particular, Working with NSSE Data: A Facilitator's Guide is an instruction manual that provides step-by-step directions for the facilitator of a workshop or retreat to explain to faculty and others what their institutional results mean. This document follows a train-the-trainer approach to disseminating information where in lieu of the experts coming to campus to present an institution's results, someone on campus is trained and then presents to others. For each topic- - such 
as working with the institutional reports - the guide provides key points to cover, exercises, and special instructional notes for the facilitator. While this model creates a perceived campus expert in interpreting the results, it has a caveat as well. The conversation is restricted or confined to points discussed in the document, potentially missing — and seemingly devaluing — other innovative ideas, strategies, or practices.

NSSE also provides resources for administrators to market the survey to students so that enough of them take the survey. Until the NSSE survey is well integrated into an institution's practices, there may be no easy way to get students to take it, resulting in a poor response rate. Furthermore, colleges and universities frequently use surveys to generate data because they are a fairly quick and inexpensive way to gather information and to demonstrate performance. According to an article in The Chronicle of Higher Education, "Want Data? Ask Students. Again and Again," students are suffering from "survey fatigue." In 2011 the article reported, "more than a third of the colleges had less than thirty percent of their students respond" (Lipka). To address this concern, NSSE developed strategies for helping colleges and universities increase survey participation (National Survey of Student Engagement, Tips). In addition, in the examples they highlight, institutions make a commitment to students that educational practice will improve as a result of the students completing the survey. To illustrate, the University of Ontario Institute of Technology uses a poster that reads "NSSE Returns Help Us Shape the Future" (National Survey of Student Engagement, University of Ontario). The University of Wisconsin, LaCrosse poster has more details, and explicitly tells students their responses will make a difference: "We will use the information you share to better 
understand the impact of our academic and campus programs, identify our strengths, and give us ideas on how to improve" (National Survey of Student Engagement, University of Wisconsin).

NSSE is also playing a role in establishing an engaged student experience (defined by their criteria) as an expectation for prospective students. NSSE accomplishes this through a publication that suggests a series of questions - categorized by benchmark - that students should ask when on a campus visit. To illustrate, under the benchmark "supportive campus environment" category, there is a brief description informing the student why an encouraging atmosphere is important and then provides a list of suggested questions:

- How well do students get along with other students?

- Are students satisfied with their overall educational experience?

- How much time do students devote to co-curricular activities?

- To what extent does the school help students deal with their academic and social needs? (National Survey of Student Engagement, Pocket Guide)

By producing this publication NSSE is communicating to students (and the universities attempting to recruit them) that the measures associated with the benchmarks are what constitute a meaningful college experience. NSSE does not offer any suggestions as to what might be considered an appropriate response to any of these questions. Instead, 
students (and their parents) are left to interpret the answers but leaves them with the impression that these are the criteria that matter.

NSSE administrators have also suggested ways for colleges and universities to discuss their results with external constituencies without necessarily disclosing numerical information, calling it "reflective accountability" (McCormick, "Toward Reflective Accountability" 97). In a milieu of accountability where consumer-based demands for greater transparency are growing, administrators find such strategies useful. For example, NSSE suggests that schools identify trends or common themes revealed in the data and describe actionable ways to improve. This tactic, they argue, allows schools to publicly demonstrate a commitment to quality without numeric results (McCormick, "Toward Reflective Accountability"101). In addition, some schools have begun to publicize portions of their benchmark data online, promoting the results to interested constituents. For example, the DePaul University's online alumni magazine highlights their NSSE results for one question by indicating "that DePaul students are much more likely than students at other urban universities to say their college experience has contributed to their understanding of diversity" (DePaul University). Making such statements, however, is a step in the direction of making the data public. Some schools have gone as far as giving their data to U.S. News and World Report and USA Today (U.S. News Staff; Coddington, DeBarros and Palmer). Neither publication ranks school based on their NSSE results, but it is not too hard to imagine that scenario unfolding over time.

In short, the way in which NSSE produces and presents the survey results has a normalizing effect that facilitates comparisons and encourages competition based in the 
benchmarks NSSE has created. Furthermore, NSSE's efforts to explain how the survey results should be interpreted and used prescribe how student engagement should be understood. In addition, creating messaging specifically for prospective students positions student engagement as an expectation understood in terms of the benchmarks. Combined, these practices subtly define the student experience in market terms, reflecting power relations in the existing milieu of accountability as much as the power of NSSE.

\section{Resisting and Normalizing Practice-changing Knowledge}

This examination of NSSE also brings into stark relief an existing tension on many campuses: the competition for resources between academic units and student affairs departments. The decision to use NSSE, like many other decisions in a complex organization are often ascribed to "the institution" as if it had an independent will, as if no people were involved. However, it is individual people, their relations, and the practices they adopt—or reject— that constitute the organization. Furthermore, because decision-making in higher education is often decentralized, the groups who analyze a problem and make recommendations do so in the name of "the institution," but those recommendations do not become internalized or part of an institution's practice until they have been acted on by others. Hence, when national reforms such as the one represented by NSSE are implemented by colleges and universities, their effects will vary widely and the power relations will play out differently on every campus. However, general patterns emerge. 


\section{$\underline{\text { Unequal Benefits }}$}

What happens with the data NSSE produces depends on who controls it, and how or even if they attempt to use it. The data are frequently gathered by an institutional research office but tend to belong either to academic or student affairs (Kuh, "The National Survey of Student Engagement" 14). It is likely that the survey results may be of interest to both areas, but the group responsible for the data only has the authority to respond directly to influence the practices they have control over. As Stuart Hall notes, "Foucault argued that not only is knowledge always a form of power, but power is implicated in the questions of whether and in what circumstances knowledge is to be applied or not" (48).

Hence, who manages NSSE on campus matters. Academic units tend to value students' progress in acquiring disciplinary knowledge and to discount the contributions of student affairs professionals (Hirt 245). Student affairs professionals, on the other hand, are more interested in the development of the whole student and the student's overall experience, and often see faculty as being uninterested in their efforts to actively involve students in learning opportunities outside the classroom. While these units have overlapping priorities, how they execute their respective activities differs, which complicates institutional decision-making. Often when the data belong to academic affairs, student affairs professionals are excluded from conversations about how to use these data effectively. According to Welsh and Metcalf, faculty have "concerns about the ability of campus administrators to effectively implement institutional effectiveness strategies" (447). Similarly, student affairs professionals find it difficult to engage faculty 
in any substantive changes outside the academic organizational structure (Pace, Blumreich and Merkle 303). As a result, the survey results tend to become a tool for one organizational unit or the other, reinforcing this long standing schism in the academy. Also tied up in these dynamics is a competition for financial resources between academic and student affairs units. For academic areas, many of the practices that NSSE encourages result in changes in behavior that are perceived to require little, if any new funding. For example, providing feedback to students in a timely manner, being available to student outside of class, and assigning challenging work are historic expectations of faculty and are practices many already engage in at various levels. Given their multiple priorities though, faculty are often unable to do more, and resources to support such efforts are difficult to secure. In contrast, the primary focus of student affairs organizations is to deliver the sort of educational out-of-class experiences such as learning communities that are expected by students (and parents) as part of the college experience. Given that institutions are branding themselves, in part, on these experiences, administrators are willing to provide the financial resources needed to deliver these programs and services to strengthen the brand. As such, these resources are being invested in ways that are responsive to the market.

\section{Resisting Normalizing Efforts of Student Engagement}

Most commonly, academic units use NSSE results primarily for compliance in the accreditation process and for little else. Alexander McCormick, director of NSSE, claims that in some cases there isn't enough organizational energy to use the results in more significant ways. Another factor is the degree to which faculty are sovereign in their 
classrooms. According to David Paris, executive director of the New Leadership Alliance for Student Learning and Accountability, "there is no authority or dominant professional culture that could impel any faculty member to apply what NSSE teaches about engaged learning” (Jaschik, "Turning Surveys into Reforms").

Indeed using NSSE results to guide changes in practice at the level of the individual tenured faculty member, presents challenges. Typically, tenured faculty see themselves as autonomous in their classrooms, guided by their academic discipline and not directly governed by the university. As such, the imposition of changes as a result of NSSE-guided efforts to improve teaching practices can be seen as an intrusion. After all, the population-level data generated by NSSE fail to account for the individual expertise that faculty members bring to their classrooms. In addition, for faculty, a certain amount of authority and academic freedom is usurped when instruments like NSSE are embraced, and the survey questions begin to redefine pedagogical standards and establish new systems of control (Lather 763). Furthermore, faculty are faced with multiple demands that include significant research and publication expectations and often operate under a reward structure that reinforces these activities. George Kuh argues that these pressures from the academy result in faculty entering into what he terms the "disengagement compact" with students:

That is, I won't make you work too hard (read a lot, write a lot) so that I won't have to grade as many papers or explain why you are not performing well. The existence of the bargain is suggested by the fact that at a relatively low level 
of effort, many students get decent grades-B's and sometimes better ("What We're Learning About Student Engagement from NSSE” 28).

This agreement works for students who welcome a reduced workload and the possibility of securing decent grades without a lot of effort.

There is also skepticism over changing practices based on how students respond to the questions that NSSE asks. In fact, a 2010 USA Today article about what NSSE has learned in its first ten years indicated that faculty are generally skeptical about the approach adopted by NSSE (Marklein, "NSSE Changes How Colleges Judge Success, Weakness"). For the faculty, the premise of the survey is similar to the premise of teaching evaluations. They question the notion that students can accurately report and assess the quality of their experiences and that their judgment can be reduced to a quantifiable measure. Thus, using NSSE to guide improvement decisions raises many of the same contentious questions as using teaching evaluations, albeit on a different scale. Yet while teaching assessments have faced considerable criticism over the years, their use is now common practice. According to Berk, "a survey of 40,000 department chairs indicated that $97 \%$ used "student evaluations" to assess teaching performance" (50). In addition, Berk points to McKeachie who indicated that "student ratings are the single most valid source of data on teaching effectiveness" (50). Typically, evaluation results serve two purposes - one formative which uses the information to improve instruction and the other, summative which uses the evidence as part of an overall summary of 
performance (Berk 50). NSSE data are intended be used in a similar way: formatively to improve institutional practices and summatively as evidence of institutional quality.

However, there is a significant difference between teaching evaluation results and the knowledge NSSE produces. Teaching evaluations are an individualized measure of effectiveness whereas NSSE data describe the practices of the population of faculty and administrators at a given institution. In addition, institutions that use NSSE data for the purpose of improving educational practices are making those decisions based on the aggregated experiences of the student population. For example, one question on the survey asks students to assess how frequently they "received prompt written or oral feedback from faculty on [their] academic performance” (National Survey of Student Engagement, College Student Report). The obvious reason for this question is that giving students feedback focuses their learning, helps them to improve, and provides an opportunity for them to build on what they know (Chickering and Gamson 5). It's valuable for an institution to know how frequently this practice is occurring or not. However, the practices of the institution and not individual faculty and administrators are being assessed. Yet changes at the level of the faculty population, for example, requires changes in classroom practices, and prescribing classroom practices erodes the tenets of autonomy and academic freedom.

Further complicating matters is that some faculty see NSSE as a tool for assessing student learning, failing to consider that NSSE is actually producing knowledge more about institutional practices than students. For example, this blogger who posted in response to Sara Lipka's article in The Chronicle of Higher Education, "It's Not How 
Much Student Data you Have, but How You Use It" gave up on the usefulness of NSSE data after evaluating it as a tool for assessing students rather than university practices:

I confess - I tried to use NSSE for assessment and could not make the square peg fit into the round hole. I chalked it up to not knowing enough about the instrument and not being in assessment full-time. So I went to a NSSE-sponsored regional workshop, complete with George Kuh and a national office team. Still felt square in a round hole. NSSE information is still collected by my institution, but it is not useful in helping us move forward because the information is not specific enough to departments. It captures snapshots of student's opinions, but it does not compare a student's growth over time....We will not use it for assessment anytime soon. Sorry NSSE (Cjones599).

Another faculty member, quoted in reporter Mary Beth Marklein's USA Today blog, questioned the value of NSSE more directly and criticized it as measuring nothing more than students' affections for their institution:

"My students think NSSE is a joke," writes Jeanne Phoenix Laurel, an English professor at Niagara University. "There is no incentive for any particular answer. Why should they be honest? Even with more specific questions, all we can really measure is whether students feel warm and fuzzy 
enough about the school to put down the answer they know is the desired one."

These comments reflect the ambiguity of NSSE. NSSE contributes to this by claiming that the survey measures student engagement and the student engagement is a proxy for learning, which suggests that it is learning — not educational practices — that NSSE is attempting to evaluate. But what is also being assessed is the ability of an institution to deliver an engaging education.

\section{$\underline{\text { Normalizing Practices }}$}

Even though there is resistance on the part of faculty to embrace the use of NSSE as an assessment tool, some schools are using the survey results to guide institutional reforms. As Alexander McCormick, the current director of NSSE, points out, "the surest way that an institution can teach to the test (act strategically to improve scores) is to ensure that effective educational practices are widespread" (McCormick, "Toward Reflective Accountability" 105). Such a strategy, though, also represents the college or university normalizing more and more practices. For example, Youngstown State University included the use of NSSE in their 2011-2020 strategic plan (Youngstown State University 15). At Washington State University, a program was instituted that offered curriculum improvement grants to faculty for the purpose of improving the university's benchmarks scores on student-faculty interaction and active and collaborative learning would improve. Similarly, at Hendrix College, NSSE results are being used to evaluate the success of some of its collaborative learning programs (National Survey of Student 
Engagement, New Search Tool). Finally, at the University of Calgary, a NSSE Action Team was established for the purpose of improving student success.

The mandate of the NSSE Action Team is to use the NSSE results to identify areas where the university might develop curricular, co-curricular or extracurricular strategies to improve student engagement and thereby enhance the quality of the student experience and promote student success. The team will recommend and assist in the implementation of these strategies and monitor progress towards improvement in identified areas. The goal is to ensure an institution-wide response to NSSE that addresses our overall goal of student success.

Additionally, the team will assist faculties and other units as they affect changes guided by NSSE results, and will strive to ensure that these changes are appropriately coordinated so that they contribute to the institution's overall goal (University of Calgary).

The result of this team's effort was a three-year action plan that identified four main objectives along with numerous strategies to be implemented both in the curriculum as well as in student services. The strategies were mapped to NSSE questions and improvements are to be measured by changes in NSSE results over time (University of Calgary). 
NSSE explicitly encourages campuses to offer faculty development opportunities as a strategy for changing practices. To illustrate, the 2008 NSSE annual report, Promoting Engagement for All Students: The Imperative to Look Within, highlights a program at Clemson University in which a series of activities were offered to faculty to suggest ways to incorporate diversity issues into the classroom. Clemson offered these programs because on their NSSE results students reported minimal class discussions that included diverse perspectives (race, religion, genders, political beliefs, etc.). NSSE described the effort in this way:

Preserving the classroom as a safe space for conversations on diversity is very important to the University and faculty have been offered opportunities to learn more about teaching methods to engage students in this types of discussions. In addition, workshops on other types of pedagogical strategies have been developed and offered to faculty members (23).

In this case, a university with low diversity scores was developing a way to help their faculty become more comfortable in addressing diversity-related issues in order to include more class conversations centered on issues of diversity. Such an effort reflects a move on Clemson's part to change practices in a direction consistent with what NSSE measures, potentially having a normalizing effect on faculty.

Although such programs are typically voluntary, other accountability mechanisms that encourage attendance can certainly be imaged. For example, a less than subtle way to 
get faculty to pay more attention to the practices suggested by NSSE is to build elements of it into existing practices like the teaching evaluation process. Such a strategy allows for direct intervention with individual faculty instead of a talking about the data in terms of the population without any specific requirements for the faculty. Indeed, if student evaluations matter for pay raises and promotion decisions and if faculty are motivated to improve their evaluations for those reasons, they may be more likely to attend a program that helps them do so.

This normalization of classroom practices reflects larger issues of control in the academy, one complicated by NSSE's effort to shift the conversation about collegiate quality away from reputational rankings and toward effective educational practices. Reputational rankings such as the ones produced by U.S. News certainly influence institutional decisions, but the metrics used by U.S. News are not directly tied to classroom practices. Efforts to move up in the rankings usually involved few changes in the classroom. To illustrate, student selectivity reflects how well an institution is able to recruit and enroll students in the top ten percent of their high school classes and accounts for fifteen percent of a school's U.S. News score. The reputation of academic programs, which accounts for twenty-two percent of an institution's ranking, is based on what deans of admissions, provosts, and presidents know about the schools they are evaluating. To improve their score on this metric, universities began preparing a flurry of marketing materials to be sent around the country in hopes of influencing the voting. In a final example, the financial support of alumni counts for five percent of the ranking and according to U.S. News reflects "an indirect measure of student satisfaction" (Morse and 
Flanigan, "How U.S. News Calculates the College Rankings”). Institutionally though, soliciting annual gifts translates to a campaign by the development office telling alumni directly that a contribution to the annual fund improves the school's ranking and therefore the value of their degree. This is how Carnegie Mellon University explains the importance of giving annually to their alumni on their website:

Each gift of any amount counts equally in the criteria that many publications — including U.S. News \& World Report

- use to produce annual rankings. An increase of one percentage point in CMU's alumni giving rate can make a real impact on how the university fares in these highly competitive rankings. When your alma mater is ranked highly, people notice. From attracting top students to top employers, higher rankings add real value to your CMU degree.

In other words, the institutional practices that ensure a place in the reputational rankings are far removed from the faculty and their daily routines. In challenging the rankings, NSSE has called into question the ability of institutions to improve their educational practices without any changes in the classroom. As this notion has gained momentum, faculty have come greater scrutiny and risk losing some their autonomy. Hence, at the same time that NSSE is facilitating the flow of resources into student affairs organizations, academic departments are being expected to make uniform changes in response to student assessments of the university's educational practices. In a milieu of 
accountability dominated by market forces, normalizing practices working through mechanisms such as NSSE, also, especially over the long term, privilege market forces.

\section{Critiques of NSSE}

Clare O'Farrell in her monograph, Michel Foucault, makes the point that "those who set rules regulating truth and falsity, valid and invalid knowledge and ways of acquiring knowledge are in position to exercise considerable power" (13). In the existing milieu of accountability, it is those who argue that higher education is a private good and should be governed by competitive markets alone that occupy this position. Although NSSE is embedded in this milieu of accountability and plays a role in mediating the governance of faculty and administrators by distant forces, it is not what is driving colleges and universities to compete with one another. Instead, NSSE can be viewed as a relatively fluid assessment tool capable of serving a number of purposes, including those associated with helping schools become more responsive to market forces.

Critiques of NSSE, however, generally do not focus on the power relations in which the instrument is enmeshed. Rather, most of NSSE's critiques have focused largely on technical issues with only a few addressing the conditions that empower its use. At the same time, these critiques - whether meant to be a form of resistance against the instrument or are offered for the purpose of improving NSSE's ability to measure what it says it measures - have become part of the power relations surrounding NSSE and are worth examining. Indeed, strong arguments challenging the validity and reliability of NSSE might suggest that what is valuable about the instrument is not the quality of the data it produces but its ability to normalize practices in ways that markets value. 
Several scholars critique NSSE in ways that challenge the assumptions on which it is based. For example, Adrianna Kezar, associate professor of higher education at the University of Southern California, raises questions about the demographic model of higher education NSSE presumes. She argues that NSSE assumes a robust residential experience within a stable campus community. But for many undergraduates today, Kezar notes, students are balancing multiple responsibilities - they may be taking classes at more than one institution, are working, and in some cases, have family obligations that limit the time they have to be involved on campus. As well, as the labor patterns change at many institutions and more adjunct faculty are teaching, questions related to facultystudent interaction outside of class may be unrealistic as adjuncts may not have offices or opportunities to be involved in campus life beyond the classroom (Jaschik, "Turning Surveys into Reforms").

Other scholars challenge the assumption that there is a set of educational practices that apply to all institutions and disciplines. For example, in an empirical study that challenges some of the assumptions on which NSSE is based, Brint, Cantwell, and Hannerman argue that there are no "normative conceptions of good educational practices in so far as they are considered to be equally relevant to students in all higher education institutions and all majors fields of study" (303). Perhaps in deference to the authority of the NSSE design team though, they position their effort "as an alternative approach" (386).

We wish to emphasize that our approach is not intended as a critique of NSSE or of the reform projects that NSSE has 
helped to inspire. On the contrary, in our view NSSE and the reform projects inspired by it have made a valuable contribution to American higher education. Instead, we intend to take a different look at the issue of academic engagement by starting from the ground up and by focusing on the particular learning environment of the research university (386).

Several others critique the assumption that engagement is a proxy for learning. Indeed, if the goal really is to measure learning, some argue that there are instruments that do that more precisely than NSSE and, as a result, better. For example, the Collegiate Learning Assessment (CLA) which was mentioned alongside NSSE in the Spellings Report is considered to be an exemplary learning assessment tool. The CLA was designed to evaluate "core outcomes espoused by all of higher education-critical thinking, analytical reasoning, problem-solving and writing," and the popular book, Academically Adrift is based on data generated by this instrument (Arum and Roksa 21). According to Arum and Roksa, quoted in an Inside Higher Ed article, "educational practices associated with academic rigor improved student performance, while collegiate experiences associated with social engagement did not." They make the point that it depends on your desired goals and the outcome you are trying to achieve: "if the outcome is student retention and student satisfaction, then engagement is a great strategy. If, however, you want to improve learning and enhance the academic substance of what you are up to, then it is not necessarily a good strategy" (Jaschik, "Academically Adrift"). 
Like NSSE, the CLA is also an assessment option in the Voluntary System of Accountability (VSA) although the CLA administrators seem uncomfortable being associated with it. They argue that the purpose of VSA and CLA are different: "The VSA by design focuses on assessment for accountability; the CLA, by contrast, has always been driven by a commitment to assessment for improvement. These are not wholly incompatible, but they are nevertheless distinct" (emphasis is theirs) (Benjamin, Chun and Jackson 4).

More recently, several of the scholarly critiques of NSSE have challenged the instrument on narrower technical terms, on whether it measures what it claims to measure. Some directly caution institutions about making wide-spread organizational changes based on the data. This concern was specifically articulated in "How Sound Is NSSE?: Investigating the Psychometric Properties of NSSE at a Public, ResearchExtensive Institution” by Campbell and Cabrera:

Our findings question the extent to which NSSE benchmarks are a universal tool for appraising institutional quality, and whether they predict such student outcomes as GPA. We echo Gordon, Ludlum, and Hoey’s (2008) advice to institutional researchers and policymakers. They should carefully examine the extent to which the five NSSE benchmarks are reliable and valid for their own institutional contexts before committing themselves to major organizational changes (97). 
Another study expresses concerns about the inability of the major college student surveys in use today to measure what they claim to measure and uses NSSE as the example. Stephen R. Porter in "Do college student surveys have any validity?" argues that the claims of NSSE and CIRP among others fall far short what of their construction merits. According to Porter, a widely accepted model of cognition and survey response behavior shows that students are not able to accurately respond to questions about their attitudes and behavior (3). He claims that most college student surveys have minimal validity and therefore calls into question "what we think we know about college students" (4) and in turn, "raises questions of how we measure institutional performance" (34). Porter points to the academy, attributing poorly constructed surveys to a lack of educational rigor in research methods in many graduate education programs, a demand for faculty publications and, specifically in NSSE's case, the desire for "quick fixes" to solve the challenge of assessing learning.

The promise of a survey instrument that can quickly and relatively cheaply provide an alternative to actually measuring learning has, not surprisingly been alluring to many colleges. That an instrument that fails to meet basic standards of validity and reliability has been so quickly adopted by numerous institutions indicates the desire of many institutions for a solution to this issue (72).

Even concerns that are expressed on technical grounds, though, can reflect larger issues. For example, the Association for the Study of Higher Education recently 
published an issue of their peer-reviewed journal, The Review of Higher Education, dedicated to research that questioned the methodology of NSSE, with Porter's and Cabrera and Campbell's work was included. The author of the issue's Preface, Michael A. Olivas, appeared to be motivated by more than technical concerns. The Preface, which was not peer reviewed, was titled "If you Build It, They Will Assess It (or, an Open Letter to George Kuh, with Love and Respect)." This essay had, as the title reflects, a caustic tone throughout and charges that "at least assessment and evaluation should do no harm," (3) suggesting that NSSE did not live up to this standard. The insinuation is that the knowledge NSSE producing is somehow hurting institutions who have embraced it in ways that go beyond the use of unreliable data. In a podcast interview sponsored by the Johns Hopkins University Press (publisher of the journal) after the issue was published, Olivas argued that he and all of the scholars included in the issue offered their critiques with respect to the NSSE organization. It was not, he said, "intended as an attack." In these remarks, though he also argued that NSSE is an entrepreneurial effort and a "snowballing source of data" about various sectors of higher education. He also commented that critique is part of what the academy does and "after ten years it [NSSE] doesn't get a free pass" (Olivas, Review of Higher Education). He claimed his larger objection (which he also made in his essay) was that NSSE administrators don't take the scholarly critiques and suggestions of others into account. In particular, he mentioned a frustration with the lack of minority and critical scholars cited in what Kuh and his colleague, Gary Pike, call “current research" while citing their own work multiple times. 
That the issues involved are more than purely technical is also evident in the level of consternation this biting critique caused the Association for the Study of Higher Education. As reported in The Chronicle of Higher Education in the article "Education Researchers' Group Splits Over Handling Symposium on 'Nessie' Survey,” the president of the Association, Linda Serra Hagedorn, then cancelled a conference session that was to include the director of NSSE and several of the critics of NSSE, including Porter (Schmidt). She claimed that many of the association's members objected to the special issue and "she believed the planned symposium "would have upset a lot of people" and been counterproductive. Others in the association challenged Hagedorn's decision. Six former presidents of the association sent a letter urging her to reconsider, claiming that her decision "cuts to the heart of what academic freedom is about" and limits dialogue (Schmidt).

A critique that reflected more directly some of the conditions that are empowering NSSE's use appeared as a blog response to an article by Sara Lipka titled "Researchers Criticize Reliability of National Survey of Student Engagement" in an issue of The Chronicle of Higher Education that highlighted Cabrera and Campbell's work:

To say instruments like this exist to give assessors and accrediting bodies something to do simply pushes the causal question back another link. Why do we have so many assessors and accrediting bodies? Because we have bought into the business model...for everything, every institution, every cultural expression, every domain. 
Bottom line, value-added, economic outcome--these are our rulers. At base, the issue is political (Optimysticynic).

In short, few critique NSSE in terms of its place in a larger milieu of accountability. Instead, within the academy, NSSE is seen as an assessment tool that serves traditional processes such as accreditation and as a decision-making tool for guiding improvements in practice. As a result, most critiques are aimed at that level. However, what these critiques fail to recognize are the larger forces in operation that are reshaping the practices of colleges and universities and their members.

More specifically, NSSE's original intent was to challenge the commercial rankings and change the conversation about collegiate quality. For the creators of NSSE, this meant identifying and introducing a more meaningful set of measures. The result was a focus on measures of student engagement, which they framed as a proxy for learning. This notion, rooted in a substantial body of literature, had significant appeal within the academy as a set of metrics for guiding internal improvement. At the same time, the survey reflected NSSE's sensitivity to the idea that the knowledge it produced could be used for competitive comparisons and contribute to making higher education more responsive to the market.

The use of NSSE in a milieu of accountability that governs higher education primarily through market competition has had at least two unintended consequences. First, it escalates a long-standing tension between academic units and student affairs areas. Because NSSE expands the notion of engagement to include out-of-class experiences - and because institutions begin to compete on these measures - more 
institutional resources tend to be directed toward these activities than before.

Furthermore, investing in out-of-class activities tends to do more for improving market appeal and supporting the brand than changes in the classroom. A second consequence is associated with the notion that engagement is a proxy for learning. As engagement becomes the standard for effective educational practices and a measure of institutional quality, efforts to disseminate these strategies will have a normalizing effect that erodes faculty autonomy and their role in the educational process.

It is essential to acknowledge though, that NSSE is not the driving force behind these changes occurring in higher education. Any serious critique of this landscape must step back to examine the power relations in operation. What that step back reveals is a complex milieu of accountability, where neoliberal forces are influencing policy decisions that privilege consumers and position higher education as a private good. 


\section{Chapter Six - Conclusions}

The goal of this study was to analyze what the increasing use of the National Survey of Student Engagement (NSSE) reveals about the forces shaping the direction and practices of higher education in the twenty-first century. My analysis was informed by Foucault's concept of governmentality, briefly defined as a technology of power that influences or shapes behavior from a distance. This form of governance operates through apparatuses of security, which, include higher education. Foucault identified three essential characteristics of an apparatus - the market, the milieu, and processes of normalization — through which administrative mechanisms and practices operate and govern populations. In this project, the population being governed consists of faculty and administrators at residential colleges and universities.

\section{Findings and Alternatives}

Although NSSE served as the nodal point at which I examined the heterogeneous forces operating in higher education, the issues raised have less to do with NSSE than on the milieu of accountability in which NSSE is embedded. I argue that the existing milieu of accountability is one dominated by the neoliberal assumption that all activityincluding higher education — works best when governed by market forces alone, reducing higher education to a market-mediated private good. Under these conditions, vocational aspects of education are privileged while aspects of higher education that cannot be reduced to a private good, which depend on an independent academy and public support for mechanisms that buffer the academy from market forces, are eroded. The complex social forces in operation include numerous constituencies—funding agencies, 
professional associations, governing boards, policy makers, think tanks, businesses, and student consumers - functioning on multiple levels to influence the daily practices of faculty and administrators and ultimately determining the type of education that is delivered. Furthermore, these constituencies operate in a web of relations that elicit struggle, confrontation, and resistance, which cannot be made visible by examining terminal forms of power such as sovereignty. In the end, in a milieu of accountability that privileges competitive market forces, aspects of education responsive to those forces are also privileged.

The power relations operating in higher education can be seen in the various systems for sorting and normalizing populations that have been used over time, and the same is true in the case of NSSE. The initial notion that NSSE would significantly change the conversation about how to measure collegiate quality in part by directing attention away from commercial rankings implied a challenge to the forces that empowered the rankings in the first place. This expectation for change existed because NSSE marketed its survey to the academy as a tool for assessment and internal self-improvement and made a commitment not to release data from individual schools for comparisons. In the end, though, NSSE did not challenge the larger forces and relations in operation. Instead, it became part of them, resulting in NSSE data being used to make institutions even more responsive to market forces. Ultimately, NSSE, which attempts to measure the degree to which colleges and universities are successfully engaging students, provides colleges and universities with data about how their students perceive them. In the existing milieu of accountability, colleges and universities use these data in several ways. One way is to 
provide evidence of assessment efforts that satisfies accreditation requirements. Another is to identify aspects of engagement attractive to students—including out-of-class activities - that support larger branding efforts. Furthermore, external constituencies see the use of NSSE data as a way to facilitate competitive comparisons, with the result being that the data have come to be used for a variety of comparisons, including those made by prospective students in the college selection process as well as by states as part of their accountability systems.

On another level, NSSE data are also used to alter classroom practices in an environment driven by accountability. The normalizing powers of such efforts tend to homogenize these practices and erode the autonomy of faculty in the educational process. For example, because the NSSE survey asks questions and provides measures about specific classroom activities, those activities become the expected behavior and other activities come to be seen as outside the norm. Further, it positions students, who are reporting on their classroom experiences, as part of a system of surveillance.

Again, though, the focus here is not on NSSE per se but on the larger economic, social, and political forces that are shaping higher education. To some extent, these forces have resulted in administrators making decisions that do little more than fuel the processes that are pressuring them in the first place. The daily practices of running the university have become so complex that administrative efforts are often limited to obtaining data required for compliance purposes and for shoring up the institution's competitive position, making it difficult to consider the larger consequences. For example, Fernando Delgado, a faculty member who moved to an administrative position, 
wrote in an article titled "Reflecting on Academic Labor from the Other Side" "that priorities, perspectives, and expectations are different for administrators, with faculty simply presuming that it is someone else's responsibility to ensure that there is enough budget for everyone to accomplish their tasks" (1811). In contrast, administrators are "keenly aware of the external threat" that plagues daily decision-making (1811). Along the same line, Henry Giroux argues that "the new corporate university values profit, control, and efficiency, all hallmark values of the neoliberal corporate ethic. These far outweigh considerations about pedagogy or the role of the faculty in maintaining some control over what they teach" ("Neoliberalism, Corporate Culture, and the Promise of Higher Education" 434). These tensions bring us back to Foucault's point that "power is not totally entrusted to someone who would exercise it alone, over others, in an absolute fashion; rather, this machine is one in which everyone is caught, those who exercise power as well as those who are subjected to it" (Power/Knowledge 156).

The concern, of course, is that the powerful forces in operation are eroding the aspects of higher education that contribute to society outside of the market. Those who raise this issue are often viewed as radical, idealistic, or naïve when they call attention to what is being lost when society fails to recognize the importance of educating students to participate in a democratic society, generate knowledge that challenges the status quo, and provide opportunities for the poor and disadvantaged. These voices are often marginalized, but it is from their persistent efforts that change happens.

Still, accountability matters. It is generally accepted that, especially given the current expense of attending college, there is a need for some type of accountability 
mechanism to ensure that institutions are providing a quality education. The question though lies in how accountability gets constructed. Sociologist Martin Trow frames the issue in these terms: "How can the legitimate concerns of the public regarding the cost, efficiency, and the expanded functions of higher education be reconciled with the freedom of colleges and universities to maintain their own integrity as institutions committed to teaching and learning" (115)?

Framed in another way, how might conditions in higher education be different if colleges and universities were held accountable for educating for the public good, not only in vocational terms, which markets value as well, but also in terms of non-vocational aspects of college? What if colleges and universities were evaluated based on different values? For example, how would institutional practices be altered if institutions were rewarded for the amount of financial aid they distributed to disadvantaged students? Or, what if states took their cue from the Carnegie Foundation for the Advancement of Teaching Community Engagement Program and expected institutions to demonstrate their commitment to community-identified needs through teaching, learning, and scholarship (Rhoades)? A question, of course, is whether evidence for accomplishing such initiatives has to be quantified and measured in the first place. Can we accept that the effects of such projects may be difficult, if not impossible to quantify, and recognize, as Trow points out, that "many of the gains of the college experience may not reveal themselves for many years after graduation and indeed can only be understood in terms of the whole life and career of a college graduate" (117-118). 
The response to such a challenge, as sociologist Stanley Aronowitz points out, might likely be "yeah, we've heard that before, but what makes you think any change is possible in the era of unfettered global capitalism when the forces of progressive reason have yielded even the territory of the imagination to its adversaries" (Aronowitz, Introduction 6)? Such a response is understandable given the complexity of forces at work in the existing milieu of accountability and the extent to which institutions must compete for resources. In order for organizations to survive, it would seem that decision makers have few alternatives but to play by the powerful rules of the market as currently constructed.

There are alternatives, although there is no guarantee that actions to achieve them will produce the desired effects. As Hubert Dreyfus and Paul Rabinow note, quoting Foucault: "People know what they do; they frequently know why they do what they do; but they don't know what what they do does" (187). While we never completely know the consequences of our decisions, by examining and understanding the forces in operation, we are able to see more clearly what is possible and take steps toward a different outcome. After all, what is the point of critique if it is not, in some way, used to alter practices and to offer alternatives when considering how to proceed?

This investigation suggests three alternatives to higher education's current course. The first involves challenging the neoliberal assumption that market decisions alone are sufficient for determining society's priorities. As it stands now, from a neoliberal perspective, the notion is that societal-level decisions made through a political process are never desirable, preferring instead that such decisions be determined solely by the 
market. They call for smaller government, except for government involvement that facilitates market activity. For example, it became clear in this project that the neoliberal desire to re-frame the traditional process of accreditation in market terms has influenced government efforts to improve educational quality. If successful, this effort would marginalize the academy and, may, ultimately, remove it from the process of evaluating itself. In contrast, Stanley Aronowitz, in his book Against Schooling: For an Education that Matters, asserts that we should promote a "national debate about what is to be taught and what is to be learned if citizenship and critical thought are to remain even at the level of intention, the heart of higher learning" (76). This challenge to neoliberal assumptions would not remove the role of the market as a governing force. Instead, it would allow for conversations around communal goals and responsibilities, which then enables markets to perform in support of such priorities.

A second alternative suggested by this investigation is one in which policies reward efforts by colleges and universities for activities that contribute to society- to the public good-in ways that markets might not. For example, in a market-driven milieu, a broad liberal arts education is still valued but more for the vocational benefits associated with it rather than for the development of students' intellectual curiosity. In the long term, courses not directly relevant to the development of vocational skills risk disappearing. Here too, policies and practices must be constructed through institutional commitments to buffer such lines of inquiry from market forces, enabling the curriculum to evolve in directions that educate students more broadly and not only as a producer and consumer. 
Finally, there can be an alternative to the assumption that everything can be measured in ways that allow individuals and institutions to be compared in positivist terms taken to be neutral and objective. Indeed, Foucault explicitly questioned privileging positivist knowledge over others forms of knowledge production (O’Farrell 89). In his examination of power relations, he saw quantification as often being used to legitimize and facilitate normalization by forces acting at a distance. In addition, when people attempt to quantify characteristics that cannot be easily measured, such as the effect of a teacher on a student, what is lost, in Trow's words, is what is most “important in a university - the human qualities of students and teachers, the social and psychological processes of teaching and learning and the individual and social gains and benefits [which] are beyond routine measure anyway" (124). The alternative is to embrace forms of knowledge production that illuminate effective teaching and learning without facilitating self-surveillance. For example, one way faculty can improve is simply to have another faculty member provide consultation on their teaching performance without reducing the experience to a metric that can be compared. It might even be desirable to decouple that consultation from a formal assessment. Instead, it would be an interchange between the two individuals and not part of an assessment effort implicated by larger forces and relations. This kind of knowledge production has the potential to foster effective educational practices, it does not lend itself to easy comparisons and the normalization of practices that are often the results of quantitative analyses. 


\section{Challenges and Limitations}

Using NSSE as a nodal point and governmentality as the lens through which to view the power relations working in higher education proved to be a useful way to examine the web of complex social, political, and economic forces in operation. This view provided insights into the subtle yet powerful ways that populations are governed by myriad forces — offering a perspective that would have been difficult to achieve had I explored these relationships simply from a functional perspective. Among other things, using governmentality as a lens constantly reminded me not to assign NSSE too much agency in the governing process but to focus instead on the effects of power operating in the practices of daily life.

In spite of the value of this approach, it is not a systematic or tidy method that can be executed following a step-by-step procedure. In The Long Revolution, Raymond Williams explains that the key to a useful analysis is to discover patterns and the relationships among them (63). To examine the web of forces in operation, the researcher must choose a starting point and explore the various circuits until patterns become obvious. If meaningful, those patterns should be visible from different perspectives. The analysis, or interpretation, then, becomes an iterative process of identifying and establishing the connections that exist within the web of forces in operation. Foucauldian scholars Dreyfus and Rabinow explain that "the investigator must produce a disciplined diagnosis of what has gone on and is going on in the social body to account for the shared sense of distress or well being" (200). It is a messy process that Larry Grossberg 
describes "as cartography of daily life" where the cultural theorist maps the contextual terrain:

That terrain may have many strata and pathways crossing each other; how it is mapped depends on the paths noticed, followed, the strata focused on. Some attempts will, at least for the moment, be dead ends. Others will open up rich possibilities, but their possibilities will never be obvious from the start. Something is discovered here, but its resonances, its significance for the larger map remains unclear. ... somewhere else, another discovery offers new possibilities, resolutions and questions. Each new discovery not only changes the maps that have already been drawn, but forces one into new directions to search for new sorts of evidence (63).

In this study, the numerous conceptual layers embedded in the notion of governmentality made identifying a starting point for this project a particular challenge. Initially, I tried to examine the individual components of the assemblage of power, knowledge, and subjectivity separately but quickly discovered that approach to be unproductive. All three elements are present in any power relationship and separating them distorted how the relationships could be understood. The same was also true when I tried to separate and examine the components of an apparatus of security — the market, the milieu, and the processes of normalization. These components function together and 
to remove them from that context proved unproductive as well. In the end, I left these concepts intertwined and examined the nodal point itself from several different perspectives.

Because I work in higher education, I also had the challenge of keeping my own experiences from influencing my interpretation and to focus instead on the forces and relations that were revealed. As someone who once had responsibility for administering NSSE, it was difficult not to place the focus on NSSE itself. The tendency was to want to analyze its internal workings as a functional technology rather than to view the larger forces shaping it and its use.

Another factor complicating my interpretation was the scope of the population I was considering: faculty and administrators at residential colleges and universities. By treating such a broad group as a monolith, I inevitably missed some nuanced differences between different types of institutions. An alternative, perhaps, would have been to focus on a specific type of institution such as all private colleges and universities and situate that population in the larger web of forces in operation. Another possibility, certainly one for future research, would be to investigate the governing influences of the student population in more detail. Or, to consider the population at large and examine the forces shaping behavior around going to college, providing instructions on the process, and prescribing how to think about a college education.

Finally, Stuart Hall notes that a common critique of Foucault is that too much weight is placed on discourse, which results in other factors such as the material being neglected (51). Given that I relied heavily on discourse and focused on reports, materials 
produced by NSSE, news articles, and research of others in order to construct my arguments, that critique is relevant here. Similarly, in a recent critique of governmentality titled "Post-Foucauldian Governmentality: What Does it Offer Critical Social Policy?" Kim McKee argues that an over-reliance on discursive analyses focuses more on "the rationales of governing" than on the concrete "art of governing." According to McKee, this results in "a disconnection between the study of the specific mentalities of rule and the social relations in which they are embedded" (473). She argues for "combining traditional discursive analysis with more ethnographic methods in order to render visible the concrete activity of governing, and unravel the messiness, complexity and unintended consequences involved in the struggles around subjectivity" (465). McKee frames this method as a "realist governmentality approach" arguing that it addresses a significant criticism of governmentality which is "a lack of attention to the specific situations in which the activity of governing is problematized" (478). An alternative then would have been to add an interview element to this research by talking with faculty and administrators. As McKee suggests, such efforts here would allow the researcher to better understand the faculty and administrators as subjects, able to reflect on their experiences and needs as well as on their institutional contexts and discourses (477). Focusing on discourse alone though, was a boundary I imposed in order to keep the project manageable.

\section{Implications}

In closing, I'd like to call attention to three conversations going on in higher education today that are linked to issues of educational quality. These conversations are 
of particular concern because, in the existing milieu of accountability, the issue of quality continues to privilege a system of measures that normalizes higher education in ways that will serve the market yet fails to account for teaching and learning beyond occupational outcomes. First, there are on-going debates about accreditation and the purpose it serves. The current system is seen by many as inadequate and fraught with significant problems. In fact, Robert Zemsky, author of Making Reform Work: The Case for Transforming American Higher Education argues in an Inside Higher Ed article that accreditation is too complex a system to try and reform, and "perhaps the largest problem is almost no one outside and very few inside the academy either care about or are familiar with how institutions are accredited” (“The Don’ts of Higher Ed Reform”). However, accreditation's link to financial aid and its role as a mechanism of accountability within the academy is currently seen as crucial. This analysis suggests that efforts to reform the accreditation process are being shaped by a neoliberal philosophy that calls for higher education to be made even more responsive to market forces. Advocating instead for forms of accreditation that buffer aspects of higher education from the market could facilitate more meaningful ways to address current issues plaguing the process.

Second, in this era of declining state funding for higher education, there are numerous policymakers advocating for performance-based funding for their states' institutions. In brief, as the name implies, policymakers would establish metrics for the purpose of evaluating the performance of institutions and reward them accordingly. Overall though, such efforts are often a strategy for determining how and where to reduce expenditures. This approach typically favors institutions that attract the best students and 
are able to compete on metrics such as retention and graduation rates. Schools that are at a competitive disadvantage, such as those that serve underprepared students, lose resources. This research suggests that there are consequences associated with this strategy that are unintended but not unforeseen. Over the long term, everyday practices in the academy will be re-shaped to support the metrics that are tied to this funding. Again, there needs to be a larger debate about what metrics should be part of the funding formula with aspects of the public good that are at a disadvantage in the market being included.

Third, and finally, the increasing growth of for-profit colleges and universities reinforces the notion that higher education is a private good. These institutions typically deliver a basic, career-focused education as efficiently as possible. To the extent that they compete with non-profit universities for students and federal dollars, they force all universities - except perhaps for an elite few-to compete on the same terms. While the for-profit industry has been under scrutiny for exploitive recruiting practices, they are seen by many policymakers as a viable alternative to non-profit institutions. Because these schools have greater incentives to cut anything does not support profits, they reinforce the neoliberal ideal and contribute to the process of higher education being seen solely as a private good. Given that the notion of a for-profit university is incompatible with a vision of higher education that benefits society as whole and not only individual students, using public funds to support these institutions should be questioned.

All three of these conversations can be informed by this work, which argues that the privileging of the market as a mechanism of governance is eroding what many in the academy believe is its essential purpose - to educate students broadly, to contribute new 
knowledge for the public good, and to serve as society's critic and social conscience (Washburn 227). If these values, which are essential to maintaining a civil society, are abandoned or left to be defined solely in market terms, the end result may be a less vibrant and, ultimately, a less just society. Recognizing that alternative directions are possible and wrestling with them as contingent rather than fixed is the on-going challenge. 


\section{Works Cited}

Academic Quality Improvement Program: Higher Learning Commission. Principles and Categories for Improving Academic Quality. Chicago: Higher Learning Commission, 2010. Print.

Aldeman, Chad and Kevin Carey. Ready to Assemble: Grading State Higher Education Accountability Systems. Washington: Education Sector, 2009. Print.

Altbach, Philip G., Robert O. Berdahl and Patricia J. Gumport, American Higher Education in the Twenty-First Century: Social, Political and Economic Challenges. Baltimore: Johns Hopkins UP, 2005. Print.

American Council on Education. National and International Projects on Accountability and Higher Education Outcomes. 2011. Web. 13 December 2011.

Aronowitz, Stanley. Against Schooling: For an Education that Matters. Boulder: Paradigm, 2008. Print.

Aronowitz, Stanley. Introduction. Pedagogy of Freedom: Ethics, Democracy and Civic Courage. By Paulo Freire. Trans. Patrick Clarke. New York: Lanham: Rowman and Littlefield, 1998. 1-20. Print.

Arum, Richard and Josipa Roksa. Academically Adrift: Limited Learning on College Campuses. Chicago: U of Chicago P, 2011. Print.

Arvidsson, Adam. Brands: Meaning and Value in Media Culture. London: Routledge, 2006. Print.

Association of American Colleges and Universities and Council for Higher Education Accreditation. New Leadership for Student Learning and Accountability: A 
Statement of Principles, Commitments to Action. Washington: AAC\&U and CHEA, 2008. Print.

Association of American Colleges and Universities. Our Students' Best Work: A Framework for Accountabiity Worthy of Our Mission. Washington: AAC\&U, 2004. Print.

Astin, Alexander W. "A Question About NSSE." Message to the author. 2 February 2010. Email.

—. "Student Involvement: A Developmental Theory for Higher Education." Journal of College Student Development 25 (1984): 297-308. Print.

Ball, Stephen J. "Managment as a Moral Technology: A Luddite Analysis." Foucault and Education: Disciplines and Knowledge. Ed. Stephen J. Ball. London: Routledge, 1990. 153-166. Print.

Banta, Trudy W. "Reliving the History of Large-Scale Assessment in Higher Education." Assessment Update 18.4 (2006). Web. 10 August 2009.

Baum, Sandy and Michael McPherson. "Is Education a Public Good or a Private Good?" Chronicle of Higher Education. Chronicle, 18 January 2011. Web. 18 January 2011.

Benjamin, Roger, Marc Chun and Chris Jackson. The College Learning Assessment's Place in the New Assessment and Accountability Space. Council for Aid to Education, Council, 5 January 2009. Web. 16 October 2011. 
Benton, Guy P., ed. Transactions and Proceedings of the National Association of State Universities in the United States of America, August 30-31, 1915: Twentieth Annual Meeting. Burlington: Free Press, 1915. Print.

Benton, Thomas H. "A Perfect Storm in Undergraduate Education, Part 2." Chronicle of Higher Education. Chronicle, 11 April 2011. Web. 11 April 2011.

Berk, Ronald A. "Survey of 12 Strategies to Measure Teaching Effectiveness." International Journal of Teaching and Learning in Higher Education 17.1 (2005): 48-62. Print.

Birnbaum, Robert. Management Fads in Higher Education: Where They Come From, What They Do, Why They Fail. San Francisco: Jossey-Bass, 2000. Print.

Bok, Derek. Our Underachieving Colleges: A Candid Look at How Much Students Learn and Why They Should be Learning More. Princeton: Princeton UP, 2006. Print.

-. Universities in the Marketplace: The Commercialization of Higher Education. Princeton: Princeton UP, 2003. Print.

Bowen, Roger W. "Institutional Autonomy, Academic Freedom, and Academic Responsibility." Montana Professor. Montana State U—Northern, Fall 2006. Web.16 December 2011.

Bowen, Stephen. "Engaged Learning: Are We All on the Same Page?" Peer Review 7.2 (2005): 4-7. Print.

Boyer, Ernest L. College: The Undergraduate Experience in America. New York: Harper, 1987. Print. 
Bratich, Jack Z., Jeremy Packer and Cameron McCarthy, Foucault, Cultural Studies and Governmentality. Albany: State U of New York P, 2003. Print.

Brint, Steven, Allison M. Cantwell and Robert A. Hannerman. "Two Cultures: Undergraduate Academic Engagement." Research in Higher Education 49.5 (2008): 383-402. Print.

Brubacher, John S. and Willis Rudy. Higher Education in Transition. 4th ed. New Brunswick: Transaction, 1997. Print.

Bullough, Robert V. "Professional Learning Communities and the Eight-Year Study." Educational Horizons 85.3 (2007): 168-180. Print.

Cahn, Steven M. Saints and Scamps: Ethics in Academia. Rev. ed. Lanham: Rowman and Littlefield, 1994. Print.

Calderón, Sara Inés. "Inigral’s Schools Application Customizes Facebook for Universities." Inside Facebook. WebMedia Brands Inc., 28 December 2008. Web. 17 December 2011.

Campbell, Corbin M. and Alberto Cabrera. "How Sound Is NSSE?: Investigating the Psychometric Properties of NSSE at a Public, Research-Extensive Institution." The Review of Higher Education 35.1 (2011): 77-103. Print.

Campbell, Donald T. "Ethnocentrism of Disciplines and the Fish-Scale Model of Omniscience." Sherif, Muzafer and Carolyn W. Sherif. Interdisciplinary Relationships in the Social Sciences. Piscataway: Aldine Transaction, 2009. 328348. Print. 
Carey, Kevin and Chad Aldeman. Ready to Assemble: A Model State Higher Education Accountability System. Washington: Education Sector, 2008. Print.

Carnegie Commission on Higher Education. Dissent and Disruption: Proposals for Consideration by the Campus. New York: McGraw, 1971. Print.

—. New Students and New Places: Policies for the Future Growth and Development of American Higher Education. New York: McGraw, 1971. Print.

Carnegie Foundation for the Advancement of Teaching. "Carnegie Selects Colleges and Universities for 2010 Community Engagement Classification." Carnegie Foundation. January 2011. Web. 17 December 2011.

Carnegie Mellon University. "Can Alumni Help Increase CMU's Ranking?" Carnegie Mellon, Web. 30 November 2011.

Cartter, Allan M. An Assessment of Quality in Graduate Education. Washington: ACE, 1966. Print.

Chickering, Arthur W. and Zelda F. Gamson. "Seven Principles for Good Practice in Undergraduate Education." AAHE Bulletin 39.3 (1987): 3-7. Print.

Christensen, Lars Thoger and George Cheney. "Self-Absorption and Self-Seduction in the Coporate Identity Game." The Expressive Organization: Linking Identity, Reputation, and the Corporate Brand. Ed. Majken Schultz, Mary Jo Hatch and Mogens Holton Larsen. Oxford: Oxford UP, 2000. 246-270. Print.

Chronicle of Higher Education. "Journal Names More Than 80 People as Leaders in Higher Education." Chronicle of Higher Education. Chronicle, 30 January 1998. Web. 17 October 2011. 
Coddington, Ron, Anthony DeBarros and Chad Palmer. "Searching for Signs of Engagement." USA Today. USA Today, 4 December 2009. Web. 18 December 2011.

Cohen, Arthur M. and Carrie B. Kisker. The Shaping of American Higher Education: Emergency and Growth of the Contemporary System. 2nd ed. San Francisco: Jossey-Bass, 2010. Print.

Cohen, Todd. National Research Report Lauds KU for 'Effective Educational Practices'. Lawrence: U of Kansas, 22 April 2004. Web. 16 December 2011.

Cole, Jonathan R. The Great American University. New York: Public Affairs, 2009. Print.

College Student Experiences Questionnaire (CSEQ). Pace, C. Robert and George D. Kuh. 4th ed. Bloomington: Indiana U, 1998. Print.

Conant, James B. My Several Lives: Memoirs of a Social Inventor. New York: Harper, 1970. Print.

Dean, Mitchell. Governmentality: Power and Rule in Modern Society. Los Angeles: Sage, 1999. Print.

Deflem, Mathieu. Power/Knowledge, Society and Truth: Notes on the Work of Michel Foucault. Unpublished paper. April 1999. Web. 14 April 2010.

Delgado, Fernando. "Reflecting on Academic Labor from the Other Side." International Journal of Communications 5 (2011): 1808-1814. Print. 
DePaul University. "Data Points: National Survey of Student Engagement (NSSE) Demonstrates DePaul's Impact on Understanding of Diversity." DePaul, Web. 11 December 2011.

Dolan, Patrick W. The Rankings Game: The Power of the Academic Elite. Lincoln: Evaluation of Higher Education Committee of the Study Commission on Undergraduate Education and the Education of Teachers, 1976. Print.

Dreyfus, Hubert L. and Paul Rabinow. Michel Foucault: Beyond Structuralism and Hermeneutics. Chicago: U of Chicago P, 1982. Print.

Driscoll, Amy. "Carnegie's Community Engagement Classification: Intentions and Insights." Change January/February 2008: 38-41. Print.

Eaton, Judith. "Accreditation 2.0." Inside Higher Ed. Inside Higer Ed, 18 January 2010: Web. 18 January 2010.

—. "Accreditation and the Federal Future of Higher Education." Academe Online. AAUP, September-October 2010. Web.10 September 2011.

-. An Overview of US Accreditation. Washington: CHEA, 2009. Print.

Edgerton, Russell and Peter Ewell. Invitation letter to Fredrick Dobney to participate in the first annual National Survey of Student Engagement. 21 September 1999. TS. Business file of the author. Houghton.

Edler, Frank H. W. How Accreditation Agencies are Pushing Total Quality Management: A Faculty Review of the Academic Quality Improvement Program (AQIP). Unpublished paper. 2003. Web. 30 July 2009. 
Finkin, Matthew W. "The Unfolding Tendency in the Federal Relationship to Private Accreditation in Higher Education." Law and Contemporary Problems 57.4 (1994): 89-120. Print.

Fish, Stanley. "Neoliberalism and Higher Education." New York Times. NYT, 8 March 2009: Web. 31 January 2010.

Flexner, Abraham. Medical Education in the United States and Canada. Boston: Merrymount Press, 1910. Print.

—. The American College: A Criticism. New York: Century Co., 1908. Print.

Forest, James J.F. and Kevin Kinser. Higher Education in the United States. Santa Barbara: ABC-CLIO, 2002. Print.

Foucault, Michel. Discipline and Punish: The Birth of the Prison. New York: Vinatage Books, 1977. Print.

—. "Governmentality." The Foucault Effect: Studies in Governmentality. Ed. Graham Burchell, Colin Gordon and Peter Miller. Chicago: U of Chicago P, 1991. 87-104. Print.

—. Power. Ed. James D. Faubion. New York: New Press, 2000. Print.

—. Power/Knowledge: Selected Interviews and Other Writings, 1972-1977. Ed. Colin Gordon. New York: Pantheon Books, 1980. Print.

—. Security, Territory, and Population: Lectures at the College de France, 1977-1978. New York: Picador, 2007. Print.

—. The History of Sexuality, Volume I: An Introduction. New York: Vintage Books, 1978. Print. 
Giroux, Henry A. "Academic Unfreedom in America: Rethinking the University as a Democratic Public Sphere." Works and Days 26 and 27 (2008-09): 45-71. Print.

—. "Higher Education Under Siege: Implications for Public Intellectuals." The NEA Higher Education Journal: Thought and Action 22 (2006): 63-78. Print.

—. "Neoliberalism, Corporate Culture, and the Promise of Higher Education: The University in the Democratic Public Sphere." Harvard Educational Review 72.4 (2002): 425-464. Print.

Gladieux, Lawrence E. and Thomas R. Wolanin. Congress and the Colleges. Lexington: D. C. Heath and Company, 1976. Print.

Glenny, Lyman A. and Thomas K. Dalglish. Public Universities, State Agencies, and the Law: Constituional Autonomy in Decline. Berkeley: Center for Research and Development in Higher Education, 1973. Print.

Goral, Tim. Commission Report Leaves Higher Ed Questions Unanswered. Rersource Library, September 2006. Web. 13 September 2010.

Gordon, Colin. "Governmental Rationality: An Introduction." The Foucault Effect: Studies in Governmentality. Ed. Graham Burchell, Colin Gordon and Peter Miller. Chicago: U of Chicago P, 1991. 2- 51. Print.

Gourman, Jack. The Gourman Report: Ratings of American Colleges. Phoenix: Continuing Education Institute, 1967. Print. Gray, Andrew and Stephen Harrison. Governing Medicine: Theory and Practice. Berkshire: Open UP, 2004. Print. 
Greenberg, Milton. "The GI Bill of Rights: Changing the Social, Economic Landscape of the United States." International Information Programs: U.S. Dept. of State. 3 April 2008. Web. 13 October 2010.

—. "What Administrators Should Know About Accreditation." Chronicle of Higher Education. Chronicle, 26 October 2001. Web. 10 September 2011.

Grossberg, Lawrence. We Gotta Get Out of This Place: Popular Conservatism and Postmodern Culture. New York: Routledge, 1992. Print.

Haas, Eric. "False Equivalency: Think Tank References on Education in the News Media." Peabody Journal of Education 82.1 (2007): 63-102. Print.

Hall, Stuart ed. Representation: Cultural Representations and Signifying Practices. Thousand Oaks: Sage with Open UP, 1997. Print.

Harland, Tony. "The University, Neoliberal Reform and the Liberal Educational Ideal." Tight, Malcom, et al. The Routledge International Handbook of Higher Education. New York: Routledge, 2009. 511-521. Print.

Harvey, David. A Brief History of Neoliberalism. New York: Oxford UP., 2005. Print. Hawes, Gene R. Hawes Comprehensive Guide to Colleges. New York: New American Library, 1978.Print.

Hawthorne, Joan. "Accountability and Comparability: What's Wrong with the VSA Approach?" Liberal Education 94.2 (2008): 24-29. Print.

Hazelkorn, Ellen. "Questions Abound as the College-Rankings Race Goes Global." Chronicle of Higher Education. Chronicle, 13 March 2011. Web. 10 September 2011. 
Heritage Foundation. "About." Web. 10 December 2011.

Higher Education Act of 1965. "Pub. L. No. 89-329; 79 Stat.1236." 8 November 1965. Web. 10 December 2011.

Higher Learning Commission. Criteria for Accreditation. HLC, 2011. Web. 17

December 2011.

—. Dues and Schedule for 2011-2012. HLC, 24 June 2011. Web. 17 December 2011.

Hirt, Joan B. "The Student Affairs Profession in the Academic Marketplace." NASPA Journal 44.2 (2007): 245-264. Print.

Hoecht, Andreas. "Quality Assurance in UK Higher Education: Issues of Trust, Control, Professional Autonomy, and Accountability." Higher Education 51.4 (2006): 541563. Print.

Hossler, Don and Erin M. Foley. "Reducing the Noise in the College Choice Process: The Use of College Guidebooks and Ratings." New Directions for Institutional Research 88 (1995): 21-30. Print.

Howe, Neil and William Strauss. Millennials Go to College. Great Falls: LifeCourse Associates, 2007. Print.

Hughes, Raymond M. A Study of the Graduate Schools of America. Oxford: Miami University, 1925. Print.

IBM. IBM 805 Test Scoring Machine. IMB Archives. Web. 23 October 2010.

Immerwahr, John and Jean Johnson. Squeeze Play 2009: The Public's View on College Costs Today. Washington: Public Agenda and The National Center for Public Policy and Higher Education, 2009. Print. 
Immerwahr, John, Jean Johnson and Paul Gasbarra. Campus Commons? What Faculty, Financial Officers, and Others Think About Controlling College Costs. Washington: Public Agenda, 2009. Print.

Jaschik, Scott. "'Academically Adrift'." Inside Higher Ed. Inside Higher Ed, 18 January 2011. Web. 10 December 2011.

—. "Turning Surveys into Reforms." Inside Higher Ed. Inside Higher Ed, 26 October 2009. Web. 10 December 2011.

Johnson, Davi. "Psychiatric Power: The Post-Museum as a Site of Pehtorical Alignment." Communication and Critical/Cultural Studies 5.4 (2008): 344-362. Print.

Kantrowitz, Mark. The SmartStudent Guide to Financial Aid: Tuition Inflation. Fin Aid!, 2010. Web. 16 October 2010.

Katz, Joseph. "Personality and Interpersonal Relations in the College Classroom." The American College: A Psychological and Social Interpretation of the Higher Learning. Ed. Nevitt Sanford. New York: John Wiley and Sons, 1962. 365-395. Print.

Kelderman, Eric. "Under Obama, Accreditors Are Still in the Hot Seat." Chronicle of Higher Education. Chronicle, 12 September 2010 Web. 18 January 2010.

Kelly, Andrew P. and Chad Aldeman. False Fronts? Behaind Higher Education's Voluntary Accountability Systems. Washington: Education Sector and American Enterprise Institute, 2010. Print.

Kementz, Anna. DIY U: Edupunks, Edupreneurs, and the Coming Transformation of Higher Education. White River Junction: Chelsea Green, 2010. Print. 
Kennedy, Edward M. Senator Kennedy Testifies on Reducing the Voting Age to 18 by Statute. Washington: Office of Senator Edward M. Kennedy of Massachusetts, 9 March 1970. Print.

Kentucky Council on Postsecondary Education. NSSE 2005 Benchmark Summary Report. Kentucky Public Four-Year Universities. 2006. Print.

Kerr, Clark. The Uses of the University. Cambridge: Harvard UP, 2001. Print.

Kezar, Adrianna J. "Creating a Metamovement: A Vision Toward Regaining the Public Social Charter." Higher Education for the Public Good. Ed. Adrianna J. Kezar, Tony C. Chambers, and John C. Burkhardt. San Francisco: Jossey-Bass, 2005. 4354. Print.

King, Stephen. "Brand Building in the 1990s." Revealing the Corporation. Ed. John M.T. Balmer and Stephen A.Greyser. New York: Routledge, 2003. 259-271. Print.

Kirp, David L. Shakespeare, Einstein, and the Bottom Line: The Marketing of Higher Education. Cambridge: Harvard UP, 2003. Print.

Klein, Naomi. No Logo. New York: Picador, 2000. Print.

Kuh, George D. and Stanley Ikenberry. More Than You Think, Less Than We Need: Learning Outcomes Assessment in American Higher Education. Urbana: University of Illinois and Indiana University, National Institute for Learning Outcomes Assessment, 2009. Print.

Kuh, George D. High-Impact Educational Practices: What They Are, Who Has Access to Them, and Why They Matter. Washington: AAC\&U, 2008. Print. 
—. "The National Survey of Student Engagement: Conceptual and Empirical Foundations." New Directions for Institutional Research 141 (2009): 5-20. Print.

—. "What We're Learning About Student Engagement from NSSE: Benchmarks for Effective Educational Practices." Change 35.2 (2003): 24-32. Print.

Kuh, George D., et al. Involving Colleges: Successful Approaches to Fostering Student Learning and Devemlopment Outside the Classroom. San Francisco: Jossey-Bass, 1991. Print.

—. Student Success in College: Creating Conditions that Matter. San Francisco: JosseyBass, 2005. Print.

Lather, Patti. "Scientific Research in Education: A Critical Perspective." British Educational Research Journal 30.6 (2004): 759-772. Print.

Lawrence, Judith K. and Kenneth C. Green. A Question of Quality: The Higher Education Ratings Game. Washington: AAHE and ERIC Clearinghouse on Higher Education, 1980. Print.

Lederman, Doug. "Assessing the Assessments." Inside Higher Ed, Inside Higher Ed, 5 November 2009. Web. 5 November 2009.

—. "Defining Accountability." Inside Higher Ed, Inside Higher Ed,18 November 2009. Web. 18 November 2009.

—. "More Meaningful Accreditation." Inside Higher E. Inside Higher Ed, 22 April 2009. Web. 22 April 2009.

—. "Whither Accreditation?" Inside Higher Ed. Inside Higher Ed, 28 January 2009. Web. 28 January 2009. 
Lee, Stephanie. "Making Student Engagement Official." Inside Higher Ed. Inside Higher Ed, 23 July 2009. Web. 23 July 2009.

Lemann, Nicholas. The Big Test: The Secret History of the American Meritocracy. New York: Farrar, Straus, and Giroux, 1999. Print.

Lemke, Thomas. "The Birth of Bio-Politics - Michel Foucault's Lecture at the Collège de France on Neo-Liberal Governmentality." Economy and Society 30.2 (2001): 190207. Print.

Lipka, Sara. "Researchers Criticize Reliability of National Survey of Student Engagement." Chronicle of Higher Education. Chronicle, 18 November 2010. Web. 18 November 2010.

—. "Want Data? Ask Students. Again and Again." Chronicle of Higher Education 12 August 2011: 1, 6A. Print.

—. "It's Not How Much Student Data You Have, but How You Use It." Chronicle of Higher Education. Chronicle, 4 November 2010.Web. 19 November 2011.

London, Scott. Higher Education for the Public Good: A Report from the National Leadership Dialogues. Ann Arbor: National Forum on Higher Education for the Public Good, 2003. Print.

Longwood University. Longwood University Among Few Chosen for National Education Study. 8 October 2002. Web. 20 December 2011.

Machung, Anne. "Playing the Rankings Game." Change 30.4 (1998): 12-16. Print. 
Marklein, Mary Beth. "A Laboratory of Learning to Helps Students Thrive: Student Engagement Survey Changes How Colleges Judge Success, Identify Weaknesses." USA Today 9 November 2009: 4D. Print.

—. "Mary Beth Marklein's Page." USAToday. 4 December 2009. Web. 18 December 2011.

—. "NSSE Changes How Colleges Judge Success, Weakness." USA Today. 6 January 2010. Web. 6 January 2010.

Markula, Pirkko. "Governing Obese Bodies in a Control Society." Junctures: The Journal for Thematic Dialogue 11 (2008): 53-65. Print.

Marshall, James D. "Foucault and Educational Research." Foucault and Education: Disciplines and Knowledge. Ed. Stephen Ball. New York: Routledge, 1990. 1128. Print.

Martinez, Elizabeth and Arnoldo Garcia. What is Neoliberalism? CorpWatch, Web. 28 March 2009.

Massy, William F. "Auditing Higher Education to Improve Quality." Chronicle of Higher Education, Chronicle, 20 June 2003. Web. 18 January 2010.

McCormick, Alexander C. and Chun-Mei Zhao. "Rethinking and Reframing the Carnegie Classification." Change 37.5 (2005): 51-57. Print.

McCormick, Alexander C. "Toward Reflective Accountability: Using NSSE for Accountability and Transparency." New Directions for Institutional Research 141 (2009). Print. 
McDonough, Patricia M., et al. "College Rankings: Democratized College Knowledge for Whom?" Research in Higher Education 39.5 (1998): 513-537. Print.

McGann, James G. Think Tanks and Policy Advice in the U.S. Philadelphia: Foreign Policy Research Institute. 2005. Print.

McKeachie, Wilbert J. "Student Ratings: The Validity of Use." American Psychologist 52 (1997): 1218-1225. Print.

McKee, Kim. "Post-Foucauldian Governmentality: What Does It Offer Critical Social Policy? " Critical Social Policy. 29 (2009): 465-486. Print.

Miller, Peter and Nikolas Rose. Governing the Present. Cambridge: Polity Press, 2008. Print.

Mitcham, Carl. Think Through Technology: The Pathe between Engineering and Philosophy. Chicago: U of Chicago P, 1994. Print.

Moffatt, Michael. Coming of Age in New Jersey: College and American Culture. New Brunswick: Rutgers UP, 1989. Print.

Molotch, Harvey. Where Stuff Comes From: How Toasters, Toilets, Cars, Computers, and Many Other Things Come to Be as They Are. New York: Routledge, 2003. Print.

Morley, Louise. Quality and Power in Higher Education. Philadelphia: Society for Research into Higher Education and Open University Press, 2003. Print. Morrill Federal Land Grant Act of 1862. "Pub. L. 37-108. Stat. 503." 2 July 1862.Web. 11 August 2010. 
Morse, Robert and Sam Flanigan. "How U.S. News Calculates the College Rankings." U.S. News \& World Report. U.S. News, 12 September 2011. Web. 1 September 2010.

—. "How We Calculate the Rankings." U.S. News \& World Report. U.S. News, 23 February 2009. Web. 11 December 2010.

Morse, Robert. "Higher Education Falls Short in Efforts to Become More Accountable." U.S. News \& World Report. U.S. News, 11 March 2010. Web. 11 December 2011.

—. "The Birth of College Rankings: How "Best Colleges" Became the Top Source for Information on Higher Education." U.S. News \& World Report. U.S. News, 31 January 2009. Web. 17 December 2011.

Nadesan, Majia Holmer. Governmentality, Biopower, and Everyday Life. New York: Routledge, 2008. Print.

National Association of Independent Colleges and Universities. University and College Accountability Network (U-CAN). National Association of Independent Colleges and Universities, 2009. Web. 16 December 2011.

National Center for Education Statistics. Collge Navigator. Institute of Education Sciences, 2011. Web. 16 December 2011.

National Center for Public Policy and Higher Education. Measuring Up 2008: The National Report Card on Higher Education. San Jose: National Center for Public Policy and Higher Education, 2008. Print. 
National Institute of Standards and Technology. Baldrige Performance Excellence Program. NIST,17 February 2010. Web. 16 December 2011.

National Survey of Student Engagement. Tips for Your NSSE Survey Administration. Bloomington: Indiana University Center for Postsecondary Research, n.d. Print. —. "About NSSE." Indiana University Center for Postsecondary Research, 2011. Web. 24 January 2009.

—. Accreditation Toolkit: Mapped to 2009 NSSE Survey Questions, Higher Learning Commission - North Central Association (HLC-NCA). Bloomington: Indiana University Center for Postsecondary Research, February 2009. Print —.Assessment for Improvement: Tracking Student Engagement Over Time.

Bloomington: Indiana University Center for Postsecondary Research, 2009. Print.

—. Benchmark Comparisons Report. Bloomington: Indiana University Center for Postsecondary Research, August 2009. Print.

-. Benchmarks of Effective Educational Practice. Bloomington: Indiana University Center for Postsecondary Research, n.d. Print.

—. College Student Report. Bloomington: Indiana University, 2008. Print.

-. Converting Data into Action: Expanding Boundaries of Institutional Improvement.

Bloomington: Indiana University Center for Postsecondary Research, 2003. Print. —. Cost of Survey Participation Indiana University Center for Postsecondary Research, 2011. Web. 24 January 2009.

-. Experiences that Matter: Enhancing Student Learning and Success. Bloomington: Indiana University Center for Postsecondary Research, 2007. Print. 
—. Frequency Distributions Report. Indiana University Center for Postsecondary

Research, August 2009. Web. 24 January 2009.

—. Major Differences: Examining Student Engagement by Field of Study. Bloomington:

Indiana University Center for Postsecondary Research, 2010. Print.

-. National Survey of Student Engagement: Tenth Anniversary Report. Bloomington:

Indiana University Center for Postsecondary Research, 2009. Print.

—.New Search Tool for Examples of NSSE, FSSE, and BCSSE Data Use. Indiana

University Center for Postsecondary Research, 2011. Web. 21 December 2011.

—. NSSE Position Statement: Public Disclosure of Student Engagement Results. Indiana

University Center for Postsecondary Research, August 2009. Web. 24 January 2009.

—. NSSE Regional Accreditation Toolkits. Indiana University Center for Postsecondary Research, 2011. Web. 17 December 2011.

—. NSSE Report Builder. Indiana University Center for Postsecondary Research, 24

October 2010. Web. 17 December 2011.

—. Our Origins and Potential. Indiana University Center for Postsecondary Research,.

24 January 2009. Web. 17 December 2011.

—.Pocket Guide to Choosing a College: Questions to Ask on your College Visits.

Bloomington: Indiana University Center for Postsecondary Research, n.d. Print.

-. Promoting Engagement for All Students: The Imperative to Look Within.

Bloomington: Indiana University Center for Postsecondary Research, 2008. Print. 
-. University of Ontario Institute of Technology Poster. Indiana University Center for Postsecondary Research, n.d. Web. 21 December 2011 <http://nsse.iub.edu/institute/images/promo/UOIT_poster.pdf>.

—. University of Wisconsin, LaCrosse. Indiana University Center for Postsecondary Research, n.d. Web. 21 December 2011 <http://nsse.iub.edu/institute/images/promo/UWi_Lacrosse_poster.pdf>. —. Using NSSE Data. Bloomington: Indiana University Center for Postsecondary Research. n.d. Print.

—. Working with NSSE Data: A Facilitator's Guide. Bloomington: Indiana University Center for Postsecondary Education, 2008. Print.

Neal, Anne D. Why Accreditation Doesn't Work and What Policymakers Can Do About It. Washington: American Council of Trustees and Alumni, 2007. Print. Noble, David F. American by Design: Science, Technology, and the Rise of Corporate Capitalism. New York: Oxford UP, 1977. Print.

O'Farrell, Clare. Michel Foucault. Thousand Oaks: Sage, 2005. Print.

Old Dominion University. Advertisement. Chronicle of Higher Education 3 June 2011: A77. Print.

Olins, Wally. "How Brands are Taking Over the Corporation." The Expressive Organization: Linking Identity, Reputation, and the Corporate Brand. Ed. Majken Schultz, Mary Jo Hatch and Mogens Holton Larsen. Oxford: OU Press, 2000. 5165. Print. 
Olivas, Michael A. "If You Build It, They Will Assess It (or an Open Letter to George Kuh with Love and Respect." Review of Higher Education 35.1 (2011): 1-15. Print.

—. Review of Higher Education. Johns Hopkins UP, 29 September 2011. Podcast.

Pace, C. Robert. "Recollections and Reflections." Higher Education: Handbook of Theory and Research. Volume XIII. Ed. John C. Smart. Bronx: Agatha Press, 1998. 1-34. Print.

Pace, Diana, Kathleen M. Blumreich and Bart H. Merkle. "Increasing Collaboration between Student and Academic Affairs: Application of the Intergroup Dialogue Model." NASPA Journal 43.2 (2006): 301-515. Print.

Packer, Jeremy. "Mapping the Intersections of Foucault and Cultural Studies." Foucault, Cultural Studies, and Governmentality. Ed. Jack Z. Bratich, Jeremy Packer and Cameron McCarthy. Albany: State U of New York P, 2003. 23-46. Print.

Pascarella, Ernest T. and Patrick T. Terenzini. How College Affects Students: Findings and Insights from Twenty Years of Research. San Francisco: Jossey-Bass , 1991. Print.

Porter, Stephen R. "Do College Student Surveys Have Any Validity?" The Review of Higher Education 35.1 (2011): 45-76. Print.

Pulley, John L. "Romancing the Brand." Chronicle of Higher Education. Chronicle, 24 October 2003. Web. 17 December 2011.

Rabinow, Paul, ed. The Foucault Reader. New York: Pantheon Books, 1984. Print. Readings, Bill. The University in Ruins. Cambridge: Harvard UP, 1996. Print. 
Rhoades, Gary. "Carnegie, Dupont Circle and the AAUP: (Re)Shaping a Cosmopolitan, Locally Engaged Professoriate." Change January-February 2009: 8-15. Print.

Riesman, David. On Higher Education: The Academic Enterprise in an Era of Rising Student Consumerism. New Brunswick: Transaction, 1998. Print.

Rose, Nikolas. "Governing "Advanced" Liberal Democracies." Foucault and Political Reason. Ed. Andrew Barry, Thomas Osborne, Nikolas Rose. Chicago: U of Chicago P, 1996. 37-63. Print.

- Governing the Soul: The Shaping of the Private Self. London: Free Association Books, 1989. Print.

—. "Government, Authority and Expertise in Advanced Liberalism." Economy and Society 22.3 (1993): 283-299. Print.

—. Powers of Freedom. London: Cambridge UP, 1999.

Rose, Nikolas, Pat O'Malley and Mariana Valverde. "Governmentality." Annual Review of Law and Social Science 2 (2006): 83-104. Print.

Ruben, Brent D., Laurie Lewis and Louise Sandmeyer. Assessing the Impact of the Spellings Commission. Washington: National Association of College and University Business Officers, 2008. Print.

Rudolph, Frederick. The American College and University: A History. Athens: U of Georgia P, 1990. Print.

Sanford, Nevitt. "Higher Education as a Field of Study." The American College: A Psychological and Social Interpretation of the Higher Learning. Ed. Nevitt Sanford. New York: John Wiley and Sons, 1962. 31-73. Print. 
Sauder, Michael and Wendy Nelson Espeland. "The Discipline of Rankings: Tight Coupling and Oragnizational Change." American Sociological Review 74 (2009): 63-82. Print.

Sawyer, Ralph A. "Rating Graduate Schools." Physics Today (August 1966): 75-76. Print.

Schmidt, Peter. "Education Researchers Group Splits Over Handling of Symposium on 'Nessie' Survey." Chronicle of Higher Education. Chronicle, 6 October 2011. Web. 6 October 2011.

Schray, Vickie. Assuring Quality in Higher Education: Key Issues and Questions for Changing Accreditation in the United States. Issue paper to inform the work of the Spellings Commission, 2006. Web. 28 December 2010.

Selingo, Jeffrey. "A Self-Published College Guide Goes Big Time, and Educators Cry Foul." Chronicle of Higher Education. Chronicle, 7 November 1997. Web. 15 July 2010.

Sevier, Robert A. Brand as Relevance. Cedar Rapids: STAMATS, 2000. Print.

Shanteau, James, et al. "Performance-Based Assessment of Expertise: How to Decide if Someone is an Expert or Not." European Journal of Operational Research 136 (2002): 253-263. Print.

Simola, Hannu, Sakari Heikkinen and Jussi Silvonen. "A Catalog of Possibilities: Foucaultian History of Truth and Education Research." Foucault's Challenge. Ed. Thomas S. Popkewitz and Marie Brennan. New York: Teacher's College Press, 1998. 64-90. Print. 
Slack, Jenifer. "Contextualizing Technology." Rethinking Communication. Ed. Brenda Dervin, Lawrence Grossberg, Barbara J. O’Keefe and Ellen Wartella. Newbury Park: Sage Publications, 1989. 329-345. Print.

Slate, Audrey N. The Association of Graduate Schools in the Association of American Universities. Astin: U of Texas at Austin, 1994. Print.

Slaughter, Shelia and Gary Rhoades. Academic Capitalism and the New Economy: Markets, State, and Higher Education. Baltimore: Johns Hopkins UP, 2004. Print.

Soares, Louis. Putting the Customer First in College: Why We Need an Office of Consumer Protection in Higher Education. Washington: Center for American Progress, 2009. Print.

Spellings, Margaret. A Test of Leadership: Charting the Future of U.S. Higher Education. Washington: U.S. Department of Education, 2006. Print. State Higher Eudcation Executive Officers. Accountability for Better Results: A National Imperative for Higher Education. Boulder: State Higher Eudcation Executive Officers, 2005. Print.

Stecklow, Steve. "Colleges Inflate SATs and Graduation Rates in Popular Guidebooks: Schools Say They Must Fib to U.S. News and Others to Compete Effectively" Wall Street Journal 5 April 1995, Eastern Edition ed.: 1, 8A. Print.

Stewart, Campbell. "The Place of Higher Education in a Changing Society." The American College: A Pyschological and Social Interpretation of the Higher Learning. Ed. Nevitt Snaford. New York: John Wiley and Sons, 1962. 894-939. Print. 
Study Group on the Conditions of Excellence in American Higher Education. Involvement in Learning: Realizing the Potential of American Higher Education. Final Report. Washington: National Institue of Education, 1984. Print.

Thacker, Lloyd, ed. College Unranked: Ending the College Admissions Frenzy. Cambridge: Harvard University Press, 2004. Print.

Trow, Martin. "The Public and Private Lives of Higher Education." Daedalus 104.1 (1975): 113-127. Print.

Tuchman, Gaye. Wannabe U: Inside the Corporate University. Chicago: U of Chicago P, 2009. Print.

U.S. Census Bureau. "Statistical Abstract of the United States: 20th Century Statistics 867. Section 31." 1999. 876. Print.

U.S. News Staff. "About the National Survey of Student Engagement: Seniors Have Their Say." U.S. News \& World Report, U.S. News, 17 October 2008. Web. 18 December 2011.

United States Dept. of Commerce and Labor. "The National Bureau of Standards." Washington: GPO, 1911. Print.

University of Calgary. "Undergraduate Student Engagement 3-Year Action Plan: Four Areas of Focus Rubric." NSSE Action Team. 11 February 2011. Web. 21 December $2011<$ http://www.ucalgary.ca/nsse/files/nsse/3yearactionplanFeb142011.pdf>. 
University of Maryland Libraries. Collections by Subject: Vietnam-Era Protest Activities on the University of Maryland, College Park, Campus. 2007. Web. 14 October 2010 <http://digital.lib.umd.edu/archivesum/rguide/viet.jsp>.

USA Today. Searching for Signs of Engagement. USA Today, 4 December 2009. Web. 22 December 2011.

Voluntary System of Accountability. College Portrait. Association of Public Land-Grant Universities and American Association of State Colleges and Universities, 2011. Web. 16 December 2011.

Washburn, Jennifer. University Inc: The Corporate Corruption of Higher Education. New York: Basic Books, 2005. Print.

Webster, David S. "The Bureau of Education's Suppressed Ratings of Colleges 19111912." History of Education Quarterly 24.4 (1984): 499-511. Print.

Wehlburg, Catherine M. Promoting Intergrated and Transformative Assessment. San Francisco: Jossey-Bass, 2008. Print.

Welner, Kevin G. and Alex Molnar. "Truthiness in Education." Education Week. Education Week, 28 February 2007. Web. 21 December 2011.

Welsh, John F. and Jeff Metcalf. "Faculty and Administrative Support for Institutional Effectiveness Activities: A Bridge Across the Chasm?" Journal of Higher Education 74.4 (2003): 445-468. Print.

Wernick, Andrew. "Rebranding Harvard." Theory Culture Society 23 (2006): 566-567. Print. 
Wilkinson, Rupert. Aiding Students, Buying Students: Financial Aid in America. Nashville: Vanderbilt UP, 2005. Print.

Williams, Raymond. The Long Revolution. London: Penguin Books, 1961. Print.

Yettick, Holly. "Media, Think Tanks, and Educational Research." Academe Online.

AAUP, May-June 2011. Web. 21 December, 2011.

Youngstown State University. YSU 2020: The Strategic Plan of Youngstown State Unversity 2011-2020. Youngstown: Youngstown State University, 2011. Print. Zemsky. "The Don'ts of Higher Ed Reform." Inside Higher Ed. Inside Higher Ed, 4 September 2009. Web. 4 September 2009.

Zemsky, Robert, Gregory R. Wegner and William F. Massy. Remaking the American University Market Smart and Mission Centered. New Brunswick: Rutgers UP, 2005. Print.

Zumeta, William. "Public University Accountability to the State in the Late Twentieth Century: Time for a Rethinking?" Policy Studies Review 15.4 (1998): 5-22. Print. 